\title{
Unscrambling butterfly oogenesis
}

\author{
Jean-Michel Carter', Simon C Baker², Ryan Pink ${ }^{3}$, David RF Carter ${ }^{3}$, Aiden Collins', Jeremie Tomlin', \\ Melanie Gibbs ${ }^{4^{*}}$ and Casper J Breuker ${ }^{1 *}$
}

\begin{abstract}
Background: Butterflies are popular model organisms to study physiological mechanisms underlying variability in oogenesis and egg provisioning in response to environmental conditions. Nothing is known, however, about; the developmental mechanisms governing butterfly oogenesis, how polarity in the oocyte is established, or which particular maternal effect genes regulate early embryogenesis. To gain insights into these developmental mechanisms and to identify the conserved and divergent aspects of butterfly oogenesis, we analysed a de novo ovarian transcriptome of the Speckled Wood butterfly Pararge aegeria (L.), and compared the results with known model organisms such as Drosophila melanogaster and Bombyx mori.
\end{abstract}

Results: A total of 17306 contigs were annotated, with 30\% possibly novel or highly divergent sequences observed. Pararge aegeria females expressed $74.5 \%$ of the genes that are known to be essential for D. melanogaster oogenesis. We discuss the genes involved in all aspects of oogenesis, including vitellogenesis and choriogenesis, plus those implicated in hormonal control of oogenesis and transgenerational hormonal effects in great detail. Compared to other insects, a number of significant differences were observed in; the genes involved in stem cell maintenance and differentiation in the germarium, establishment of oocyte polarity, and in several aspects of maternal regulation of zygotic development.

Conclusions: This study provides valuable resources to investigate a number of divergent aspects of butterfly oogenesis requiring further research. In order to fully unscramble butterfly oogenesis, we also now also have the resources to investigate expression patterns of oogenesis genes under a range of environmental conditions, and to establish their function.

Keywords: Oogenesis, Pararge aegeria, Lepidoptera, Bombyx mori, Drosophila melanogaster, Transcriptome, Eco-evo-devo, Reproductive physiology, Maternal effects, Early embryogenesis

\section{Background}

Successful development relies heavily on parental contribution over and above the direct effect of maternal and paternal genes. For example, maternal effect genes, which have been particularly well studied in Drosophila melanogaster, are involved in setting up; 1) the location of the germ plasm and subsequent germ cell line development in the offspring [1-3] and, 2) a basic framework of positional information, which is interpreted by the embryo's own genetic program $[4,5]$. Furthermore, insect embryos rely on nutrients for growth derived from the

\footnotetext{
*Correspondence: mela1@ceh.ac.uk; cbreuker@brookes.ac.uk

${ }^{4}$ NERC Centre for Ecology and Hydrology, Maclean Building, Benson Lane, Crowmarsh Gifford, Wallingford OX10 8BB, UK

'Evolutionary Developmental Biology Research Group, Faculty of Health and Life Sciences, Department of Biological and Medical Sciences, Oxford Brookes University, Gipsy Lane, Headington, Oxford OX3 OBP, UK

Full list of author information is available at the end of the article
}

mother in the form of yolk deposited in the egg [6-9]. The investigation of insect egg production (i.e. oogenesis) is thus not only crucial in understanding reproductive, and consequently fitness variation [10-12], it is also a popular model system for studying epigenetic programming $[13,14]$, the apoptotic pathway [15,16], stem cell behaviour [17-20], cell cycle regulation [21,22] and developmental patterning mechanisms in general [4,5,23-25].

Research into the physiological mechanisms underlying insect oogenesis and egg provisioning has a rich history [26], particularly in moths and butterflies (Lepidoptera) $[7,8,27,28]$. However, to date sufficiently detailed developmental genetic data to allow us to comprehensively understand the gene regulatory mechanisms underlying oogenesis and maternal effect gene expression controlling early embryogenesis only really exist for the model organism D. melanogaster [3-5,15,21]. Developmental genetic studies focussing on species other than $D$. melanogaster

\section{() Biomed Central}


provide us with the opportunity to investigate how the Gene Regulatory Networks (GRNs) underlying insect oogenesis might have evolved [3-5,23].

Maternal effects can have consequences that extend well beyond embryonic or juvenile development, affecting offspring fertility and longevity [28,29]. The exact nature of the maternal effects and thus the contribution of a female to the phenotype (and fitness) of her offspring are not static, however, but to a large extent depend on her own internal state, resource availability $[12,30]$ and in general the environmental conditions she experienced during her life (both biotic and abiotic) [31-34]. As such maternal effects constitute a form of non-genetic transmission of environmental conditions across generations. This means that elements of the regulatory states from the oogenesis GRN of a mother can be passed on to the next generation. There is thus a developmental framework in place with mothers having the possibility to influence the fecundity and survival of their offspring in response to their own environment, thereby providing an alternative system of inheritance with profound consequences for phenotypic evolution [32,35-38]. However, much of life history theory has been developed without regard to the actual developmental genetic basis of the variation in the traits being investigated, such as reproductive output and maternal effects [39-41]. What has been lacking is a powerful model system to study the developmental genetics of insect reproduction in an evolutionary ecological context [42]. Lepidoptera are ideal candidates to undertake such ecological evolutionary developmental (eco-evo-devo) studies given the vast amount of physiological data on oogenesis [8], as well as very detailed information, for butterflies in particular, on reproductive variability in relation to environmental variability [10,11,43-46].

Recently, valuable functional genomic tools have been developed for butterflies [47]; for example, for Melitaea cinxia to study life history variation [48], Bicyclus anynana to study wing colour patterning [49], the monarch butterfly Danaus plexippus to study longdistance migration [50], Heliconius species to study mimicry [51] and for both Erynnis propertius and Papilio zelicaon to study variability among populations in response to environmental heterogeneity and climate change [52]. The information that has been missing so far in butterflies is a detailed description of the ovarian transcriptome, including maternal regulation of patterning the embryo along its axes and mRNA contributed maternally to eggs. In fact, in Lepidoptera, there is a distinct lack of such developmental studies; only in the silkmoth Bombyx mori have a number of recent studies on candidate genes in maternal regulation of early embryogenesis (e.g. establishing positional information) been undertaken $[53,54]$.
The Speckled Wood butterfly Pararge aegeria (L.), a temperate zone species, is a popular model species for evolutionary ecology studies, for example on plasticity in female reproduction [10,11,55-57]. Female $P$. aegeria mate soon after emergence and usually mate only once [58]. At eclosion they have no or just a few [56] mature oocytes and if mated on the day of emergence, usually they start ovipositing $48 \mathrm{hrs}$ later on the third day of their life $[10,11]$. In female $P$. aegeria resources for reproduction are, to a significant degree, obtained during the larval stage and there is little opportunity to obtain more nitrogenous resources for reproduction through adult feeding [59] or nuptial gifts. Like many other butterflies [8], P. aegeria has meroistic ovaries with 8 ovarioles. Each ovariole consists of a germarium (i.e. stem cell region), previtellogenic primary oocytes, vitellogenic eggs and mature chorionated eggs [8] (Figure 1). A total of seven nurse cells transfer maternal proteins, and mRNA of maternal effect genes into developing oocytes, whilst the somatic follicle cells surrounding the oocyte are involved in choriogenesis and vitellogenesis, as well as oocyte patterning [8].

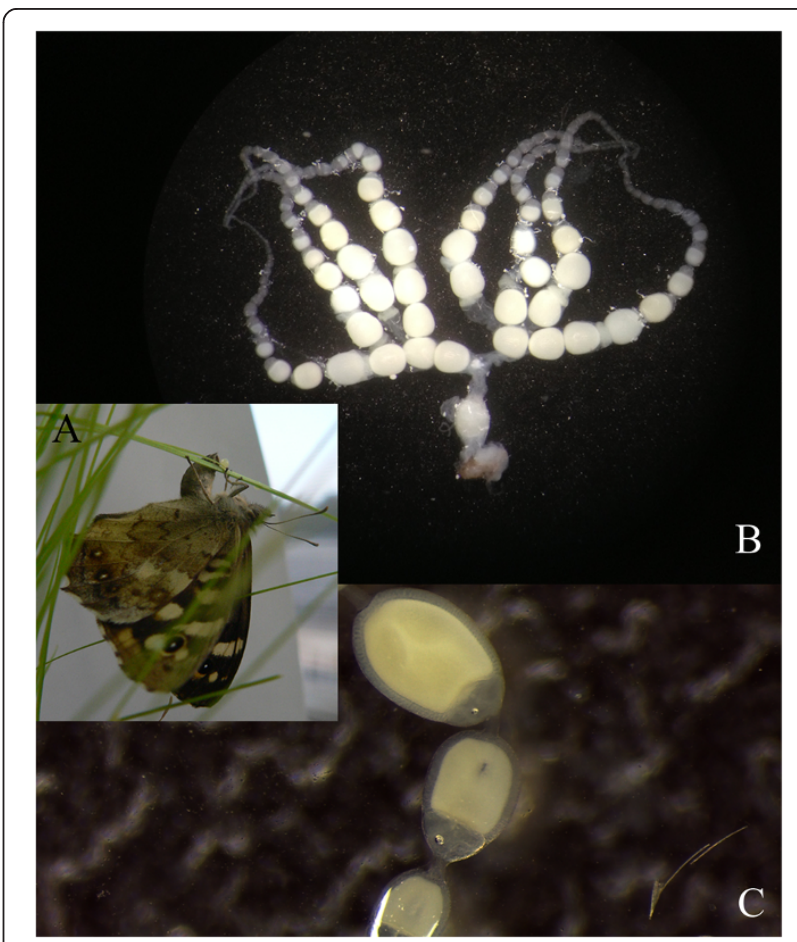

Figure 1 Overview ovarian morphology of the Speckled Wood butterfly Pararge aegeria. (A) Female P. aegeria laying an egg. (B) Complete meroistic $P$. aegeria ovary, consisting of a total of 8 ovarioles. Two times 4 ovarioles are attached to each other in the germarium region. Ovary in photo is still attached to the oviduct and part of the ovipositor. Only the ovaries were used for sequencing in this study. (C) Detail of previtellogenic eggs, with nurse and follicle cells visible. 
In this paper, we present a comprehensive study of the genes expressed during oogenesis for the butterfly $P$. aegeria, using de novo transcriptome sequencing and qPCR. Given the wealth of data on reproductive physiology in Lepidoptera, the genes implicated in hormonal control of reproduction will be investigated in particular detail in this study. Furthermore, as a first step in determining the conserved and divergent elements of the butterfly oogenesis GRN (including maternal regulation of zygotic gene expression and embryonic patterning), we investigated which of the genes known to play an essential role in $D$. melanogaster or B. mori oogenesis were also transcribed by $P$. aegeria.

Although the number of ovarioles differs among D. melanogaster, $P$. aegeria and B. mori, these species have similar organisation of their meroistic ovaries, making for an ideal comparison. Furthermore, within Lepidoptera, the silkmoth B. mori and butterflies (including $P$. aegeria) belong to the more derived division Ditrysia within the infraorder Heteroneura and thus are likely to share developmental characteristics [60,61]. Many aspects of maternal regulation of early $D$. melanogaster embryogenesis can be explained by the fact that it is a long germ band insect [5]. Within the order of Lepidoptera there is a transition from a short germ in the more ancestral species to something more similar to long germ in the more derived species, such as those belonging to Ditrysia [60]. This fact, again, makes for an interesting comparison between the three species.

We describe particular features of the $P$. aegeria ovarian transcriptome that were revealed during assembly and annotation, including orthologs of genes involved in several major conserved signaling pathways, maternal regulation of early embryogenesis, vitellogenesis and choriogenesis. We observed that $P$. aegeria differed most significantly from $D$. melanogaster (and many other insect species) in terms of stem cell maintenance in the germarium, EGF signalling in establishing oocyte polarity along anterior-posterior (AP) and dorsal-ventral (DV), and the signalling mechanisms used at the termini of the oocyte. Furthermore, we observed a high proportion of apparently unique sequences in the transcriptome, and we discuss how future exploration of the function and expression patterns of these unique sequences will undoubtedly provide valuable insights into the evolution of insect oogenesis.

\section{Results}

The main aim of this study was to identify the genes expressed in the ovaries involved in oocyte formation, establishing oocyte polarities and the RNA transcripts transferred into the eggs by the mother, which either regulate early embryogenesis or are needed during early embryogenesis. Drosophila melanogaster is arguably the best studied insect species in terms of ovarian gene expression and maternal effect gene function. Additional file 1 contains an extensively referenced list of the key essential oogenesis genes. FlyBase [62] and SilkBase [63] were used as a starting point to conduct the comprehensive literature search. The vast majority of papers thus mainly concern the model species $D$. melanogaster and $B$. mori. Furthermore, for D. melanogaster genes, a highthroughput developmental time series database was consulted for FPKM (Fragments Per Kilobase of exon per Million of fragments mapped) -based gene expression levels [64] (see also Methods), as well as an in-situ database for maternal transcript contribution to the oocyte [65]. The oogenesis genes discussed in this paper have been classified into functional groupings and were identified predominantly from $D$. melanogaster studies (and to a lesser extent B. mori studies). Studies on D. melanogaster oogenesis are too numerous to list exhaustively, but key relevant papers (and references therein) have been cited to enable the reader to explore the role of each particular gene during oogenesis further. It should of course be noted that quite a number of genes are expressed in different functional contexts during oogenesis, such as genes encoding the components of various signalling pathways or a gene such as cornichon, which is involved in setting up both AP and DV axis polarity as well as oocyte nucleus localisation in D. melanogaster [66]. Such genes only occur once in Additional file 1 and the tables presented in this paper, but the references to and discussion of such genes will highlight their pleiotropic functions.

\section{Annotation and verification of expression by means of qPCR}

Pararge aegeria egg and ovary RNA was sequenced using Illumina short read RNA-Seq technology. Of the 25266 contigs, 17306 contigs were of sufficient quality and length to be annotated (both automated and manually) with $30 \%$, possibly novel or highly divergent, remaining uncharacterised (Table 1; Additional file 2; see Methods). The presence or absence of $P$. aegeria orthologs in the transcriptome data of 1035 essential oogenesis genes listed in Additional file 1 was verified manually; 833 were found, which is $80.5 \%$. A total of 994 genes out of the 1035 had been identified in D. melanogaster studies. Pararge aegeria expressed 741 of these, which is $74.5 \%$. A further 56 genes were found to be expressed for which functionality during oogenesis can be inferred, but which have not been verified experimentally. Specific genes will be discussed elsewhere in this paper. A large number of these genes are not only transcribed during oogenesis to produce an oocyte, but maternal transcripts were also found to be present in the oocyte itself (Additional file 2; Figure 2). Exceptions include genes encoding chorion proteins as well as yolk and associated proteins. Large amounts of transcripts of these 
Table 1 Transcript abundance

\begin{tabular}{lll}
\hline Ovary/Egg LOG2 fold change & Egg/Ovary LOG2 fold change & FPKM - value \\
\hline spherulin-2A & signal transducing adapter molecule 1 & ribosomal protein LP2 \\
\hline PACG20471 & nucleolar GTP-binding protein 2 & 40S ribosomal protein S6 \\
\hline chorion class A precursor family 5 & ubiquitin-conjugating enzyme E2 S & ribosomal protein L39 \\
\hline Bmtitin1 & SLIT-ROBO Rho GTPase-activating protein & cytochrome oxidase subunit 3 \\
\hline Egg protein 80 & mo-molybdopterin cofactor sulfurase & Bmtitin1 \\
\hline Vitellogenin & poly U binding factor 68kD & ribosomal protein L32 \\
\hline chorion class A precursor family 3 & NADH dehydrogenase subunit 6 & 40S ribosomal protein S28 \\
\hline chorion class A precursor family 4 & PACG6651 & ubiquitin \\
\hline PACG21670 & chromatin regulatory protein sir2 & Ferritin 2 - light chain homolog \\
\hline chorion class C precursor family 2 & PACG13792 & BmBR-C gene for Broad-Complex isoform Z2 \\
\hline putative uncharacterized protein DDB & DNA repair protein complementing XP-A cells homolog & polyubiquitin \\
\hline PACG20450 & disulfide oxidoreductase & ribosomal protein L27 \\
\hline PACG21661 & PACG710 & 60S ribosomal protein L28 \\
\hline PACG24051 & similar to phosphinothricin acetyltransferase gene & PACG20761 \\
\hline chorion class B precursor family 1 & PACG5386 & 60S ribosomal protein L18 \\
\hline chorion protein-like & abhydrolase domain-containing protein 1 & translationally controlled tumor protein \\
\hline endonuclease-reverse transcriptase & RAD51C protein & ribosomal protein S3A \\
\hline spec2 & PACG18339 & 60S ribosomal protein L38 \\
\hline PACG19208 & PACG19350 & ribosomal protein L7A \\
\hline PACG20509 & SLIT-ROBO Rho GTPase-activating protein 1-like & heat shock protein cognate 3 \\
\hline
\end{tabular}

Transcript abundance (on the basis of FPKM values) in the Pararge aegeria ovarian/oocyte transcriptome (see also Additional file 2). The first column is a measure of which transcripts were most abundant in the ovaries compared to those present as maternal transcripts in the oocytes. These are genes highly expressed in the ovaries, but with few to no maternal transcripts in the oocyte. The genes listed in column 2 have relatively high FPKM values in the oocytes compared to the ovaries, indicating large concentrations of transcripts (see also Additional file 2). The third column lists the genes most transcribed during P. aegeria oogenesis. Columns list the gene top 20, from high to low.

genes are found in the ovaries only (Additional file 2; Table 2). A number of contigs appeared to have relatively high transcript abundance (measured by means of FPKM values; see Methods) in the oocytes compared to the ovaries, suggesting that these transcripts are important as maternal effect transcripts incorporated into the oocytes in relatively large concentrations (Table 2 and Figure 2). An example of this is the gene encoding a signal transducing adaptor molecule (STAM; Table 2 and Additional file 2), which in D. melanogaster is expressed throughout oogenesis [67], but of which transcripts are detected in very high levels in early embryogenesis [68]. On the basis of the GO terms, the 838 gene orthologs appear to be representative of the annotated genes in the transcriptome as a whole (Figures 2 and 3).

For of a subset of 17 genes, sampled across the functional groups identified in Additional file 1, the expression in the ovarioles and the presence of transcripts in the oocyte were confirmed further by means of RT-qPCR. These genes were: argonaute 2 (AGO2), caudal (cad), decapentaplegic $(d p p)$, egalitarian (egl), exuperantia (exu), Fragile X mental retardation 1 (Fmr1), nanos-like (nos-like), nanos-M (nos$M)$, nanos-O (nos-O), ornithine decarboxylase antizyme (Oda), anterior open (aop), par-1, piwi, chorion b-ZIP transcription factor (CbZ), staufen (stau), vitellogenin receptor yolkless $(y l ; V g R)$ and vitellogenin $(V t g / V g)$. Two further genes, which have not been explicitly studied in the context of oogenesis (references in Additional file 1), were investigated: embryonic lethal abnormal vision (elav) and minibrain (mnb). Furthermore, 3 housekeeping genes were selected to be used as reference genes: RNA polymerase II 215 KD subunit (RPII215), TATA binding protein (Tbp) and zwischenferment ( $z w, G 6 P D H)$ (Additional file 3).

The qPCR results were used to confirm the presence of expression as well as the levels of expression (as indicated by means of FPKM values) in the transcriptome dataset (Figure 4; Additional files 4, 5, and 6). Transcripts of vitellogenin were not transferred into the oocytes and very few $d p p$ transcripts were transferred into the egg (Figure 4). All of the other oogenesis genes investigated by means of qPCR were included as maternal effect gene transcripts in the oocytes (see also Additional file 2). Specific qPCR results will be discussed in the remainder of the paper.

\section{Discussion}

\section{Germ-line and ovarian stem cells}

In $D$. melanogaster three major signalling pathways play a significant role in cystoblast differentiation, and the maintenance and division of germ-line and ovarian stem cells; TGF-beta, Wnt and hedgehog signalling [69-71]. 


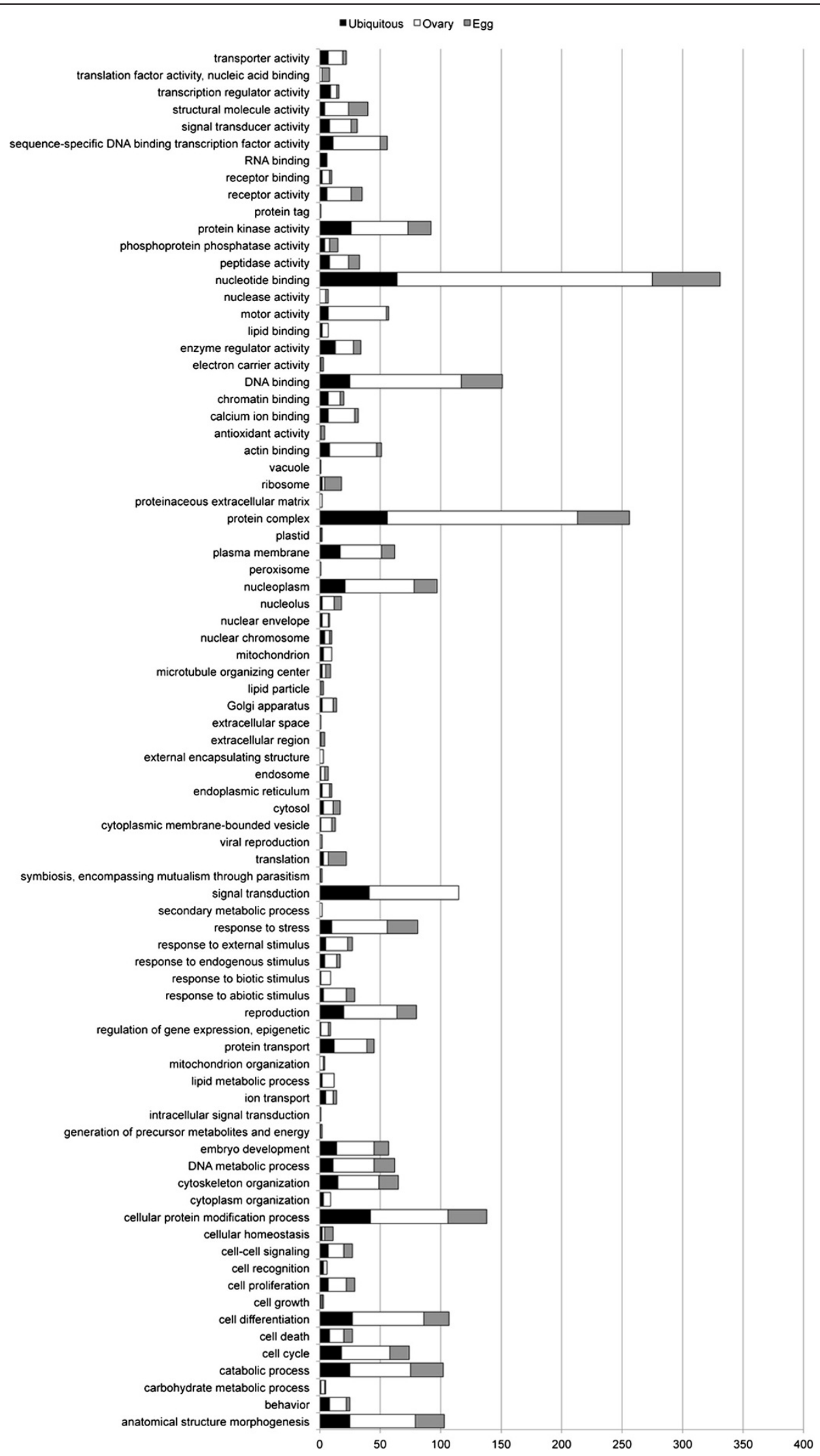

Figure 2 (See legend on next page.) 
(See figure on previous page.)

Figure 2 Gene Ontology manually annotated genes. The presence or absence of orthologs of essential oogenesis genes listed in Additional file 1 has been manually verified. The Gene Ontologies (GO) of genes that were present were determined by BLAST2GO and GO terms were subsequently condensed using the generic GO Slim subset. The histogram details the number of Pararge aegeria manually verified contigs (note, as has been observed for many de novo assemblies, for some genes multiple contigs were present in the transcriptome) for each GO term. FPKM estimates were used to compare the levels of transcripts found in the ovaries and as maternal transcripts in the egg. Using a Log2 fold change threshold of 1, genes were classified in the histogram as present in similar amounts in the egg and ovarian transcriptome (labelled Ubiquitous), used predominantly during oogenesis to make an egg, but not or hardly used as a maternal transcript (labelled Ovary), or highly concentrated in the egg as maternal transcripts (labelled Egg).

Components of all three signalling pathways have been identified for P. aegeria (Table 3 and Additional file 1). However, it is not clear, to what extent these signalling pathways are essential in the Lepidopteran germarium, as they were not identified as such in B. mori using SAGE analyses [72]. Rather than signalling, for example, a previously unidentified non-coding RNA appears to regulate cystoblast differentiation in B. mori [72].

The TGF-beta ligands glass bottom boat $(g b b)$ and $d p p$ were expressed in $P$. aegeria ovarioles (qPCR results; Table 3). The type I TGF-beta receptors used were thickveins $(t k v)$ and an activin type 1 receptor similar to baboon (ATR1) (Additional files 1 and 2), the latter of which is present in the D. melanogaster oocyte as a maternal transcript necessary for early embryogenesis [73]. No evidence, however, could be found for an ortholog of activin type I receptor saxophone (sax) (Table 3). No ortholog of the activin type II receptor punt (pnt) was found, although PACG16964 was found to be a type II BMP receptor (Additional file 2). The P. aegeria transcriptome contained orthologs of two SMAD family genes; Mothers against $d p p(\mathrm{Mad})$ and Smad on X (Smox), but not of medea nor of the anti-SMAD Daughters against decapentaplegic (Dad), which have been shown to be of importance in D. melanogaster germline stemcell maintenance [71]. Furthermore, the negative regulator of Dpp signalling dullard $(d d)$ was found to be expressed in $P$. aegeria ovaries. In $D$. melanogaster this gene plays a role in wing vein formation [74], and although it has been found to be maternally deposited [65], its role in oogenesis has not been verified. Another negative regulator of Dpp signalling, brinker (brk), which plays a role in eggshell patterning in D. melanogaster [75,76], was also expressed by $P$. aegeria. In $D$. melanogaster, bag of marbles (bam) interacts with Dpp signalling to regulate stem cell maintenance and differentiation in the germarium [77]. However, bam is a Drosophila unique gene and is not found in $P$. aegeria.

During oogenesis $P$. aegeria females express two Wnt receptors, which show orthology to frizzled-2 and frizzled-7 (Table 4 and Additional file 1). Furthermore, they express the Wnt receptor $l(2) 43 E a$ (boca), which plays a role in D. melanogaster vitellogenesis [78], as well as dishevelled $(d s h)$, which is part of the Wnt receptor complex (Table 3 and Additional files 1 and 2). Other components of the Wnt pathway expressed include armadillo (arm), pangolin (Tcf/LEF), groucho (gro), axin (axn), sugarless (sgl), legless (lgs), pygopus (pygo) and shaggy (sgg; Zw3),

Table 2 Sequencing and annotation summary

\begin{tabular}{lllllll}
\hline Location/Feature & Contigs annotated & Manually curated & Av. Contig (bp) & Av. CDS (bp) & Av. 5' UTR (bp) & Av. 3'UTR (bp) \\
\hline Genomic & $\mathbf{1 6 9 1 9}$ & $\mathbf{1 5 6 4}$ & $\mathbf{6 2 5 . 9 9}$ & $\mathbf{4 5 9 . 8 9}$ & $\mathbf{6 9 . 6 1}$ & $\mathbf{7 5 . 1 7}$ \\
\hline Complete CDS & 4530 & 473 & 1022.96 & 667.12 & 142.07 & 210.79 \\
\hline Homology & 3055 & 466 & 1196.75 & 855.06 & 124.15 & 214.53 \\
\hline Novel & 1475 & 7 & 663.02 & 277.87 & 179.18 & 203.02 \\
\hline Partial CDS & 11842 & 992 & 485.34 & 393.59 & 45.11 & 26.77 \\
\hline Homology & 8054 & 975 & 521.96 & 454.21 & 51.65 & 12.67 \\
\hline Novel & 3788 & 17 & 407.48 & 264.69 & 31.20 & 56.73 \\
\hline Partial mRNA & 547 & 99 & 383.36 & 179.24 & 0.00 & 0.00 \\
\hline Mitochondrion & $\mathbf{3 8 7}$ & $\mathbf{1 1}$ & $\mathbf{7 2 8 . 6 4}$ & $\mathbf{5 6 3 . 2 0}$ & $\mathbf{8 3 . 1 8}$ & $\mathbf{7 5 . 3 2}$ \\
\hline Complete CDS & 177 & $\mathbf{7 1 2}$ & 996.59 & 719.80 & 115.86 & 157.94 \\
\hline Partial CDS & 201 & 3 & 510.06 & 443.30 & 58.13 & 5.95 \\
\hline Partial mRNA & 9 & 1 & 340.67 & 161.22 & 0.00 & 0.00 \\
\hline Grand Total & $\mathbf{1 7 3 0 6}$ & $\mathbf{1 5 7 5}$ & $\mathbf{6 2 8 . 2 8}$ & $\mathbf{4 6 2 . 2 0}$ & $\mathbf{6 9 . 9 1}$ & $\mathbf{7 5 . 1 8}$ \\
\hline
\end{tabular}

A total of 17306 sequences have been submitted. The sequences are classified below according to their location (i.e. nuclear or mitochondrial genome), completeness and annotation status (i.e. whether orthoogous sequences could be found in other Metazoa or not). Characteristics of the contigs are listed, such as average size of the contig, coding sequence and the $3^{\prime}$ and $5^{\prime}$ UTRs (all in base-pairs, bp). 


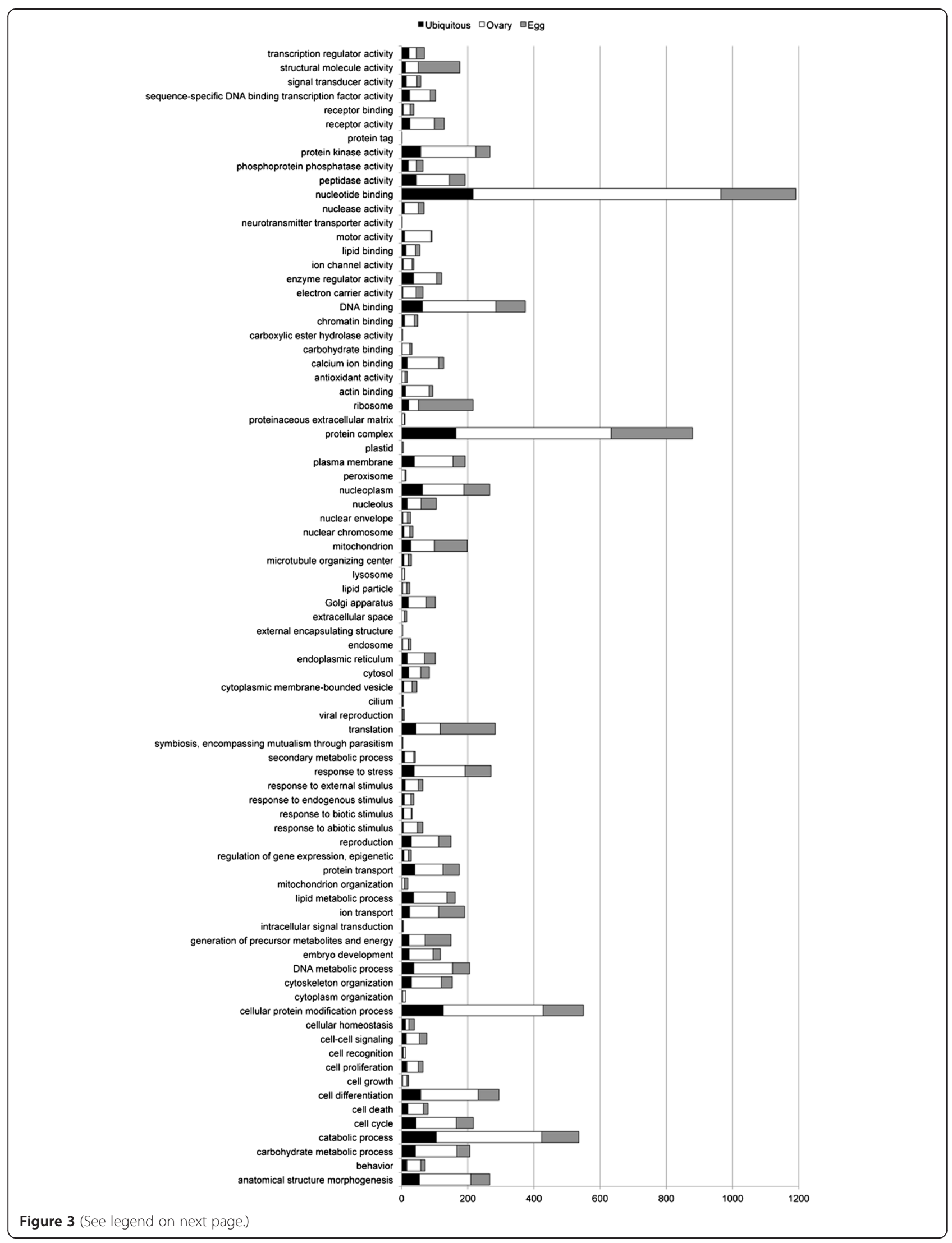


(See figure on previous page.)

Figure 3 Gene Ontology total transcriptome. The Gene Ontologies (GO) of succesfully annotated genes in the total transcriptome were determined by BLAST2GO and GO terms were subsequently condensed using the generic GO Slim subset. The histogram details the number of Pararge aegeria contigs (note, for some genes multiple contigs were present in the transcriptome) for each GO term. FPKM estimates were used to compare the levels of transcripts found in the ovaries and as maternal transcripts in the egg. Using a Log2 fold change threshold of 1, genes were classified in the histogram as present in similar amounts in the egg and ovarian transcriptome (labelled Ubiquitous), used predominantly during oogenesis to make an egg, but not or hardly used as a maternal transcript (labelled Ovary), or highly concentrated in the egg as maternal transcripts (labelled Egg).

as well as wntless (wls)(Table 3 and Additional file 2; references in Additional file 1). Maternal transcripts of each of these genes were found in the oocyte (Table 3; Additional files 1 and 2), with the exception of $s g l$. Asymmetric localisation of maternal axn RNA has been shown to be involved in AP formation in Tribolium castaneum [79]. Rather interestingly, the ligand wingless (wg) was not found in the assembled transcriptome (Table 3 and Additional file 2). However, 201 ovary and 100 oocyte raw RNA-seq reads mapped against the complete $w g$ CDS from our unpublished $P$. aegeria genome (approximately between $3.2 \times$ and $6.5 \times$ coverage, displaying a discontinuous transcript with a number of gaps not covered by reads; Additional file 7). In D. melanogaster, transcripts of $w g$ are not found in the oocyte [65] and although Wnt signaling has been established as present during oogenesis [69], expression levels of $w g$ are extremely low [64], making it hard to detect the transcripts. It is clear that in $P$. aegeria there is strong maternal contribution to zygotic Wnt signaling (Additional file 2), but whether Wnt signaling plays a role during oogenesis needs to be further investigated.

No ortholog of Drosophila wnt4 (a vertebrate wnt9 ortholog) was found (Table 3), which in D. melanogaster is involved in regulating cell movement during ovarian morphogenesis [80]. Finally, transcripts of an ortholog of shifted (shf) were present both in the ovary and oocyte in $P$. aegeria (Table 3 and Additional file 2). This gene encodes an EGF-like protein acting as a Wnt inhibitory factor 1 , which in D. melanogaster stabilises hedgehog signalling and transcripts of which are deposited in the oocyte [81]. Hedgehog ( $h h$ ) itself, as well as components of the pathway including smoothened (smo), fused (fu), Suppressor of fused (Sufu), and cubitus interruptus (ci) were all found to be expressed and maternal transcripts

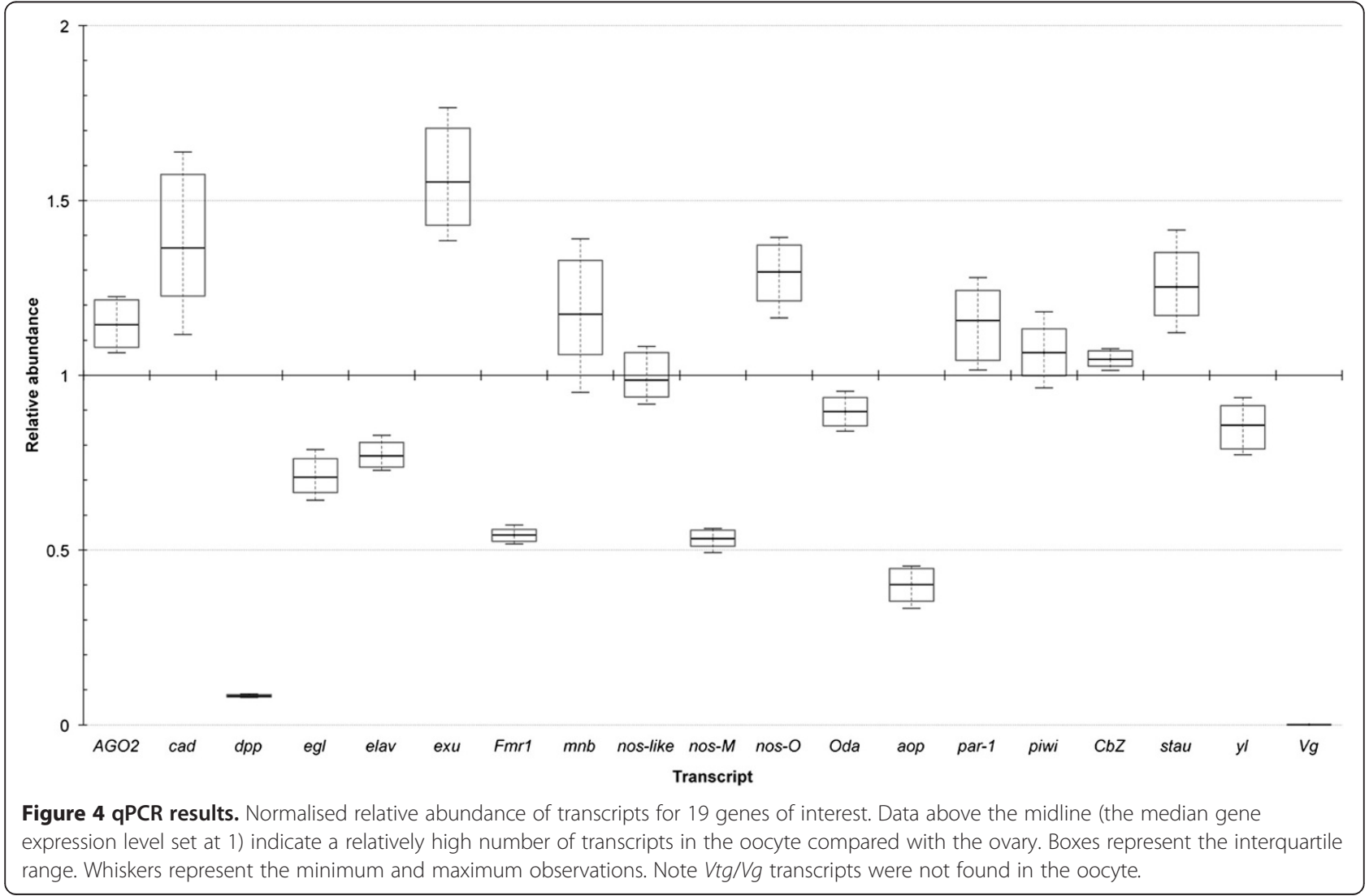


Table 3 Maintenance and division of germ-line and ovarian somatic stem cells

\begin{tabular}{|c|c|c|c|}
\hline armadillo (arm) & Y & shutdown (shu) & Y \\
\hline axin; axis inhibition protein (axn) & Y & FK506-binding protein (FKBP59) & Y \\
\hline dishevelled (dsh) & Y & vasa; vasa-like gene (vasa homolog in Lepidoptera) (vas; vlg) & Y \\
\hline shaggy; gsk-3 (sgg; Zw3) & Y & outstretched (upd; sisc) & $\mathrm{N}$ \\
\hline sugarless; UDP glucose6 dehydrogenase (sgl; UDPGDH) & Y & bag of marbles (bam & $\mathrm{N}$ \\
\hline legless (Igs; BCL9) & Y & mei-p26 (mei-p26) & $\mathrm{N}$ \\
\hline pygopus (pygo; gam) & Y & brain tumor (brat) & Y \\
\hline wingless (wg) & $Y ?$ & benign gonial cell neoplasm (bgcn) & $\mathrm{N}$ \\
\hline wntless; evenness interrupted (w/s; Evi) & Y & within bgen (wibg; pym) & Y \\
\hline hedgehog (hh) & Y & decapentaplegic (dpp) & Y \\
\hline shifted; wht inhibitory factor 1 precursor (shf; wif1) & Y & kekkon5 (kek5) & $\mathrm{N}$ \\
\hline $\operatorname{costa}(\cos 2)$ & $\mathrm{N}$ & Mothers against dpp (Mad) & Y \\
\hline skinny hedgehog; hedgehog acyltransferase; CG32281 (ski) & Y & Smad on X (Smad2; Smox) & Y \\
\hline roadkill; similar to speckle-type POZ protein $(r d x)$ & Y & saxophone (type I Dpp receptor) (sax) & $\mathrm{N}$ \\
\hline patched (ptc) & $\mathrm{N}$ & thickveins (type I Dpp receptor) (tkv) & Y \\
\hline smoothened (smo) & Y & punt (type II Dpp receptor) (pnt) & $\mathrm{N}$ \\
\hline cubitus interruptus (ci) & Y & medea (med; SMAD4) & $\mathrm{N}$ \\
\hline engrailed (en) & $\mathrm{N}$ & Daughters against dpp (Dad) & $\mathrm{N}$ \\
\hline pangolin (pan; Tcf/LEF) & Y & glass bottom boat (gbb) & Y \\
\hline wnt oncogene analog 4 (wnt4) & $\mathrm{N}$ & dullard $(d d)$ & Y \\
\hline dicer-1 (dcr-1) & Y & quo vadis; schnurri (quo; shn) & $\mathrm{N}$ \\
\hline loquacious (loqs) & Y & lethal with a checkpoint kinase (smurf; lack) & Y \\
\hline mir-184 (mir-184) & $\mathrm{N}$ & supernumerary limbs (slimb) & Y \\
\hline effete (eff; UbcD1) & Y & starry night; flamingo (stan; fmi) & $\mathrm{N}$ \\
\hline$\overline{f_{s}(1) Y b(Y b)}$ & $\mathrm{N}$ & $\begin{array}{l}\text { roughened; similar to ras-related protein rap-1a; enhancer of faf; similar to } \\
\text { Bombyx mori ras3 }(r \text {; rap } 1 \text {; dras3) }\end{array}$ & Y \\
\hline fused; similar to serine/threonine kinase 36 (fu) & Y & ras-associated protein 2-like; ras-related protein 2 (rap2l) & Y \\
\hline Suppressor of fused (Su(fu)) & Y & fruitless isoform a (fru) & Y \\
\hline bicaudal (bic) & Y & fruitless isoform $k$ (fru) & Y \\
\hline otefin (ote) & $\mathrm{N}$ & fruitless (fru) & Y \\
\hline piwi (piwi) & Y & sex-lethal (sxl) & $\mathrm{N}$ \\
\hline pelota (pelo) & Y & pre-mRNA-splicing regulator wtap; similar to female lethal d; CG6315 (ff(2)d ) & $\mathrm{N}$ \\
\hline pumillio (pum) & Y & maleless; ATP-dependent RNA helicase a-like (mle; dhx9; nap) & Y \\
\hline penguin (pen) & Y & lamin c (lamc) & Y \\
\hline sans fille; U1 small nuclear ribonucleoprotein $A$; fs(1)1621 (snf) & Y & clift; eyes absent (cli; eya) & Y \\
\hline bric a brac (bab) & $\mathrm{N}$ & slowmo (s/mo) & $\bar{Y}$ \\
\hline
\end{tabular}

Genes identified mainly from the Drosophila melanogaster literature as functioning early for the maintenance and division of germ-line and ovarian somatic stem cells. Presence $(\mathrm{Y})$, possible presence $(\mathrm{Y}$ ?) or absence $(\mathrm{N})$ of orthologous transcripts in the Pararge aegeria transcriptome is indicated.

of all were present in the oocyte (Table 3; Additional files 1 and 2). Both costa ( $\cos 2)$ and the receptor patched (ptc) were not expressed during oogenesis by $P$. aegeria (Table 3; Additional file 1). Although Ptc protein has been detected in the D. melanogaster germarium [70], detecting $p t c$ transcripts may prove more difficult because $p t c$ appears to be transcribed in very low amounts [64], and it is possible that this is why ptc transcripts were also not found in P. aegeria. As has been observed for Wnt signalling, there is a maternal contribution to zygotic Hh signalling, but presently it is not clear whether this signalling pathway plays a significant role during $P$. aegeria oogenesis.

\section{Cytoskeleton and actomyosin contractile ring assembly}

Orthologs of the vast majority of genes that have been described as affecting the cytoskeleton and actomyosin contractile ring during $D$. melanogaster oogenesis were expressed in P. aegeria (Table 4). One of the genes not found is ovarian tumor (otu), which plays a crucial role during $D$. melanogaster oogenesis. Otu is involved in cytoskeletal formation, cyst formation in germ-line cells, 
Table $\mathbf{4}$ Cytoskeleton and actomyosin contractile ring assembly

\begin{tabular}{|c|c|c|c|}
\hline abnormal spindle (a microtubule-associated protein) (asp) & $\mathrm{N}$ & dedicator of cytokinesis 6,7; similar to CG11376 (dock6; dock7) & Y \\
\hline javelin-like (microtubule-associated protein); similar to CG3563 (jvl) & Y & myoblast city; dedicator of cytokinesis 1 (mbc; dock180) & Y \\
\hline $\begin{array}{l}\text { mini spindles (microtubule-associated protein; belongs to xmap215/tog } \\
\text { family of genes) (msps; xmap215) }\end{array}$ & $\mathrm{Y}$ & $\begin{array}{l}\text { spaghetti squash; myosin light polypeptide 9; myosin regulatory } \\
\text { light chain } 9 \text { (sqh; mrlc) }\end{array}$ & Y \\
\hline a-kinase anchor protein 200 (akap200) & N & $\begin{array}{l}\text { nonmuscle myosin essential light chain; myosin II essential light } \\
\text { chain }(m / c-c)\end{array}$ & Y \\
\hline capulet; act up, bcDNA:Id24380, CG5061 (capt) & N & myosin regulatory light chain interacting protein (mylip) & Y \\
\hline$c d c 42(c d c 42)$ & Y & $\begin{array}{l}\text { genghis kahn; cdc42 binding protein kinase alpha or beta } \\
\text { (gek; cdc42bpb) }\end{array}$ & $\bar{Y}$ \\
\hline $\begin{array}{l}\text { Bombyx mori cdc42 small effector 2-like protein (LOC692865) } \\
\text { (cdc42-sep2; spec2) }\end{array}$ & Y & jaguar/myosin VI (jar; mhc95f; myo6) & Y \\
\hline p21/cdc42/racl activated kinase (pak) & Y & myosin heavy chain (similar to CG17927) (mhc) & Y \\
\hline rac1; ras-related c3 botulinum toxin substrate 1 (rac1) & Y & myosin heavy chain 2; zipper (zip; mhc2) & Y \\
\hline specifically Rac1 associated protein; Fmr1-interacting protein (sra-1; cyfip) & Y & myosin light chain kinase; bent; titin-like (bt) & Y \\
\hline engulfment and cell motility protein; ced-12 homolog (ced-12; elmo) & $\mathrm{Y}$ & myosin 1 light chain; myosin alkali light chain 1 (m/c) & $\bar{Y}$ \\
\hline centrosomin (cnn) & Y & myosin 1; myosin 61f (myo 1b) & Y \\
\hline aurora-a (aur) & $\mathrm{Y}$ & $\begin{array}{l}\text { dilute class unconventional myosin; myosin } V_{;} \text {myosin-Va } \\
\text { (myoV; myo-Va; didum) }\end{array}$ & $\bar{Y}$ \\
\hline chickadee (homolog of profilin) (chic) & Y & unconventional myosin class XV (myo10a) & Y \\
\hline citron; sticky (sti; dck) & $\mathrm{N}$ & myosin heavy chain like (mhcl) & Y \\
\hline focal adhesion kinase-like; fak56(D) (fak56D) & Y & CG17293; WD40 protein type (wdr82) & Y \\
\hline diaphanous (dia) & Y & washout (wash; p63; p65) & $\mathrm{N}$ \\
\hline frizzled; frizzled-7-like (fz7-l) & Y & james bond (bond) & $\mathrm{N}$ \\
\hline frizzled; frizzled-2-like (fzz-l) & Y & $\begin{array}{l}\text { kette; hem-protein; similar to membrane-associated protein hem } \\
\text { (dhem-2); similar to membrane-associated protein gex-3 } \\
\text { (hem; kte; nap 1; dhem2) }\end{array}$ & Y \\
\hline chromosome bows; mast; orbit; clasp (chb) & $\mathrm{N}$ & $\begin{array}{l}\text { short stop; kakapo; similar to bullous pemphigoid antigen } 1 \\
\text { (Homo sapiens); microtubule-actin cross linking factor } 1 \text { (shot) }\end{array}$ & Y \\
\hline shotgun; E-Cadherin (shg; E-Cad) & Y & vacuolar protein sorting 35 (vps35) & Y \\
\hline mushroom body defect (mud) & $\mathrm{N}$ & $\begin{array}{l}\text { rotund; racGTPase-activating protein; roughened eye } \\
\text { (rn; roe; rnracgap) }\end{array}$ & $\bar{Y}$ \\
\hline dishevelled associated activator of morphogenesis-1 (daam-1) & Y & twinstar; actin-depolymerizing factor 1 cofilin (tsr) & Y \\
\hline karst (also known as betaheavy spectrin) (kst) & Y & slingshot (mkp; ssh) & Y \\
\hline flightless I (flil) & Y & subito; double or nothing; Bombyx mori kinesin-like protein c (sub) & Y \\
\hline klarsicht (klar; marb) & Y & Ipll-aurora-like kinase; aurora b (kinase) (aurb) & Y \\
\hline muscle-specific protein 300 (msp-300) & Y & $\begin{array}{l}\text { tumbleweed; racGAP50c; similar to racGTPase-activating protein } \\
\text { (tum; racGAP) }\end{array}$ & Y \\
\hline lissencephaly-1 (lis-1) & Y & arp2; actin-related protein 14d (arp2; arp14d) & Y \\
\hline cortactin(-like) (cortactin) & Y & arp3; actin-related protein $66 b$ (arp3; arp66b) & Y \\
\hline src oncogene at $42 a(\operatorname{src} 42 a)$ & Y & suppressor of profilin 2 (also known as arpc1) (sop2; arpc1; arc41) & $\bar{Y}$ \\
\hline src oncogene 1 (src64b) & Y & arp2/3 complex subunit p34; $\operatorname{arpc2}(\operatorname{arpc2} ;$ arc-p34) & Y \\
\hline a actinin (actn) & Y & arp2/3 complex 21kD subunit p21; arpc3b (arpc3; arpc3b) & $\bar{Y}$ \\
\hline ovarian tumor; $f_{s}(1) m 101 ; f_{s}(1) 231$ (otu & $\mathrm{N}$ & arp2/3 complex subunit p20; arpc4 (arpc4; arc-p20) & Y \\
\hline Guanyl cyclase at 32e (Gyc32e) & $\mathrm{N}$ & arp2/3 complex 16kD subunit p16; arpc5 (arpc5; p16-arc) & Y \\
\hline Guanylyl cyclase at 76c; receptor-type Guanylate cyclase (Gyc76c) & $\mathrm{Y}$ & kinesin associated protein 3 (kap3; kap) & $\bar{Y}$ \\
\hline stand still (stil) & $\mathrm{N}$ & kinesin-like protein at 68d; kinesin II; kinesin-2 (klp5; klp68d) & Y \\
\hline hold up (hup) & $\mathrm{N}$ & kinesin-like protein at 64d; kinesin family member 3a (klp64d; kif3a) & Y \\
\hline dicephalic (dic) & $\mathrm{N}$ & pericentrin-like protein (ср309) (ср309) & $\bar{N}$ \\
\hline
\end{tabular}


Table 4 Cytoskeleton and actomyosin contractile ring assembly (Continued)

\begin{tabular}{lll}
\hline kelch (kel) & $Y$ & $\begin{array}{l}\text { rho-type Guanine exchange factor; pak-interacting exchange factor; } \\
\text { AGAP007877 (rtgef; dpix) }\end{array}$ \\
\hline similar to kelch domain containing 4 (klhdcp) & $Y \quad \begin{array}{l}\text { SCAR; actin binding protein; (in vertebrates) wiskott-aldrich } \\
\text { syndrome protein family member 2; wasp family protein } \\
\text { member 2 (SCAR; wave) }\end{array}$ \\
\hline cullin 3 (cul3) & $\begin{array}{l}Y \\
\text { quail; villin (qua) }\end{array}$ \\
\hline
\end{tabular}

Genes identified mainly from the Drosophila melanogaster literature as important in cytoskeleton and actomyosin contractile ring assembly. Presence ( $\mathrm{Y}$ ) or absence $(\mathrm{N})$ of orthologous transcripts in the Pararge aegeria transcriptome is indicated.

nurse cell chromosome dispersion and gurken (grk) mRNA localisation [82]. For 14 genes no P. aegeria orthologs could be found in the dataset (Table 4). For a number of these, this is not surprising, as in general it has proven to be difficult to find orthologs outside the genus Drosophila; for example dicephalic (dic), mushroom body defect (mud), hold up (hup) and stand still (still)(references in Additional file 1).

Pararge aegeria females were found to express $E$ Cadherin (Table 4). E-Cadherin-dependent adhesion underlies the positioning of the oocyte at the posterior of the cyst, which in turn plays a role in establishing the AP polarity in D. melanogaster during very early oogenesis [83].

\section{Oocyte determination (including fusome formation) and formation of the anterior-posterior polarity during the early stages of oogenesis}

Three genes have been described in the literature as important in $D$. melanogaster follicle ring canal formation; visgun (vsg), nasrat $\left(f_{s}(1) N\right)$ and scraps (scra) $[84,85]$. Only $f_{s}(1) N$ was not transcribed by $P$. aegeria females (Additional file 1). Fusomes, regions of spectrin-rich cytoplasm, are essential in D. melanogaster to establish a system of directional transport between cystocytes underpinning oocyte determination and subsequent oocyte polarity [86]. The majority of genes that are expressed early in D. melanogaster oogenesis regulating the formation of the fusome (e.g. alpha and beta spectrin and hu-li tai shao) were also transcribed by $P$. aegeria, as well as the genes involved in establishing initial AP polarity, including par-1 and egalitarian (egl) (Figure 4 qPCR results and Table 5; references in Additional file 1). Par-1 in particular is essential in D. melanogaster for both oocyte determination and for establishing AP polarity through its effects on the organisation of the microtubule cytoskeleton in conjunction with a number of other proteins [87]. Among the proteins with which Par-1 interacts in establishing AP polarity are Bazooka (Baz/Par3), Bicaudal D (BicD), Lkb1/Par4, Egl, 14-3-3epsilon, and Dynein proteins (references in Additional file 1). The genes encoding these proteins were all expressed by $P$. aegeria (Table 5). Transcripts of both par- 1 and $e g l$ were also present in the oocyte (Figure 4 qPCR results and Additional file 2).
Soon after the posterior localisation of the oocyte in the D. melanogaster cyst, EGF signalling takes place in the posterior between the oocyte (Grk ligand) and the overlying follicle cells (Torpedo receptor) [88,89], further consolidating AP polarity. Orthologs of the fastevolving grk are difficult to find outside the genus Drosophila [24]. Two genes encoding EGF ligands and likely to be paralogs of grk, spitz (spi) and keren (krn), are involved in the regulation of border cell migration in D. melanogaster [90]. A single spi/krn-like EGF ligand has been found in the genomes of $N$. vitripennis and $T$. castaneum, and has been argued to be functionally similar to grk in DV patterning in these species [24]. Pararge aegeria females expressed an ortholog of this single spi/krn-like EGF ligand, with the sequence displaying significant similarity to Harpegnathos saltator spi (Additional file 2; Table 6). Large amounts of these transcripts were detected in the $P$. aegeria oocyte (Additional file 2), suggesting a significant role for its use during early embryogenesis as observed in D. melanogaster [65]. Given the expression of a spi/krn in P. aegeria and the significance of EGF signalling in insect oogenesis in general, and establishing oocyte polarity in particular [24], it is very surprising that only weak evidence was found for expression of egfr, the gene encoding the EGF receptor, in $P$. aegeria ovaries (Table 6). None of the contigs in our de novo assembly could be clearly identified as an egfr transcript. However, 780 raw RNA-seq reads did map against the complete efgr CDS from our unpublished $P$. aegeria genome (approximately $7.1 \times$ coverage, displaying a discontinuous transcript with a number of gaps not covered by reads; Additional file 7). Intriguingly, all of the raw reads that mapped successfully came from the ovariole transcriptome, not the oocyte transcriptome, consistent with the importance of EGF signalling during oogenesis itself. Transcript levels of egfr are low to moderate in D. melanogaster ovaries [64], and thus there is always the possibility, as was suggested for the absence of ptc transcripts in our study, that $P$. aegeria egfr transcript levels were not high enough to be accurately detected. However, it is intriguing that as for a number of other components of the EGF pathway involved in DV patterning in $D$. melanogaster, $P$. aegeria also did not transcribe, 
Table 5 Oocyte determination, fusome and AP polarity

\begin{tabular}{|c|c|c|c|}
\hline transitional endoplasmic reticulum ATPase; ter94 (ter94) & Y & atypical protein kinase c; CG10261 (apkc) & $\mathrm{N}$ \\
\hline capping protein alpha (сра) & Y & typical protein kinase c (pkc) & Y \\
\hline leonardo (14-3-3zeta; leo) & Y & protein kinase c inhibitor; similar to CG2862 (pkc inhibitor) & Y \\
\hline bazooka (baz; par3) & Y & rab-protein 6; small (monomeric) GTPase (rab6) & Y \\
\hline bicaudal C (bicC) & Y & rhino (rhi) & $\mathrm{N}$ \\
\hline bicaudal D (bicD) & Y & B1 tubulin 1 (tub1) & Y \\
\hline bicaudal D-related (CG32137) & Y & B1 tubulin 2 (tub2) & Y \\
\hline glued; dynactin (gl) & Y & $\beta$-tubulin at 60d (tub3; betatub60d) & Y \\
\hline egalitarian; 3'-5' exonuclease domain-like-containing protein (egl) & Y & $\beta$-tubulin at 56d (betatub56d) & Y \\
\hline stonewall; fs(3)02024 (stwl) & $\mathrm{N}$ & $\begin{array}{l}\text { homologous to Drosophila } y \text {-tubulin at 37c; gamma tubulin (in general) } \\
\text { (gammatub37c; gamma tub 1) }\end{array}$ & Y \\
\hline $\begin{array}{l}\text { egghead; zeste-white 4; beta-1,4-mannosyltransferase } \\
\text { (egh; zw4; bre3) }\end{array}$ & Y & $\begin{array}{l}\text { gamma-tubulin complex component 3; lethal (1) discs degenerate } 4 \\
\text { (tubgcp3; gcp3; dgrip91) }\end{array}$ & $Y$ \\
\hline 4ehp (4ehp) & $\mathrm{N}$ & $\begin{array}{l}\text { gamma-tubulin complex component 2; gamma-tubulin ring protein } 84 \\
\text { (Drosophila) (tubgcp2; gcp2; dgrip84) }\end{array}$ & $Y$ \\
\hline pipsqueak (BTB/POZ containing gene) (psq) & N & alpha tubulin tual; similar to Drosophila alpha-tubulin at $84 b$ (atub; tua1) & Y \\
\hline BTB/POZ domain containing gene (BTB-POZ) & Y & alpha tubulin tua2; similar to Drosophila alpha-tubulin at $84 b$ (atub; tua2) & Y \\
\hline BTB domain containing protein 2 (BTBd2) & Y & deadlock (del) & $\mathrm{N}$ \\
\hline spindle c (spnc) & $\mathrm{N}$ & mo25; calcium-binding protein 39 (mo25) & Y \\
\hline coracle; band 4.1-like protein (cora) & Y & 14-3-3ع (14-3-3epsilon) & Y \\
\hline alpha spectrin (alpha-spec) & Y & par-1; map/microtubule affinity-regulating kinase (par-1) & Y \\
\hline beta spectrin (beta-spec) & Y & serine/threonine kinase Ikb1; partitioning defective 4 (Ikb1; par4; stk11) & Y \\
\hline hu-li tai shao (hts) & Y & partitioning defective 6 (par-6) & $\mathrm{N}$ \\
\hline ankyrin; similar to ankyrin 2,3/unc44; AGAP002272-PA (ank) & Y & combgap (cg; mig) & Y \\
\hline neuroglian (ceb; nrg) & Y & dynein heavy chain 64C; cytoplasmic dynein heavy chain (dhc64c; dhc) & Y \\
\hline inscuteable (insc) & $\mathrm{N}$ & cut up (ddlc-1; cdlc1; dynein light chain) & Y \\
\hline sec61 alpha (sec61 alpha) & Y & kinesin heavy chain (khc) & Y \\
\hline sec61 gamma (sec61 gamma) & Y & kinesin light chain (klc) & Y \\
\hline $\sec 63(\sec 63)$ & Y & rhomboid-2; stem cell tumor; brother of rhomboid (stet; rho-2) & $\mathrm{N}$ \\
\hline tropomodulin (tmod) & Y & ensconsin (ens) & Y \\
\hline p38 MAPK (p38MAPK) & Y & $\begin{array}{l}\text { helicase at 25e; ATP-dependent RNA helicase; } d d \times 39 \text { (in vertebrates) } \\
\text { (hel25E; } d d \times 39 \text { ) }\end{array}$ & Y \\
\hline $\begin{array}{l}\text { protein kinase a; CAMP-dependent protein kinase 1; dc0, pka } \\
(p k a-c 1)\end{array}$ & Y & $\begin{array}{l}\text { licorne; similar to dual specificity mitogen-activated protein kinase kinase 3; } \\
\text { similar to dual specificity mitogen-activated protein kinase kinase } \\
\text { (in Nasonia); dual specificity mitogen-activated protein kinase kinase } 6 \\
\text { (mainly in vertebrates) (lic; MAPKK; mek3) }\end{array}$ & Y \\
\hline CAMP-dependent protein kinase $r 1$ (pka-r1) & Y & protein tyrosine phosphatase 10D (ptp10D) & Y \\
\hline CAMP-dependent protein kinase $r 2$ (pka-r2) & Y & $\begin{array}{l}\text { protein tyrosine phosphatase } 4 E \text {; similar to protein tyrosine phosphatase } \\
100 \text { (ptp4E) }\end{array}$ & Y \\
\hline
\end{tabular}

Genes identified mainly from the Drosophila melanogaster literature acting early in the egg for oocyte determination (including fusome formation) and formation of the anterior-posterior (AP) axis. Presence $(\mathrm{Y})$ or absence $(\mathrm{N})$ of orthologous transcripts in the Pararge aegeria transcriptome is indicated.

for example, rho during oogenesis (Table 6). Spatial restriction dorsally of rhomboid (rho), encoding a ligandprocessing protease in the EGFR pathway, is necessary in D. melanogaster both for DV axis formation as well as for correct patterning of the eggshell [89] (further references in Additional file 1). Although further study is required, at present it thus seems that EGF signalling either does not play a significant role in $P$. aegeria during oogenesis or a highly divergent one. This will be discussed further in the next section.
Genes acting early in the ovariole to establish dorsal-ventral polarity and genes promoting follicle cell motility such as border cell migration

Quite a number of genes involved in establishing DV polarity in the oocyte are also important for choriogenesis and dorsal appendage formation in D. melanogaster (references in Additional file 1). Apart from aforementioned $g r k$, pipe was also not expressed by $P$. aegeria. Pipe plays an essential role in establishing DV polarity in D. melanogaster oocytes, with its expression being confined to ventral 
Table 6 Follicle cell gene expression and border cell migration

\begin{tabular}{|c|c|c|c|}
\hline capping protein beta $(c p b)$ & Y & innexin 3 (inx3) & Y \\
\hline hepatocyte growth factor regulated tyrosine kinase substrate (hrs) & Y & zero population growth (inx4; zpg) & Y \\
\hline Calpain-B (CalpB) & $\mathrm{N}$ & crumbs (crb) & Y \\
\hline big brain (bib) & $\mathrm{N}$ & stardust; weakly similar to maguk p55 subfamily member 5 (sdt; std) & Y \\
\hline brainiac (brn) & Y & quit (qui) & $\mathrm{N}$ \\
\hline mastermind (mam) & $\mathrm{N}$ & $\begin{array}{l}\text { dual-specificity a-kinase anchor protein spoonbill; CG3249; } \\
\text { homologous to akap149 (spoon; yu) }\end{array}$ & $\mathrm{N}$ \\
\hline neuralized (neur) & Y & lethal (2) giant larvae (|gl) & Y \\
\hline derailed (drl; lio) & $\mathrm{N}$ & $\begin{array}{l}\text { myosin light chain 2; similar to Bombyx mori myosin regulatory light } \\
\text { chain } 2(\mathrm{mlc}-2)\end{array}$ & Y \\
\hline delta $(d l)$ & Y & deep orange; Vacuolar sorting protein 18 (dor; Vps18) & Y \\
\hline notch; abruptex (ax), split (spl) (N) & Y & $\begin{array}{l}\text { Vacuolar protein sorting 9; sprint; rab GDP/GTP exchange factor (gef) } \\
\text { (Vps9; spri) }\end{array}$ & Y \\
\hline presenilin (psn) & Y & twinfilin (twf) & Y \\
\hline nicastrin (nct) & $\mathrm{Y}$ & toucan (toc) & $\bar{Y}$ \\
\hline $\begin{array}{l}\text { gamma-secretase subunit aph-1; anterior pharynx defective 1; } \\
\text { presenilin-stabilization factor (aph1) }\end{array}$ & $\mathrm{Y}$ & abrupt (ab) & $\overline{\mathrm{N}}$ \\
\hline presenilin enhancer (pen-2) & $\mathrm{Y}$ & taiman/ p160 coactivator fisc (DAIB1; tai) & Y \\
\hline strawberry notch (sno) & Y & puckered; hearty; similar to dual specificity phosphatase 10 (puc; hrt) & $\mathrm{N}$ \\
\hline notchless (nle) & $\mathrm{Y}$ & $\begin{array}{l}\text { misshapen; traf2 and nck interacting kinase; homolog of serine/ } \\
\text { threonine-protein kinase mig-15 (c. elegans) (msn; tnik) }\end{array}$ & $\bar{Y}$ \\
\hline $\begin{array}{l}\text { cut; similar to CCAAT displacement protein; similar to homeobox } \\
\text { protein cut (ct; cux) }\end{array}$ & $\mathrm{N}$ & fusilli; e(cacte10)7 (fus) & Y \\
\hline fringe (fng) & $\mathrm{Y}$ & dribble; krr1 small subunit processome component homolog (dbe) & Y \\
\hline bunched; shortsighted (bun) & $\mathrm{Y}$ & $\begin{array}{l}\text { kuzbanian; similar to disintegrin and metalloproteinase domain- } \\
\text { containing protein } 10(\mathrm{kuz})\end{array}$ & Y \\
\hline dodo; similar to Bombyx mori rotamase pin 1 (dod) & Y & tie; tie-like receptor tyrosine kinase (tie) & $\mathrm{N}$ \\
\hline Broad-Complex core protein isoform $6(b r ; B r-C)$ & Y & fk506-binding protein (fkbp 13) (fkbp 13) & $\bar{Y}$ \\
\hline $\begin{array}{l}\text { zinc finger and BTB domain-containing protein weak homology to } \\
\text { Broad-Complex core protein isoforms } 1,2,3,4,5 \text { (br; Br-C) }\end{array}$ & Y & m6; myelin protolipid (m6) & $\bar{Y}$ \\
\hline daughterless (da) & $\mathrm{Y}$ & tanc2-like rolling pebbles; antisocial (ants; rols) & $\bar{Y}$ \\
\hline ets at 97D; tiny eggs (ets97D; tny) & $\mathrm{N}$ & amphiphysin; bridging integrator (damph) & $\bar{Y}$ \\
\hline pointed; similar to protein c-ets 1 (pnt; D-ets-1) & $\mathrm{N}$ & fasciclin II (fas2) & $\bar{N}$ \\
\hline dystroglycan (dg) & $\mathrm{Y}$ & semaphorin; fasciclin-IV (fas4; sema-1a) & $\bar{Y}$ \\
\hline discs lost; tight junction pdz protein patj (dlt) & Y & kayak (kay; fos) & Y \\
\hline filamin; cheerio (fln; cher) & $\mathrm{Y}$ & src homology 2, ankyrin repeat, tyrosine kinase (shark) & $\bar{Y}$ \\
\hline jitterbug; filamin-related (jbug) & $\mathrm{Y}$ & bullwinkle (bwk) & $\mathrm{N}$ \\
\hline leukocyte-antigen-related-like; tyrosine-protein phosphatase lar (lar) & $\mathrm{N}$ & basket; jun amino terminal kinase (djnk); c-jun nh2-terminal kinase (bsk) & Y \\
\hline discs large $(d \lg 1)$ & $\mathrm{Y}$ & Cad74A (Cad74A) & $\bar{N}$ \\
\hline scribble(d) (scrib) & Y & locomotion defects; regulator of g protein signaling (rgs) (loco) & Y \\
\hline singed (sn) & Y & blistered; serum response factor; pruned (bs; serf) & $\mathrm{N}$ \\
\hline slow border cells; homologous to Bombyx C/EBP (slbo; bmC/EBP) & $\mathrm{Y}$ & $\begin{array}{l}\text { calmodulin-binding protein related to a rab3 gdp/gtp exchange protein; } \\
\text { weakly similar to denn domain-containing protein } 4 \mathrm{C} \text { (crag) }\end{array}$ & $\bar{Y}$ \\
\hline midline fasciclin (mfas) & $\mathrm{N}$ & $\begin{array}{l}\text { G protein-coupled receptor kinase 1; similar to beta-adrenergic receptor } \\
\text { kinase } 2 \text { (Gprk1) }\end{array}$ & $\bar{Y}$ \\
\hline brinker (brk) & Y & $\begin{array}{l}\text { G protein-coupled receptor kinase 2; similar to beta-adrenergic receptor } \\
\text { kinase } 1 \text { (Gprk2) }\end{array}$ & $\bar{Y}$ \\
\hline egf-r; torpedo; der (egfr; der) & Y? & $\begin{array}{l}\text { rutabaga; similar to ca(2+)/calmodulin-responsive adenylate cyclase; } \\
\text { similar to adenylate cyclase } 1 \text { (rut) }\end{array}$ & Y \\
\hline rhomboid-1; rhomboid; veinlet (rho) & $\mathrm{N}$ & dunce; cAMP-specific 3',5'-cyclic phosphodiesterase (dnc) & Y \\
\hline spitz (spi); spitz/keren-like & $\mathrm{Y}$ & jun related antigen (jra) & Y \\
\hline
\end{tabular}


Table 6 Follicle cell gene expression and border cell migration (Continued)

\begin{tabular}{|c|c|c|c|}
\hline ovarian serine protease encoding nudel (ndl) & Y & myocardin-related transcription factor (mrtf) & Y \\
\hline kekkon-1 (kek1) & N & similar to rolling stone (rost) & Y \\
\hline vein (similar to a vertebrate neuregulin) (vn) & N & jing (jing) & $\mathrm{N}$ \\
\hline $\operatorname{argos}(a o s)$ & Y & yan; anterior open; similar to ets DNA-binding protein pokkuri (aop) & Y \\
\hline 18 wheeler (18w) & Y & $\begin{array}{l}\text { adherens junction protein p120; armadillo repeat protein; catenin delta; } \\
\text { CG17484 (p120ctn) }\end{array}$ & Y \\
\hline hopscotch (hop; jak) & N & $\begin{array}{l}\text { G protein sa 60a; G protein alpha s subunit GS1 (Bombyx mori) } \\
\text { (G-salpha60a) }\end{array}$ & $\mathrm{N}$ \\
\hline star; asteroid (S) & $\mathrm{N}$ & protein tyrosine phosphatase 99a (ptp99a) & $\mathrm{N}$ \\
\hline ran-binding protein $m$ (ranbpm) & Y & diacyl glycerol kinase $\varepsilon$ (dgke) & $\mathrm{N}$ \\
\hline PDGF- and VEGF-receptor related (PVR) & Y & ovary protein-29kD (op29) & $\mathrm{N}$ \\
\hline innexin 2 (inx2) & Y & & \\
\hline
\end{tabular}

Genes identified mainly from the Drosophila melanogaster literature acting in follicle cells early and late and promoting their motility such as border cell migration (and in Drosophila important for choriogenesis and dorsal appendage formation). Presence (Y), possible presence ( $\mathrm{Y}$ ?) or absence (N) of orthologous transcripts in the Pararge aegeria transcriptome is indicated.

follicle cells as a result of localised EGF signalling [91]. Recently, however, it has been proposed that pipe is not necessary in a number of insect species studied [4] and even in $D$. melanogaster there appears to be a second mechanism in establishing DV [92] that may involve delayed induction by graded maternal Dpp signalling in the perivitelline space [93]. Whatever the mechanism employed by Lepidoptera, it is clear from B. mori research that the factors determining DV polarity are associated with the egg cortex [94].

Despite significant differences found in expression patterns of genes involved in EGF signalling in a number of insects, this pathway has been argued to be the ancient mechanism for establishing DV polarity in insect eggs [4]. Transcription factors that have been discussed as mediators of EGF signalling include pointed (pnt), aop and capicua (cic) [91]. Only the latter two were expressed by $P$. aegeria and present as maternal transcripts, but whether they play a role in establishing DV polarity remains to be investigated (Tables 6 and 7, and Additional file 2; qPCR results). The ETS transcription factor Aop also plays a role in border cell migration and does not receive input exclusively from EGF, but from a number of signalling pathways including Notch [95]. All components of the Notch signalling pathway were expressed in the ovarioles, with only Notch $(N)$ itself not being present as maternal transcripts in the oocyte (Table 6 and Additional file 2). Maternal $\mathrm{N}$ transcripts are also not found in D. melanogaster.

The Notch pathway interacts with the EGF pathway in establishing oocyte polarity in D. melanogaster, in particular through its effects on follicle cell differentiation at both termini of the oocyte [96]. As has been established in this study, there is only weak evidence at present for the use of the EGF pathway during $P$. aegeria oogenesis, and it is striking that the iroquois-class homeodomain protein Mirror is not expressed by $P$. aegeria (Table 7). This protein appears essential in $D$. melanogaster in integrating EGF and Notch signalling in follicle differentiation and thus establishing AP and DV polarity [97].

Table 7 Dorsal ventral polarity

\begin{tabular}{|c|c|c|c|}
\hline cappuccino; formin 1/2 (capu) & Y & maelstrom (mael) & Y \\
\hline spire (spir) & Y & pipe (encoding a sulfotransferase) (pip) & $\mathrm{N}$ \\
\hline cornichon (cni) & Y & okra (a spindle gene); rad54; rad54-like (okr; rad54) & Y \\
\hline$f_{s}(1) k 10\left(f_{s}(1) k 10\right)$ & $\mathrm{N}$ & spindle $B($ spnB) & $\mathrm{N}$ \\
\hline sec61 beta (sec61 beta) & Y & spindle D (spnD) & N \\
\hline mirror; iroquois-class homeodomain protein irx (mirr) & $\mathrm{N}$ & orb; oo18 RNA-binding protein (orb) & $\mathrm{N}$ \\
\hline groucho; Enhancer of split m9/10 (gro; E(spl)m9/10) & Y & heterogeneous nuclear RNA-binding protein 40; squid (sqd; hrp40) & Y \\
\hline capicua (cic) & Y & $\begin{array}{l}\text { heterogeneous nuclear ribonucleoprotein at 27c; similar to Bombyx mori } \\
\text { hnrnpa/b-like } 28 \text { (hrp48; hrb27c; hnrnpa/b-like 28) }\end{array}$ & Y \\
\hline gurken (grk) & N & $\begin{array}{l}\text { heterogeneous nuclear ribonucleoprotein at 87f; similar to Bombyx mori } \\
\text { heterogeneous nuclear ribonucleoprotein a1 (hrp36; p11) }\end{array}$ & Y \\
\hline trailer hitch (tral) & $\mathrm{N}$ & transportin; importin 3, karyopherin beta $2 b(\mathrm{imp} \beta 2)$ & Y \\
\hline
\end{tabular}


Apart from the EGF pathway, Notch interacts with a number of other proteins in patterning the follicle cells surrounding the oocyte, including Toucan and Daughterless (references in Additional file 1). These were expressed by $P$. aegeria (Table 6), suggesting that the Notch pathway is essential for correct patterning of the follicle cells and possibly oocyte polarity, but in $P$. aegeria it may not require an interaction with the EGF pathway. Further studies are required to establish whether butterflies have dispensed with EGF signalling and localised pipe expression in establishing oocyte polarity and instead rely on, for example, the Notch and Dpp pathway.

\section{Anterior and posterior system genes}

The Lepidopteran Bombyx mori displays features of both short and long germ band type insects, in which orthodenticle (otd) and cad maternal mRNA are localised to establish the embryonic AP-axis [53]. Both were expressed during $P$. aegeria oogenesis (Table 8 ) and indeed were present as mRNA in the oocytes (Additional file 2; Figure $4 \mathrm{qPCR}$ results for cad). Bicoid $(b c d)$ is Drosophila-specific and although no ortholog was found to be expressed, the genes that are involved in bcd localisation were, including exu and stau, but not swallow (swa) (Table 8; Figure 4 qPCR results). As observed in D. melanogaster, transcripts for both exu and stau were also present in significant amounts in $P$. aegeria oocytes (Figure 4 qPCR results; Additional file 2) [65]. The use of $b c d$ in translational repression of $c a d$ is unique to Drosophila. It is very likely that the ancestral mechanism for translational repression of cad is by means of the $\mathrm{KH}$-domain containing protein encoded for by mex-3 [98]. Pararge aegeria females expressed an ortholog of mex-3 (Table 8). Furthermore, in $D$. melanogaster, $b c d$ interacts with genes such as bicoid interacting protein 3 (bin3), eIF4E, larp1, polyA binding protein $(p A b p)$ and $A G O 2$ in order to repress cad translation [99]. All of these were found to be expressed in $P$. aegeria, and similarly to $D$. melanogaster $[64,65]$, present as maternal transcripts in the oocytes (Tables 8 and 9, and Additional file 2; Figure 4 qPCR results for $A G O 2)$.
Drosophila melanogaster includes maternal hunchback $(\mathrm{hb})$ transcripts into the egg, the protein of which will form an AP gradient during early embryogenesis and cooperate with Bcd to specify the anterior of the embryo, whilst being repressed at the posterior by Nos [100]. Although there is variation between insect species as to whether maternal $h b$ RNA or protein is transferred to the egg, as well as in the significance of the maternal contribution to the $\mathrm{Hb}$ gradient for $\mathrm{AP}$ patterning, the transcription of $h b$ during oogenesis appears conserved [5,101]. For example, although only zygotic $\mathrm{Hb}$ is necessary for AP patterning in the grasshopper Schistocerca americana embryo, maternal $h b$ transcripts appear to be involved in distinguishing embryonic from extra-embryonic cells along the AP axis, whilst in D. melanogaster maternal and zygotic $\mathrm{Hb}$ are redundant for AP patterning of the embryo [101]. In $B$. mori, the $h b$ transcripts detected appear to be transcribed by the zygote, not the mother [53,101]. Pararge aegeria also did not express $h b$ during oogenesis (Table 8), suggesting that Lepidoptera, or at least Ditrysia, may have dispensed with a maternal contribution to the Hb gradient in the embryo.

Nanos is involved in both the differentiation of the germ plasm and posterior patterning in D. melanogaster [102], although these two functions can be mechanistically uncoupled [103]. Lepidopteran primordial germ cells (PGCs) develop in a midventral position and in the germ disk after blastoderm formation, not posteriorly before the blastoderm is formed as in D. melanogaster [54]. It is therefore unlikely in Lepidoptera that the genes involved in setting up the embryonic posterior will interact with and be dependent on the genes involved in the localisation of germline determinants, as shown to occur in D. melanogaster $[54,60]$. Bombyx mori contains a number of nos paralogs (nos- $M,-O,-P$ and -like (also called $-N)$ ), which indeed appear to have divided up these functions [54]. Although it has been argued that $B$. mori does not have a germ plasm, the location of maternal $B$. mori nos-O transcripts in the embryo seems to correspond with where the PGCs will form [54]. These nos paralogs, with the exception of nos- $P$, are expressed during

Table 8 Maternal specification of embryonic anterior-posterior axis

\begin{tabular}{llll}
\hline bicoid (bcd) & $\mathrm{N}$ & bicoid-interacting protein 3 (bin3) & \\
\hline orthodenticle; Drosophila ocelliless (oc; otd) & $\mathrm{Y}$ & larp1 (larp1) & \\
\hline exuperantia (exu) & $\mathrm{Y}$ & Eukaryotic initiation factor 4E; similar to Bombyx mori Eukaryotic initiation factor 4E-2 (elf4E) & Y \\
\hline swallow; fs(1)1502 (swa) & $\mathrm{N}$ & argonaute 2 (AGO2) & Y \\
\hline maternal expression at 31B (me31B) & $\mathrm{Y}$ & caudal (cad) & $\mathrm{Y}$ \\
\hline staufen (stau) & $\mathrm{Y}$ & hunchback (hb) & $\mathrm{N}$ \\
\hline muscle excess 3 (mex-3) & $\mathrm{Y}$ & & \\
\hline
\end{tabular}

Genes in anterior-posterior axis specification, identified from a wide variety of insects. Presence (Y) or absence (N) of orthologous transcripts in the Pararge aegeria transcriptome is indicated. 
Table 9 Maternal specification of embryonic posterior

\begin{tabular}{|c|c|c|c|}
\hline apontic (apt) & $\mathrm{N}$ & mago nashi (mago) & Y \\
\hline nanos; nanos-like (LOC100125608) (nos-like) & $Y$ & tsunagi/y14 (tsu/y14) & Y \\
\hline nanos-M (nos-M) & Y & ranshi; similar to zinc finger protein 195; CG9793 (ranshi) & Y \\
\hline nanos- $P($ nos $-P)$ & N & glorund (glo; p67) & $\mathrm{N}$ \\
\hline nanos-O (nos-O) & Y & smaug (smg) & $\bar{Y}$ \\
\hline shavenbaby; ovo (ovo) & Y & twin; CCR4 (part of CCR4-Not complex) (twin; CCR4) & $\mathrm{N}$ \\
\hline armitage (armi) & Y & not1 (part of CCR4-Not complex) (Not1) & Y \\
\hline arrest (also known as bruno) (aret/bru) & Y & not2 (part of CCR4-Not complex); Regena (Not2; Rga) & Y \\
\hline lasp (lasp) & Y & not3 (part of CCR4-Not complex); I(2)nc136 (Not3) & Y \\
\hline oskar (osk) & $\mathrm{N}$ & $\begin{array}{l}\text { chromatin assembly factor } 1 \text { (part of CCR4-Not complex); similar to } \\
\text { CG4236 (caf1) }\end{array}$ & $\bar{Y}$ \\
\hline poly(a)-binding protein ( $p A b p)$ & Y & Pop2; similar to CG5684; CCR4-Not transcription complex subunit 7 (Pop2) & Y \\
\hline Eukaryotic translation initiation factor 4AIII (elF4AIII) & Y & hiiragi (Poly A Polymerase) (hrg; PAP) & $\bar{Y}$ \\
\hline barentsz; elF4alll binding protein; weak localizer (wkl; btz) & Y & rabenosyn-5; rabenosyn (rbsn-5) & Y \\
\hline syntaxin $1 a(\operatorname{syx} 1 a)$ & Y & ypsilon schachtel (Bombyx mori Y-box protein) (yps; ybp) & Y \\
\hline moesin-like; dmoesin (ezrin, radixin, moesin gene) (moe; ERM1) & Y & ubiquitin specific protease 9; fat facets (faf) & Y \\
\hline $\begin{array}{l}\text { Eukaryotic translation initiation factor } 4 \text { e transporter similar to cup } \\
\text { (cup; } f_{s}(2) \text { cup; } f_{s}(1) \text { cup) }\end{array}$ & Y & $\begin{array}{l}\text { hephaestus; polypyrimidine tract-binding protein; heterogeneous nuclear } \\
\text { ribonucleoprotein I (heph; ptb; hnrnp I) }\end{array}$ & Y \\
\hline Eukaryotic translation initiation factor $2 a$ (elF2alpha) & Y & synaptotagmin (syt 1; syt) & Y \\
\hline miranda (mira) & $\mathrm{N}$ & $\begin{array}{l}\text { synaptotagmin; similar to Drosophila melanogaster extended } \\
\text { synaptotagmin } 2 \text { (esyt2) }\end{array}$ & Y \\
\hline
\end{tabular}

Genes identified mainly from the Drosophila melanogaster literature involved in posterior pole specification. Presence $(\mathrm{Y})$ or absence (N) of orthologous transcripts in the Pararge aegeria transcriptome is indicated.

oogenesis in both B. mori and P. aegeria, with maternal transcripts detectable in $P$. aegeria eggs (Figure 4 qPCR results; Additional file 2 and Table 9) [53]. Nanos-P is primarily zygotically expressed during embryogenesis in B. mori and may be implicated in stabilising the embryonic AP-axis [53]. The nos paralogs have also been found in the monarch butterfly (D. plexippus) genome [50] and phylogenetic analysis of nos sequences shows nos- $P$ to be quite different from the other paralogs (Additional file 8), suggesting it may have a different functional role.

Translational repression of D. melanogaster nos RNA is accomplished during oogenesis by proteins encoded by glorund (glo) and in the early embryo by smaug (smg) [104]. Transcripts of both are found in D. melanogaster oocytes [65]. A P. aegeria ortholog of smg was found, which was present as RNA in the oocyte, but not of glo (Table 9 and Additional file 2). Furthermore, Smg protein bound to the nos 3' UTR recruits the deadenylation complex CCR4-NOT in D. melanogaster [105]. Rapid deadenylation leads to decay of nos RNA, which is essential in establishing the AP gradient of nos RNA [105]. Although it has been argued above that Lepidoptera in all likelihood do not use nos paralogs during oogenesis in establishing the posterior, $P$. aegeria does express all the genes that encode proteins that form this complex, despite the absence of an obvious ortholog for twin/ CCR4 (Table 9). In D. melanogaster it is the germ plasm protein Oskar (Osk) that prevents rapid deadenylation at the posterior pole, establishing nos as a posterior defining gene [105]. Ditrysia appear not to possess an osk ortholog [3], which could be another reason why the identified nos paralogs may not being involved in AP axis formation during oogenesis. Indeed, $P$. aegeria also does not possess an ortholog of osk (Table 9; unpublished $P$. aegeria genome).

\section{Germ plasm, polar granules, nuage and p-bodies}

Although a germ plasm type structure has been identified cytologically in the moth Pectinophora gossypiella [2], it is not clear whether Lepidoptera possess a proper germ plasm as they lack osk, which has been argued to have been co-opted as the essential gene in germ plasm formation in holometabolous insects [1,3]. Pararge aegeria may not possess an osk ortholog, but it does express two genes, which in D. melanogaster silence osk translationally during oogenesis; bruno [106] and cup [107] (Table 9 and Additional file 1). It should be noted, however, that these genes are expressed in a number of functional contexts during oogenesis in D. melanogaster (e.g. cell cycle regulation; references in Additional file 1). As part of the germ plasm, Oskar induces polar (or germ) granule formation and in doing so interacts with a number of genes that characterise these polar granules, in particular tudor (tud), vasa (vas) and valois (vls) $[3,103]$. Only valois (vls) could not be found in the $P$. aegeria transcriptome (Tables 9 and 10). 
Table 10 Ovarian nuage and piRNA pathway

\begin{tabular}{|c|c|c|c|}
\hline capsuléen; Arginine n-methyltransferase 5 (csul; prmt5) & $Y$ & tejas; similar to tudor domain containing 5 (tej; TDRD5) & Y \\
\hline valois (v/s) & N & vreteno; similar to CG4771 (vret) & $\mathrm{N}$ \\
\hline aubergine (related to elF2c; a piwi protein) (aub) & Y & similar to tudor domain containing CG9925 and CG9684 (TDRD1) & Y \\
\hline ATP-dependent helicase; cap; belle (cap; bel) & Y & similar to CG8920; similar to tudor domain containing 7 (TDRD7) & Y \\
\hline cutoff (cuff) & N & homeless; fs(3); spindle E; similar to tudor domain containing 9 (hls; spnE; TDRD9) & Y \\
\hline squash (squ) & N & CG14303; similar to tudor domain containing 4 (TDRD4) & $\mathrm{N}$ \\
\hline piwi-like protein; argonaute 3 (AGO3; siwi) & Y & tudor-SN (tudor-SN) & Y \\
\hline zucchini (zuc) & N & Brother of Yb; CG11133 (BoYb) & $\mathrm{N}$ \\
\hline tudor; similar to tudor domain containing 6 (tud) & Y & Sister of Yb; CG31755 (SoYb) & $\mathrm{N}$ \\
\hline krimper (mtc; krimp) & $\mathrm{N}$ & & \\
\hline
\end{tabular}

Ovarian nuage and piRNA pathway genes identified mainly from the Drosophila melanogaster literature. Presence $(\mathrm{Y})$ or absence $(\mathrm{N})$ of orthologous transcripts in the Pararge aegeria transcriptome is indicated.

Both the ovarian nuage, an electron-dense perinuclear structure found predominantly in nurse cells [108], and polar granules are characterised by a number of the same genes, including tud, vas and vls (references in Additional file 1). The nuage appears not only to play a role in protecting germline cells against the expression of selfish genetic elements in the majority of animals, but also in establishing the polar granules in D. melanogaster $[108,109]$. It is therefore not surprising that PIWI proteins and their bound PIWI-interacting RNAs (piRNAs) have been identified as important for both nuage and polar granule formation [109,110]. Many of these genes encode TUDOR-domain containing proteins and seem to evolve rapidly making it difficult to find orthologs outside Drosophila; e.g. vreteno (vret), Brother of $Y b(B o Y b)$ and Sister of $Y b(\mathrm{SoY} b)$ [110]. Indeed, no orthologs of these genes could be found in the $P$. aegeria transcriptome (Table 10). Other genes encoding TUDOR-domain containing proteins seem more conserved, such as TDRD1, tejas (TDRD5), TDRD7 and spindle E/homeless (TDRD9) $[3,110]$ and these were expressed by $P$. aegeria (Table 10). What is interesting about TDRD7 is that it shares the OST-HTH/LOTUS functional domain with osk [1,3]. It is likely that this domain is involved in RNA binding and thus for regulating mRNA translation and/ or localisation in germ cell development [111].

There are three genes that encode PIWI proteins; piwi, aubergine (aub) and argonaute 3 (AGO3) [112]. All three were expressed during oogenesis by $P$. aegeria (Figure 4 qPCR results; Tables 1 and 10). Piwi also plays an essential role in the D. melanogaster germarium and is thus involved in the establishment, maintainance and renewal of germline stem cells [113]. Furthermore, mutations in D. melanogaster piRNA (Piwi-interacting RNA) pathway genes often disrupt the axes of the developing oocyte, through their effects on the microtubule cytoskeleton; for example maelstrom (mael), zucchini (zuc) and squash (squ) affect DV polarity $[114,115]$. The latter two also interact with aub in $D$. melanogaster in silencing osk translation during oogenesis [115]. Similarly, the RNAi pathway gene armitage (armi) affects axis formation and is involved in osk translational silencing in D. melanogaster [107]. Neither $z u c$ nor $s q u$ was found in the P. aegeria transcriptome, but mael and armi were (Tables 7 and 10).

Ovarian processing bodies (i.e. P-bodies) are aggregates of translationally inactive ribonucleoproteins (RNPs). In D. melanogaster these can be found in nurse cells, but also appear to be involved in compartmentalisation of mRNA decay and translation repression, for example of osk $[116,117]$. With the exception of EDC4/Ge-1 and pacman ( $p c m)$, genes that encode the essential components of P-bodies were expressed in P. aegeria (described in the context of oogenesis or otherwise, Table 11 and references in Additional file 1). RNA of P-body components, for example $D c p 1$, are also transferred to oocytes during $D$. melanogaster oogenesis and are necessary for early embryogenesis [116]. This was also observed in $P$. aegeria (Additional file 2).

Once the germ plasm has been established at the posterior in D. melanogaster, a number of (late-acting) maternal-effect genes are essential in germline formation during early embryogenesis ([118]; further references in Additional file 1). Pararge aegeria females do express similar genes to the fruit fly, including genes associated traditionally with $D$. melanogaster pole plasm, such as arrest/bruno (aret) and imp [119]. However, there are some notable exceptions, the most significant of which are germ cell-less $(\mathrm{gcl})$ and polar granule component $(p g c)$ (Tables 12, and 13, and Additional file 1). These genes are essential in $D$. melanogaster, but there are no known $p g c$ orthologs outside the genus Drosophila. Although orthologs can be found for $g c l$ even in vertebrates, none can be found in genomic databases for the Lepidoptera, including the new data presented here. The gene wunen (wun) is involved in germ cell migration in D. melanogaster embryos (references in Additional file 1). Pararge aegeria females also include wun transcripts in the oocyte (Table 13 and Additional file 1). 
Table 11 Ovarian processing bodies

\begin{tabular}{lll}
\hline $\begin{array}{l}\text { Nonsense-mediated mRNA 3 (Nmd3) } \\
\text { regulator of nonsense transcripts 1; nonsense mRNA reducing factor 1; } \\
\text { up-frameshift suppressor } 1 \text { homolog (rent1; norf1; Upf1) }\end{array}$ & $\begin{array}{l}\text { telomerase-binding protein est1a; similar to smg6 homolog, } \\
\text { nonsense mediated mRNA decay factor (smg6) }\end{array}$ & $\begin{array}{c}\text { Y decapping protein 1 (Dcp 1) } \\
\text { similar to Upf2 regulator of nonsense transcripts homolog (Upf2) }\end{array}$ \\
\hline similar to Bombyx mori Upf3 regulator of nonsense transcripts-like protein B (Upf3) & $Y$ & pacman; 5'-3' exoribonuclease 1 (XRN1; pcm) \\
\hline no-on-and-no-off-transient C (smg1) & $Y$ & EDC4; Ge-1 (Ge-1) \\
\hline smg5 (smg5) & $Y$ & \\
\hline Ovarian processing bodies genes identified mainly from the Drosophila melanogaster literature. Presence (Y) or absence (N) of orthologous transcripts in the & $\mathrm{Y}$
\end{tabular}

Maternal transcripts involved in regulating early embryogenesis - dorsal-ventral patterning of the embryo and early neurogenesis

Drosophila melanogaster uses an elaborate network of genes to pattern the DV axis during embryogenesis on the basis of the oocyte polarity established during oogenesis (discussed in $[89,120]$; further references in Additional file 1). As discussed elsewhere in this paper, the two genes essential for establishing DV polarity in D. melanogaster oocytes, grk and pipe (the latter of which is repressed dorsally [120]), were absent from the $P$. aegeria transcriptome. The genes that are subsequently involved in establishing the ventral side of the $D$. melanogaster embryo are coopted from the Toll innate immune defense pathway (including a serine protease cascade [121]). A similar cascade has been described in $T$. castaneum, but at present it is not known whether it is restricted to the ventral perivitelline space [4]. This protease cascade and associated (ventral) genes were also expressed in $P$. aegeria, but at present it is unclear in which functional context they are used. These genes include; windbeutel (wind), nudel (ndl), gastrulation defective ( $g d)$, snake (snk), easter (ea), spn27A, spz, tube (tub) and pelle ( $p l l)$ (Tables 7 and 13; Additional files 1 and 2). No orthologs for the zinc-finger gene weckle (wek) have yet been found outside Drosophila, and wek was also not found in P. aegeria (Table 13). In D. melanogaster, Toll receptor protein accumulates during the embryonic syncytial stage prior to nuclear migration, and is activated ventrally as the result of a serine/protease cascade (references in Additional file 1). The Toll-like receptor expressed by $P$. aegeria during oogenesis was found to be an ortholog of 18 wheeler $(18 w)$, rather than toll $(t l)$ (Tables 6 and 13). In D. melanogaster
$18 w$ is involved in dorsal appendage formation and follicle cell migration [122], and DV patterning [89]. While $P$. aegeria eggs do not have dorsal appendages, $18 w$ may be involved in DV patterning. In D. melanogaster $18 w$ expression in relation to eggshell patterning, and thus DV polarity, is dependent on input from Dpp and EGF signalling pathways [89]. As discussed elsewhere in the paper, there is not much evidence for EGF signalling in P. aegeria oogenesis, but there is for Dpp signalling (e.g. Figure 4 qPCR results). Furthermore, analyses of Toll receptors have shown that $B$. mori $t l$ and $18 w$ sequences were more similar to each other, than to D. melanogaster toll [123]. It thus remains to be investigated exactly which functional role $18 \mathrm{w}$ fulfils during oogenesis in Lepidoptera.

Pararge aegeria did express cactus (cact) and dorsal $(d l)$ (Table 13). Dorsal protein is distributed evenly in a D. melanogaster embryo, but a gradient in the uptake of Dorsal protein into the nucleus (high on the ventral side) is essential for subsequent DV patterning in the D. melanogaster embryo. Dorsal protein activates some genes, whilst repressing others along the DV axis $[120,124]$. While there are some differences in detail, the gene regulatory network underlying embryonic DV patterning is largely conserved in all insects [4]. The Dorsal protein represses $d p p$ ventrally and the protein encoded by grainyhead (NTF-1/grh) acts as co-repressor [124]. RNA of grh is deposited maternally into the oocyte to be translated and used ventrally during embryogenesis [124]. Repression of $d p p$ by a Dorsal gradient does not, however, occur in T. casteneum [4]. A high concentration of Dpp will eventually be restricted to the dorsal side of the D. melanogaster embryo and its concentration is further restricted ventro-laterally by Short gastrulation (Sog),

Table 12 Germ plasm formation and germline viability

\begin{tabular}{llll}
\hline rab-protein 11 (rab11) & Y & germ cell-less (gcl) & $\mathrm{N}$ \\
\hline rab-protein 5 (rab5) & $\mathrm{Y}$ & stambha a; CG8739; protein efr3 homolog b; rolling blackout (cmp44e; stma) & $\mathrm{Y}$ \\
\hline skittles; pip5k (type 1) (pip5k) & $\mathrm{Y}$ & myoglianin (myo; myg) & $\mathrm{N}$ \\
\hline rap1 GTPase activating protein (rapgap) & $\mathrm{Y}$ & mitochondrial small ribosomal RNA (mtsrRNA; 12s rRNA) & $\mathrm{N}$ \\
\hline
\end{tabular}

Genes identified mainly from the Drosophila melanogaster literature involved in germ plasm (i.e. pole plasm in $D$. melanogaster) formation - Control of endocytosis in germline and germline viability. Presence $(\mathrm{Y})$ or absence $(\mathrm{N})$ of orthologous transcripts in the Pararge aegeria transcriptome is indicated. 


\section{Table 13 Maternal effect genes}

\begin{tabular}{|c|c|c|c|}
\hline abstrakt (abs) & Y & jafrac 1; thioredoxin peroxidase 1; thiol peroxiredoxin (jafrac1; dpx-4783) & Y \\
\hline terribly reduced optic lobes; perlecan; zeste-white 1 (trol; pcan; zw1) & Y & deadhead; thioredoxin (trx-1; trx) & $\mathrm{N}$ \\
\hline $\begin{array}{l}\text { TBC1 domain family member } 1 \text {; weakly similar to Drosophila } \\
\text { melanogaster pollux }(p / x)\end{array}$ & Y & thioredoxin-like; similar to Bombyx mori thioredoxin (trxl) & Y \\
\hline out at first (oaf) & Y & thioredoxin-2; similar to Bombyx mori thioredoxin-like (trx2) & Y \\
\hline extra macrochaetae (emc) & Y & yema gene 2.8 (yemg2.8) & $\mathrm{N}$ \\
\hline wings up a; troponin 1 (tn 1; tpn 1; wupa) & Y & yema gene 3.4 (yemg3.4) & $\mathrm{N}$ \\
\hline troponin c (tpnc; tnc47d) & Y & yema gene $3 a$ (yemg3a) & $\mathrm{N}$ \\
\hline troponin $t$; wings up b; upheld (tpnt; wupb) & Y & yema gene $3 b$ (yemg3b) & $\mathrm{N}$ \\
\hline tropomyosin 1 or 2 (tm1; tm2) & Y & yema gene $3 c$ (yemg3c) & $\mathrm{N}$ \\
\hline alcohol dehydrogenase (adh) & Y & yema gene 4 (yemg4) & $\mathrm{N}$ \\
\hline polar granule component (pgc) & $\mathrm{N}$ & yema gene 9.5 (yemg9.5) & $\mathrm{N}$ \\
\hline $\begin{array}{l}\text { type III alcohol dehydrogenase; iron-containing dehydrogenase } \\
\text { (t3dh; adhfe1) }\end{array}$ & Y & yemanuclein $a$; similar to ubinuclein (yemalpha) & $\bar{Y}$ \\
\hline plutonium (plu) & N & wings down; pourquoi-pas; serendipity-cognate (pqp; wdn; sry-h1) & Y \\
\hline pan gu (png) & $\mathrm{N}$ & serendipity delta; serendipity $\delta$ (sry-delta) & Y \\
\hline giant nuclei (gnu) & $\mathrm{N}$ & serendipity a (sry-alpha) & Y \\
\hline germ cell guidance factor wunen; phosphatidate phosphatase (wun) & Y & heat shock RNA $\omega$ (hsr-omega) & $\mathrm{N}$ \\
\hline receptor for activated protein kinase c rack 1 (rack1) & Y & tiovivo; nebbish; kinesin-like protein at $38 b$ (klp38b; tio; neb) & $\mathrm{N}$ \\
\hline shuttle craft; transcriptional repressor nf-xl (stc) & Y & GTP-binding protein alpha-subunit; G protein a $73 b$ (Galpha73b) & $\mathrm{N}$ \\
\hline muscleblind (mbl) & Y & Guanine nucleotide-binding protein G(I) subunit (Galphal) & $\mathrm{N}$ \\
\hline grainyhead (NTF-1; grh) & Y & $\begin{array}{l}\text { G protein } \beta \text {-subunit 13f; heterotrimeric guanine nucleotide-binding } \\
\text { protein beta subunit (Bombyx mori) (Gbeta13f) }\end{array}$ & $\bar{Y}$ \\
\hline $\begin{array}{l}\text { dorsal (Drosophila); embryonic polarity protein dorsal (Bombyx - } 2 \\
\text { isoforms) (dl) }\end{array}$ & Y & G protein y 1; CG8261 (Ggamma1; bro4) & Y \\
\hline dorsal switch protein (dsp1; ssrp2) & Y & protein tyrosine phosphatase 69d (ptp69d) & $\mathrm{N}$ \\
\hline tosca; exonuclease 1 (tos) & Y & similar to serine/threonine kinase pelle; homologous to irak-4 (pll) & $\bar{Y}$ \\
\hline Darkener of apricot; dual specificity protein kinase clk2 (Doa) & Y & gastrulation-defective (gd) & Y \\
\hline clipper; cleavage and polyadenylation specific factor 4 (clp; cpsf30) & Y & short gastrulation (sog) & $\mathrm{N}$ \\
\hline vrille (vri; jf23) & Y & tube (tub) & Y \\
\hline absent md neurons and olfactory sensilla (amos) & $\mathrm{N}$ & similar to Bombyx mori spätzle 1 (spz) & Y \\
\hline baboon; activin receptor type 1 (ATR1) & $\mathrm{Y}$ & weckle (wek) & $\bar{N}$ \\
\hline eyelid; osa (eld; osa) & Y & cactus (cact) & Y \\
\hline gonadal (gdl) & Y & $\begin{array}{l}\text { BzArgOEtase (Bombyx mori); similar to easter; clip-domain serine } \\
\text { protease subfamily B (ea) }\end{array}$ & Y \\
\hline $\begin{array}{l}\text { éclair; transmembrane emp24 protein transport domain containing } \\
9 \text { (eca) }\end{array}$ & Y & $\begin{array}{l}\text { similar to snake (Drosophila melanogaster); similar to serine protease } \\
21 \text { (Manduca sexta); clip-domain serine protease subfamily c (snk) }\end{array}$ & Y \\
\hline baiser; transmembrane trafficking protein (bai) & Y & toll $(t)$ & $\mathrm{N}$ \\
\hline logjam (loj) & Y & $\begin{array}{l}\text { similar to Bombyx mori calpain; weakly similar to Drosophila } \\
\text { melanogaster Calpain-A (CalpA) }\end{array}$ & Y \\
\hline $\begin{array}{l}\text { bancal; (similar to) heterogeneous nuclear ribonucleoprotein } \mathrm{K} \\
\text { (hrb57A; q18) }\end{array}$ & Y & $\begin{array}{l}\text { similar to brokenheart; similar to } G \text { protein oalpha } 47 A \text {; Guanine } \\
\text { nucleotide-binding protein } G(0) \text { subunit alpha; } G \text { protein alpha } \\
\text { subunit go (G-olpha47A) }\end{array}$ & Y \\
\hline maternal transcript 89BA (mat89BA) & N & concertina; Guanine nucleotide-binding protein subunit alpha-13 (conc) & $\mathrm{N}$ \\
\hline asunder; maternal transcript 89BB (mat89BB; asun) & Y & $\begin{array}{l}\text { SNF1AVAMP-activated protein kinase - alpha subunit (SNF1-AMPK-alpha } \\
\text { subunit) }\end{array}$ & Y \\
\hline $\begin{array}{l}\text { diadenosine tetraphosphatase; similar to bis(5-nucleosyl)- } \\
\text { tetraphosphatase (datp) }\end{array}$ & Y & $\begin{array}{l}\text { SNF1AVAMP-activated protein kinase - beta subunit (SNF1-AMPK-beta } \\
\text { subunit) }\end{array}$ & Y \\
\hline
\end{tabular}


Table 13 Maternal effect genes (Continued)

\begin{tabular}{|c|c|c|c|}
\hline dopa decarboxylase; aromatic-l-amino-acid decarboxylase (ddc) & Y & $\begin{array}{l}\text { SNF1AVAMP-activated protein kinase - gamma subunit (SNF1-AMPK- } \\
\text { gamma subunit) }\end{array}$ & $Y$ \\
\hline hairless (h) & N & IGF-II mRNA-binding protein (imp; MRE11) & $Y$ \\
\hline $\begin{array}{l}\text { suppressor of hairless; j kappa-recombination signal-binding } \\
\text { protein }(s u(h))\end{array}$ & Y & similar to G protein alpha q; G protein a49b (Gaq; Galpha49b) & Y \\
\hline transcription termination factor lodestar; horka (horka; ids) & Y & map kinase activated protein-kinase-2 (mk2; MAPK-ak2) & Y \\
\hline raspberry; inosine monophosphate dehydrogenase (ras) & Y & $\begin{array}{l}\text { ptb-associated splicing factor; weakly similar to Drosophila no on } \\
\text { or off transient a (psf) }\end{array}$ & $\bar{Y}$ \\
\hline misato (mst; lb20) & Y & palmitoyl-protein thioesterase 1 (ppt1) & Y \\
\hline peanut; similar to septin 7 (pnut) & Y & abl tyrosine kinase (abl) & Y \\
\hline septin 1; innocent bystander (sep-1; iby) & Y & Abelson interacting protein (Abi) & Y \\
\hline septin $2($ sep-2) & Y & wing blister; homologous to laminin alpha 2 (merosin) (wb) & $\mathrm{N}$ \\
\hline $\begin{array}{l}\text { septin and tuftelin interacting protein; elongator complex protein 2; } \\
\text { septin interacting protein } 1 \text { (stip) }\end{array}$ & Y & supervillin; CG33232 (svil) & Y \\
\hline kurz; similar to ATP-dependent RNA helicase dhx37 (kz) & Y & cyclope; cytochrome c oxidase subunit vic (cype) & Y \\
\hline pebble (pbl) & Y & la autoantigen-like (la) & Y \\
\hline numb (numb; nb) & Y & tramtrack (ttk; ttk69) & Y \\
\hline catalase (cat) & Y & $\begin{array}{l}\text { high mobility group protein b1; dorsal switch protein } 1 \text { (HMGb1; } \\
\text { dsp1; ssrp2) }\end{array}$ & Y \\
\hline superoxide dismutase (sod1; csod; cu/znsod) & Y & zinc finger protein $43 c(a z 2)$ & $\mathrm{N}$ \\
\hline disc proliferation abnormal (mcm4; dpa) & Y & maverick (mav) & $\mathrm{N}$ \\
\hline Fragile $\times$ mental retardation 1 (Fmr1) & Y & shibire; dynamin (shi; dyn) & Y \\
\hline female sterile (2) ketel; karyopherin beta 1; importin $\beta$ (ketel; imp-beta) & Y & protein o-fucosyltransferase 1; similar to Bombyx mori fut 12 gene (pofut1) & Y \\
\hline karyopherin beta 3 (karyß3) & Y & protein o-fucosyltransferase 2; similar to Bombyx mori fut13 gene (pofut2) & Y \\
\hline cas/csel segregation protein; export karyopherin cas/cselp (cas) & Y & similar to bloated tubules; sodium/chloride dependent transporter (blot) & Y \\
\hline importin alpha 1; karyopherin a1 (imp alpha 1) & Y & $\begin{array}{l}\text { gastrulation defective protein } 1 \text { homolog; CG5543; similar to WD } \\
\text { repeat-containing } 70 \text { protein (CG5543) }\end{array}$ & Y \\
\hline importin alpha 2; karyopherin a2; pendulin (imp alpha 2) & Y & high mobility group protein $20 a(H M G 20 a)$ & Y \\
\hline importin alpha 3; karyopherin a3 (imp alpha 3) & Y & $\begin{array}{l}\text { high mobility group box-containing protein 4; hmg-box protein hmg2/1 } \\
\text { (HMGX4) }\end{array}$ & Y \\
\hline imaginal disc growth factor 1 (idgf; idgf1) & Y & $\begin{array}{l}\text { calcium atpase at 60a; sarcoplasmic/endoplasmic reticulum calcium } \\
\text { atpase (serca; kum; dserca; cap60a) }\end{array}$ & Y \\
\hline imaginal disc growth factor 2 (idgf2) & N & dacapo (chakra; dap) & N \\
\hline imaginal disc growth factor 3 (idgf3) & N & liprin-a (liprin-a) & $\mathrm{N}$ \\
\hline imaginal disc growth factor 4 (idgf4) & $\mathrm{N}$ & $\begin{array}{l}\text { mitochondrial acyl carrier protein 1; nadh-ubiquinone oxidoreductase } \\
\text { acyl carrier protein (mtacp1) }\end{array}$ & $\mathrm{N}$ \\
\hline $\begin{array}{l}\text { kinesin-like protein at 61f; urchin; kinesin-like protein klp2 } \\
\text { (in Bombyx mori) (klp61f; klp2) }\end{array}$ & Y & mitochondrial assembly regulatory factor; mitofusin (marf; mfn; mfn2) & Y \\
\hline puromycin sensitive aminopeptidase ( $p$ sa) & Y & $\begin{array}{l}\text { ripped pocket; gonad-specific amiloride-sensitive sodium channel } 1 \\
\text { (rpk; gnac1) }\end{array}$ & $\mathrm{N}$ \\
\hline cask ortholog; calmodulin-dependent kinase (caki; cmg; camguk) & Y & kurtz; similar to beta-arrestin 1 (krz) & Y \\
\hline signal transducing adaptor molecule (stam) & Y & ubiquitin carboxy-terminal hydrolase; CG4265 (uch) & Y \\
\hline $\begin{array}{l}\text { histone acetyltransferase kat2b; histone acetyltransferase pcaf; general } \\
\text { control of amino acid synthesis protein 5-like } 2 \text { (pcaf; gcn5) }\end{array}$ & Y & lark (lark) & Y \\
\hline ada2b (ada2b) & Y & semaphorin-5c (sema-5c) & $\mathrm{N}$ \\
\hline s-adenosyl-methyl transferase mraw; CG14683 (mraw) & Y & semaphorin 16 (sema-1b) & $\mathrm{N}$ \\
\hline $\begin{array}{l}\text { c-terminal binding protein; hairy-interacting protein; similar to } \\
\text { 2-hydroxyacid dehydrogenase (ctbp) }\end{array}$ & Y & selenophosphate synthetase 1; selenide, water dikinase (sps 1) & $Y$ \\
\hline
\end{tabular}


Table 13 Maternal effect genes (Continued)

\begin{tabular}{ll}
\hline $\begin{array}{l}\text { reticulated (ret) } \\
\begin{array}{l}\text { furin 1; similar to convertase subtilisin/kexin; similar to furin-like } \\
\text { convetase (fur1) }\end{array}\end{array} \quad$\begin{tabular}{l}
$\mathrm{N}$ \\
$\begin{array}{l}\text { sodium/potassium exchanging and transporting ATPase subunit beta 1 } \\
\text { nervana 1 (nrv1) }\end{array}$ \\
\hline windbeutel; thioredoxin-like motif containing gene (wbl) \\
nervana 2 (nrv2)
\end{tabular} \\
\hline
\end{tabular}

Maternal transcripts; Maternal effect genes identified mainly from the Drosophila melanogaster literature encoding various types of proteins, including enzymes, needed for early embryogenesis and germ cell formation. Presence $(\mathrm{Y})$ or absence $(\mathrm{N})$ of orthologous transcripts in the Pararge aegeria transcriptome is indicated.

which in D. melanogaster may also be maternally provided [120]. Rather interestingly, this antagonistic interaction between Dpp and Sog may already be employed during oogenesis for the establishment of DV polarity in the oocyte [125]. The vrille (vri) gene encodes a Bzip transcription factor that interacts in D. melanogaster with Dpp signalling, acting as dominant maternal enhancers of embryonic DV patterning defects caused by ea and $d p p$ mutations [126]. Two P24 proteins encoded by eclair (eca) and baiser (bai) are essential for the activity of maternal Tkv, a type I Dpp receptor [127]. Pararge aegeria females did transfer maternal transcripts of $g r h, d p p, t k v, e c a, b a i$ and vri into the oocyte, but did not express sog maternally (Figure 4 qPCR results; Tables 3 and 13; Additional files 1 and 2).

Drosophila melanogaster females express a group of genes called the yema genes (yema 2.8, 3.4, 3a, 3b, 3c, 4 and 9.5) during oogenesis, with most of them displaying strict maternal expression. This may be of importance in the development of the central nervous system of the embryo [128]. However, the exact functional roles of the yema genes are not known and there are no orthologs outside Drosophila [128]. No orthologs were found for these genes in the $P$. aegeria transcriptome (Table 13 and Additional file 1). Pararge aegeria females did, however, express a number of other genes that are implicated in embryonic brain development or in general in the nervous system; e.g. neuralized (neu), elav, brainiac (brn), Fmr1, brain tumor (brat), mnb, and terribly reduced optic lobes (trol) (Tables 3, 6 and 13; Additional file 1). Of these, $m n b$ and elav have not been explicitly studied in the context of oogenesis (references in Additional file 1). Although maternal transcripts of these genes may play a role in embryonic neural development in D. melanogaster, these genes appear to be important in establishing polarity of the oocyte and its differentiation during oogenesis (references in Additional file 1). The expressions of three of these were further investigated by means of qPCR: elav, Fmr1 and the serine/protease encoding $m n b$ (Figure 4 qPCR results). To date, of these three, only Fmrl has been described as present in $D$. melanogaster oocytes, but elav, Fmr1 and $m n b$ were all found in P. aegeria oocytes (Figure 4 qPCR results) [129]. Compared to the ovaries, the amount of elav and Fmr1 transcripts in the oocytes was quite low (Figure 4 qPCR results; Additional file 2), suggesting they are important during oogenesis. Whether these genes play a role of significance in establishing oocyte polarity in $P$. aegeria needs to be investigated.

\section{Terminal genes}

The Torso receptor tyrosine kinase (RTK) pathway has been implicated in a number of different processes during D. melanogaster oogenesis, including vitelline membrane (or envelope) biogenesis [130] and in particular terminal region specification [131]. The maternal-effect gene torso (tor) encodes a receptor whose ligand is most probably encoded for by trunk (trk). Furthermore, the protein encoded by torsolike $(t s l)$ plays a role upstream of trk in activating the Tor receptor in a localised manner, and is thought to be essential for terminal specification [132]. Although both tor and tsl are involved in terminal specification in $T$. castaneum, different tissues are patterned and Torso signalling plays a role in defining the posterior growth zone during embryogenesis in this short germband insect [133]. Torso signalling is by no means the default mechanism for terminal specification, as the honey bee (Apis mellifera) has the gene $t s l$, but not tor and trk in its genome [134]. The honey bee seems to rely on other mechanisms for terminal specification [135]. Pararge aegeria does not express clear orthologs of either tor or trk during oogenesis, but does express tsl (Table 14). Bombyx mori does have a RTK in its genome (BGIBMGA003976), which shows similarity to torso, as well as to tie-like and Cad96Ca. Pararge aegeria did not express tie-like (Table 6), but did express Cad96Ca (PACG18092; Additional file 2). This transcript was not present in oocytes and was found only in the ovarioles (Additional file 2). Furthermore, a TBLASTN of the putative $B$. mori tor against the $P$. aegeria transcriptome showed that transcript PACG7078 (complete CDS; Additional file 2) was similar $\left(\mathrm{E}\right.$-value $\left.=5.0 \mathrm{E}^{-50}\right)$, although it had greater similarity to the receptor tyrosine kinase Fps85D than to tor. This transcript is present in both $P$. aegeria oocytes and ovarioles, but its role in oogenesis has not been described in the literature. It is clear that $P$. aegeria uses RTK signalling during oogenesis and that the sequences of its ligands and receptors have diverged from those of other insects. However, at present it is unclear in which functional context RTK signalling takes place. 
Table 14 Terminal specification

\begin{tabular}{|c|c|c|}
\hline $\begin{array}{l}\text { corkscrew; similar to protein tyrosine phosphatase, non-receptor } \\
\text { type } 11 \text { (csw; ptpn11) }\end{array}$ & Y & raf; raf1; pole hole; raf kinase; effector of ras (raf; raf1; phl) \\
\hline dead ringer (dri) & Y & signal transducer and activator (stat) (stat; stat92e) \\
\hline torso (tor) & $\mathrm{N}$ & rolled; map kinase (MAPK) (rl; MAPK; erk) \\
\hline torsolike (tsl) & Y & downstream of raf1 (dsor1) \\
\hline trunk (trk) & $\mathrm{N}$ & hemipterous; mitogen-activated protein kinase kinase (hep; MAPKK; mkk7) \\
\hline female sterile (1) homeotic; fragile-chorion membrane protein $(f s(1) h)$ & Y & growth arrest and DNA-damage inducible 45 (gadd45) \\
\hline ras1 1 (ras 1 ; ras85d) & Y & $\begin{array}{l}\text { shc-adaptor protein; shc-transforming protein 1; src homology } 2 \text { domain } \\
\text { containing; CG3715 (shc) }\end{array}$ \\
\hline
\end{tabular}

Genes identified mainly from the Drosophila melanogaster literature involved in terminal specification. Presence $(\mathrm{Y})$ or absence $(\mathrm{N})$ of orthologous transcripts in the Pararge aegeria transcriptome is indicated.

\section{Chromatin regulation during oogenesis, DNA replication, general transcription and maternal regulation of zygotic transcription in general}

In general, the genes that encode proteins involved in chromatin remodelling, DNA replication and transcription are highly conserved across insects and often across the Metazoa in general (references in Additional file 1). A large number of these genes have been studied specifically in the context of oogenesis in D. melanogaster (Table 15; references in Additional 1). Pararge aegeria was found to express orthologs of a number of these genes (Table 15 and Additional file 1). The genes not expressed by $P$. aegeria seem to either have no clear insect orthologs outside Drosophila, or no such orthologs have been reported in Lepidoptera, such as B. mori. Genes not expressed by $P$. aegeria, but for which Lepidopteran orthologs exist include TATA box binding protein-related factor 2 (Trf2), sex combs on midleg (scm), and Arginine methyltransferase 1 and 8 (DART1 and $D A R T 8$, Table 15 and Additional file 1). The gene scm is a member of the polycomb group (PcG) and similar to $D$. melanogaster polyhomeotic $(p h-p)$ gene. Both play versatile and important roles in $D$. melanogaster oogenesis, particularly in ovarian follicle formation $[136,137]$. Pararge aegeria females did express and transfer orthologs of other PcG genes into the oocyte. These include the polycomb repressive complex 1 (PRC1) genes sex combs extra (sce), polycomb (ph), posterior sex combs (psc), the PRC2 genes extra sex combs (esc), Enhancer of zeste $(E(z))$ and the polycomb related genes Enhancer of polycomb $(E(p h))$ and additional sex combs (asx) (Table 15, Additional files 1 and 2; references therein). Recently these genes have also been identified in $B$. mori embryogenesis [138]. These genes encode proteins that regulate DNA and histone methylation patterns and general chromatin remodelling. However, they also appear to be important specifically during oogenesis and embryogenesis and may be implicated in transferring gene regulatory states from one generation to the next, being regarded as candidate genes in epigenetic processes [139], with possible involvement in transgenerational effects in relation to environmental heterogeneity.

\section{Genes influencing the cell cycle regulators of mitosis and meiosis}

A large number of genes that regulate mitosis have been studied in a reproductive context in D. melanogaster. These genes are not only involved in stem cell maintenance and differentiation in the germarium, but also in relation to endocycling in nurse cells and selective amplication of genes (such as chorion genes) important in oocyte production (further references in Additional file 1). As before, the genes that were not expressed by $P$. aegeria in a mitotic context seemed either to have no clear insect orthologs outside Drosophila, or no such orthologs have been reported in Lepidoptera such as B. mori (Table 16). Among these are dacapo (dap), matrimony (mtrm), microcephalin (MCPH1) and chiffon (chif) (Additional file 1). The full list of genes in Table 16 contains a large number of cyclins, which regulate cyclin dependent kinases (CDKs). Orthologs of two common cyclins could not be found in the $P$. aegeria transcriptome: cyclin $E$ and $J$ (see the discussion on choriogenesis elsewhere in this paper).

The cell cycle becomes arrested in meiotic prophase I in the majority of Metazoans oocytes. This is initiated during the first stages of oogenesis in region 2 of the D. melanogaster germarium [140]. The intriguing fact is that the gene bruno is not only essential in regulating the translation of a number of genes during oocyte differentiation, but it also appears to be involved in regulating the silencing of $\operatorname{Cdk} 1$ activity in order to achieve primary meiotic arrest [140]. It should be noted that oocyte AP and DV polarity is established during primary meiotic arrest and only once the oocyte is properly patterned by stage 14 is this arrest broken [140]. As indicated before, bruno was expressed by $P$. aegeria females (Table 9).

Meiosis during butterfly and moth oogenesis is characterised by the absence of crossing over and the formation of chiasmata [141,142]. Cytological studies have established that female Lepidoptera may form synaptonemal complexes (SC) in early meiotic prophase I, but no recombination nodules (RN) are formed subsequently. 


\section{Table 15 Regulation of transcription and chromatin structure}

\section{DNA polymerase a 180KD; DNA polymerase alpha catalytic subunit $\quad Y$} (DNApol-a180)

RNA polymerase II transcriptional coactivator single stranded-binding Y protein c31a (ssb-c37a)

\begin{tabular}{llll}
\hline polyadenylate-binding protein 2 (rox2; pabp2) & $Y$ & DNA polymerase a (180kD) (DNApol-a180; pola) \\
\hline $\begin{array}{l}\text { high mobility group protein; structure specific recognition protein. fact } \\
\text { complex subunit ssrp1 (ssrp; ssrp1) }\end{array}$ & $Y$ & DNA polymerase delta (DNApol-delta) \\
\hline similar to Drosophila melanogaster high mobility group protein d; & $Y$ & DNA polymerase $\varepsilon$ (DNApol-E; pole)
\end{tabular}

similar to Bombyx mori high mobility group protein $1 b$

(HMGd; HMG1b)

\begin{tabular}{|c|c|c|}
\hline domina; jumeau (jumu/dom) & Y & 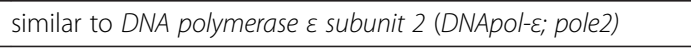 \\
\hline modulo (mod) & $\mathrm{N}$ & 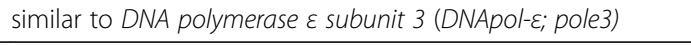 \\
\hline $\begin{array}{l}\text { Iysine-specific histone demethylase 1; suppressor of variegation 3-3 } \\
\text { (suv3-3; su(var)3-3; Isd1) }\end{array}$ & Y & DNA polymerase eta (DNApol-eta; drad30a) \\
\hline $\begin{array}{l}\text { histone methyltransferase 4-20; suppressor of variegation 4-20 } \\
\text { (suv4-20; su(var)4-20) }\end{array}$ & Y & DNA polymerase iota (drad30b; DNApol-iota) \\
\hline $\begin{array}{l}\text { Drosophila melanogaster suppressor of variegation 3-9 (suv3-9; } \\
\text { su(var)3-9) }\end{array}$ & Y & $\begin{array}{l}\text { DNA polymerase zeta; similar to mutagen-sensitive 205; rev3-like } \\
\text { (DNApol-zeta; mus205) }\end{array}$ \\
\hline pitkin(dominant) (ptn(d)) & N & replication protein al (rpa1) \\
\hline Eukaryotic translation initiation factor 2 gamma subunit (elF2g) & Y & replication protein a2 (rpa2) \\
\hline $\begin{array}{l}\text { suppressor of variegation 2-10; protein inhibitor of activated stat } \\
\text { (su(var)2-10; pias; zimp; zimpb;) }\end{array}$ & Y & replication protein a3 (гра3) \\
\hline eggless (egg; SETDB1) & Y & replication factor c 38kD subunit (rfc38) \\
\hline histone h3k9 methyltransferase dg9A ( $g 9 \mathrm{~A})$ & N & (Bombyx mori) replication factor c subunit 2; rfc40 (rfc40; bm- rfc2) \\
\hline modifier of mdg4 (mod(mdg4); e(var)3-93d) & Y & (Bombyx mori) replication factor c4; CG8142 (bm-rfc4) \\
\hline suppressor of hairy wing $(s u(h w))$ & Y & $\begin{array}{l}\text { (Bombyx mori) replication factor c (activator 1) 5; Drosophila } \\
\text { replication factor c subunit } 3 \text { (rfc3) }\end{array}$ \\
\hline trithorax-like (trl; GAGA; gaf; e(var)3; e(var)62) & N & germ line transcription factor 1; replication factor 1 (rfc1; gnf1) \\
\hline $\begin{array}{l}\text { brahma; SWISNF-related matrix-associated actin-dependent regulator } \\
\text { of chromatin subfamily A member; transcription activator brg1 } \\
\text { (smarca4; brm) }\end{array}$ & Y & recombination repair protein 1 (rrp1) \\
\hline $\begin{array}{l}\text { marcal1; SWISSNF-related matrix-associated actin-dependent regulator } \\
\text { of chromatin subfamily A member (marcal1; smarcal1) }\end{array}$ & Y & rev7 (rev7) \\
\hline $\begin{array}{l}\text { snf5-related 1; SWI/SNF-related matrix-associated actin-dependent } \\
\text { regulator of chromatin subfamily B member } 1 \text { (snr1; bap45) }\end{array}$ & Y & trf4-1; sigma DNA polymerase (trf4-1) \\
\hline $\begin{array}{l}\text { brg-1 associated factor; SWI/SNF-related matrix-associated actin- } \\
\text { dependent regulator of chromatin subfamily d member 1; brahma } \\
\text { associated protein 60kD (bap60) }\end{array}$ & Y & topoisomerase 1; topoisomerase i (top 1) \\
\hline
\end{tabular}

associated actin-dependent regulator of chromatin subfamily $E$

(bap 111; dalao)

\begin{tabular}{|c|c|c|c|}
\hline moira (mor; bap155) & Y & topoisomerase 3 alpha; topoisomerase III aplha (toplll-alpha) & Y \\
\hline imitation swi (dnurf; iswi; dchrac) & Y & topoisomerase 3 beta; topoisomerase III beta (topllI-beta) & Y \\
\hline Brahma associated protein 170kD (bap170) & Y & minichromosome maintenance $3(\mathrm{mcm} 3)$ & Y \\
\hline Brahma associated protein 55kD (bap55) & Y & minichromosome maintenance 5 ( $\mathrm{mcm} 5)$ & Y \\
\hline helicase domino (dom) & Y & minichromosome maintenance $6 ; f_{s}(1) \mathrm{k} 1214(\mathrm{mcm} 6)$ & Y \\
\hline $\begin{array}{l}\text { et/1 homologue; SWI/SNF-related matrix-associated actin-dependent } \\
\text { regulator of chromatin subfamily A containing dead/h box } 1 \\
\text { (etll; smarcad) }\end{array}$ & Y & minichromosome maintenance $7(\mathrm{mcm} 7)$ & Y \\
\hline Enhancer of zeste $(E(z))$ & Y & $\begin{array}{l}\text { minichromosome maintenance 8; recombination-defective } \\
\text { (mcm8; rec) }\end{array}$ & Y \\
\hline extra sex combs (esc) & Y & DNA methyltransferase $2(m+2)$ & Y \\
\hline additional sex combs (asx) & $\mathrm{Y}$ & poly-(adp-ribose) polymerase (parp) & $\bar{Y}$ \\
\hline sex comb on midleg $(\mathrm{scm})$ & N & TATA box binding protein-related factor 2 (Trf2; tlf) & $\mathrm{N}$ \\
\hline
\end{tabular}

homolog of regulator of chromatin condensation 2; similar to $\quad Y$ CG9135 (rcc2)

Y DNA polymerase interacting tpr containing protein (dpit47) Y

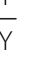


Table 15 Regulation of transcription and chromatin structure (Continued)

\begin{tabular}{|c|c|c|c|}
\hline multi sex combs $(m x c)$ & $\mathrm{N}$ & TATA box binding protein (Tbp) & Y \\
\hline polyhomeotic (ph-p) & $\mathrm{N}$ & tbp-associated factor 250kD (taf250; taf1) & Y \\
\hline $\begin{array}{l}\text { sex combs extra; similar to E3 ubiquitin-protein ligase ring1 } \\
\text { (Bombyx mori) (sce; dring) }\end{array}$ & Y & trithorax-related (trr) & Y \\
\hline polycomb (ph) & Y & supercoiling factor (scf; dcb-45) & Y \\
\hline Enhancer of polycomb $(E(p c))$ & Y & bx42; ski-interacting protein (skip) & Y \\
\hline posterior sex combs (psc) & Y & boundary element-associated factor of 32KD (beaf32) & $\mathrm{N}$ \\
\hline $\begin{array}{l}\text { lethal (3) 73ah; similar to polycomb group ring finger protein } 3 \\
\text { (I/(3)73ah) }\end{array}$ & Y & Histone h4 (H4) & Y \\
\hline $\begin{array}{l}\text { activating transcription factor; homologous to Bombyx activating } \\
\text { transcription factor of chaperone (atf-2) }\end{array}$ & Y & Histone h3.3 (H3.3) & Y \\
\hline cyclic-amp response element binding protein $(1,2,3)($ creb; dcreba) & Y & Histone h2a (H2a) & Y \\
\hline creb binding protein; similar to nejire (crebbp(a)) & Y & Histone h2a variant (H2a.v) & Y \\
\hline retinoblastoma binding protein (rbp) & Y & mutagen-sensitive 308 (Po/Q; mus308) & Y \\
\hline $\begin{array}{l}\text { retinoblastoma binding protein } 2 \text { (jumonji/arid domain containing); } \\
\text { little imaginal discs (rbp2; lid) }\end{array}$ & Y & rpd3 (hdac1; rpd3; hdac) & $\bar{Y}$ \\
\hline similar to retinoblastoma binding protein 6 (rbp6) & Y & mbd-like (mbd2/3; mbd-like) & Y \\
\hline tousled-like kinase (tlk) & Y & mediator complex subunit 6 (med6) & Y \\
\hline no child left behind; similar to wd repeat protein (nclb) & Y & mitochondrial single stranded DNA-binding protein (mtssb) & Y \\
\hline $\begin{array}{l}\text { Arginine methyltransferase 1; Arginine } n \text {-methyltransferase } 1 \\
\text { (DART1; prmt1) }\end{array}$ & N & homolog of reca (reca5) & Y \\
\hline $\begin{array}{l}\text { Arginine methyltransferase 2; Arginine } n \text {-methyltransferase } 2 \\
\text { (DART2; prmt2) }\end{array}$ & $\mathrm{N}$ & hen 1 (dmhen 1; pimet) & Y \\
\hline $\begin{array}{l}\text { Arginine methyltransferase 3; Arginine } n \text {-methyltransferase } 3 \\
\text { (DART3; prmt3) }\end{array}$ & Y & Eukaryotic translation initiation factor $4 G$ (elF4G) & Y \\
\hline $\begin{array}{l}\text { Arginine methyltransferase 4; histone-Arginine methyltransferase carm } 1 \\
\text { (DART4; prmt4) }\end{array}$ & Y & Eukaryotic translation initiation factor $4 A$ (elF4A) & Y \\
\hline $\begin{array}{l}\text { Arginine methyltransferase 6; Arginine n-methyltransferase } 6 \\
\text { (DART6; prmt6) }\end{array}$ & $\mathrm{N}$ & Eukaryotic translation initiation factor 5 (elf5) & Y \\
\hline $\begin{array}{l}\text { Arginine methyltransferase 7; Arginine } n \text {-methyltransferase } 7 \\
\text { (DART7; prmt7) }\end{array}$ & Y & retrotransposon gypsylenvelope (gypsylenv) & $\mathrm{N}$ \\
\hline $\begin{array}{l}\text { Arginine methyltransferase 8; Arginine } n \text {-methyltransferase } 8 \\
\text { (DART8; prmt8) }\end{array}$ & N & jim (ovk; ovfc.k; jim) & Y \\
\hline $\begin{array}{l}\text { Arginine methyltransferase 9; Arginine } n \text {-methyltransferase } 9 \\
\text { (DART9; prmt9) }\end{array}$ & N & zelda; vielfaltig (vfl; zld) & $\mathrm{N}$ \\
\hline absent, small, or homeotic discs 1 (ash-1; ash; dash) & Y & Fcp1 RNA polymerase I/ CTD phosphatase; CG12252 (fcp1) & Y \\
\hline
\end{tabular}
(rangef; rccl)

Genes identified mainly from the Drosophila melanogaster literature involved in regulation of chromatin structure during oogenesis, DNA replication, general transcription and maternal regulation of zygotic transcription in general. Presence $(\mathrm{Y})$ or absence $(\mathrm{N})$ of orthologous transcripts in the Pararge aegeria transcriptome is indicated.

Instead, a structure called elimination chromatin is formed [143]. Usually chiasmata are formed from retained pieces of the SC in which a RN is, or has been, present [144]. The formation of the chiasmata takes place in the cell destined to become the oocyte in the D. melanogaster germarium [140]. Four genes appear essential in D. melanogaster for $\mathrm{SC}$ formation and thus possibly chiasmata formation: crossover suppressor on 2 of Manheim $(c(2) M)$; crossover suppressor on 3 of Gowen (c(3)G); corona (cona) and nipped-B (references in Additional file 1). No genes specific for RN alone could be identified on FlyBase [62]. Pararge aegeria females only express nipped-B (Table 16 and
Additional file 1), which is involved in a number of cellular processes in D. melanogaster including mitosis [145]. It is also the only one of the four SC genes for which orthologs outside Drosophila can be identified. Rather interestingly, a large proportion of the genes involved in D. melanogaster meiotic chromosome cohesion and segregation also appeared to be Drosophila or Diptera specific and were not identified in the $P$. aegeria transcriptome. These include grauzone (grau), corona (cona), orientation disrupter (ord) and mei-S332 (Table 16; references in Additional file 1). A number of genes are, however, highly conserved and orthologs have been found 


\section{Table 16 Cell cycle tregulation during mitosis and meiosis}

\begin{tabular}{|c|c|c|c|}
\hline archipelago; WD repeat domain containing 7 (ago) & $\mathrm{N}$ & myb transforming protein; similar to CG6905 (mybtp) & Y \\
\hline dacapo (dap) & $\mathrm{N}$ & pitchoune (pit) & Y \\
\hline coiled coil domain containing protein $25(\mathrm{ccdc} 25)$ & Y & rad51(-like); spindle A (rad51; spna) & Y \\
\hline breast cancer 2, early onset homolog (brca2) & Y & tribbles (trbl) & Y \\
\hline chiffon (chif) & $\mathrm{N}$ & fizzy; cdc20 (fzy; cdc20) & $\bar{Y}$ \\
\hline cyclin-dependent kinase 1; cell division cycle 2 (cdk1; cdc2) & Y & meiotic 41 (which is the Drosophila atm/atr homolog) (mei-41; fs(1)m37) & $\mathrm{N}$ \\
\hline cyclin-dependent kinase 2 (cdk2) & Y & meiotic from via Salaria 332 (mei-S332) & $\mathrm{N}$ \\
\hline cyclin-dependent kinase 4 (cdk4) & Y & mei-4 (Forkhead domain containing) (mei4) & $\bar{Y}$ \\
\hline cyclin-dependent kinase 5 (cdk5) & Y & mei-W68 (mei-W68) & $\mathrm{N}$ \\
\hline cyclin-dependent kinase 7 (cdk7; mo15) & Y & cortex (cort) & Y \\
\hline cyclin-dependent kinase 8 (cdk8) & Y & grauzone (grau) & $\mathrm{N}$ \\
\hline cyclin-dependent kinase 9 (cdk9) & Y & CG1647; zinc-finger protein (CG1647) & Y \\
\hline cyclin-dependent kinase 10 homolog; cdc2-related kinase (cdk10) & Y & btk family kinase at 29a (btk29a; tec29a) & Y \\
\hline cyclin $A(c y c A)$ & Y & mutator 2 (mu2) & $\mathrm{N}$ \\
\hline cyclin B (cycB) & Y & myelin transcription factor 1 (myt1) & $\mathrm{N}$ \\
\hline cyclin B3; I(3)/6540 (cycB3) & $\mathrm{Y}$ & orientation disrupter (ord) & $\mathrm{N}$ \\
\hline cyclin C (cycC) & Y & mei-218 (mei-218) & $\mathrm{N}$ \\
\hline cyclin D (cycD) & Y & $\begin{array}{l}\text { altered disjunction; mps1 (a kinetochore-associated protein kinase) } \\
\text { (ald; mps 1) }\end{array}$ & $\mathrm{N}$ \\
\hline cyclin $E(c y c E)$ & $\mathrm{N}$ & no distributive disjunction (nod) & N \\
\hline COP9 complex homolog subunit 5 (csn5) & Y & sarah; nebula (sra; nla) & $\bar{Y}$ \\
\hline COP9 complex subunit 3 (csn3; dch3) & Y & calcineurin a (cana) & Y \\
\hline COP9 complex subunit 4 (csn4; dch4) & Y & calcineurin b (canb) & Y \\
\hline COP9 complex subunit 6 (csn6) & Y & mei-38 (mei38) & $\mathrm{N}$ \\
\hline COP9 complex subunit 7 (csn7) & Y & ubiquitin conjugating enzyme E2 rad6 (ubcd6; rad6) & Y \\
\hline COP9 complex subunit 8 (csn8) & Y & alpha-endosulfine (endos) & $\bar{Y}$ \\
\hline cyclin $\mathrm{H}(\mathrm{cycH})$ & Y & early girl; CG17033 (elgi) & Y \\
\hline cyclin J (cycJ) & $\mathrm{N}$ & encore (enc) & $\mathrm{N}$ \\
\hline cyclin K (cycK) & Y & cullin 1 (cul1; lin19) & $\bar{Y}$ \\
\hline cyclin L1; CG16903 (cycL 1) & Y & cullin 2 (cul2) & $\mathrm{N}$ \\
\hline cyclin $T($ cyct $)$ & Y & cullin 4 ( $a$ and b) (cul4) & Y \\
\hline cyclin fold protein; cyclin Y (cycfp; cycY) & Y & double parked (dup) & Y \\
\hline cyclin M2 (cycM2; cnnM2) & Y & cullin 5 (cul5) & Y \\
\hline cyclin-dependent kinase subunit 30a (cks30a) & Y & $\begin{array}{l}\text { gustavus; Bombyx sequence BHIBMGA008896-PA homologous to } \\
\text { spry domain-containing socs box protein } 4 \text { (ssb4) (gus; ssb4) }\end{array}$ & Y \\
\hline cyclin-dependent kinase subunit 85a (cks85a) & Y & ubiquitin conjugating enzyme 2; I(2)k13206 (ubcd2) & Y \\
\hline diminutive; dmyc (dm) & Y & ubiquitin conjugating enzyme e2 d4 (ubcd4) & Y \\
\hline$e 2 f 1(e 2 f 1)$ & Y & origin recognition complex subunit $1(O R C 1)$ & Y \\
\hline e2f5 (e2f5) & $\mathrm{N}$ & origin recognition complex subunit 2; I(3)88ab (ORC2) & Y \\
\hline$d p ;$ e2f dimerization partner 2 (dp; tfdp2) & Y & origin recognition complex subunit 5; I(2)34df (ORC5) & Y \\
\hline $\sin 3 a(\sin 3 a)$ & Y & achintya (zaa) & Y \\
\hline geminin (geminin) & Y & vismay (vis) & $\mathrm{N}$ \\
\hline matrimony ( $m$ trm; d52) & $\mathrm{N}$ & minichromosome maintenance 2 protein $(\mathrm{mcm} 2)$ & Y \\
\hline imaginal discs arrested (ida) & $\mathrm{N}$ & retinoblastoma-family protein $1($ rbfl; rb 1$)$ & $\mathrm{N}$ \\
\hline twine (twe) & $\mathrm{N}$ & grapes; serine/threonine-protein kinase chk1 (chk1; lemp; grp) & $\mathrm{N}$ \\
\hline string; cdc25 phosphatase (stg) & $\mathrm{N}$ & missing oocyte (mio) & $\mathrm{N}$ \\
\hline microcephalin (MCPH1) & $\mathrm{N}$ & megator (mtor) & Y \\
\hline inducer of meiosis 4; mta70 homologue (ime4) & Y & nucleoporin 44a; similar to sec13-like protein (seh1; nup44a) & Y \\
\hline
\end{tabular}


Table 16 Cell cycle tregulation during mitosis and meiosis (Continued)

\begin{tabular}{|c|c|c|c|}
\hline greatwall; mast-like (gwl) & Y & nucleoporin 154; tulipano (nup154; zk; nup32d; tlp) & Y \\
\hline polo (kinase); I(3)01673 (polo) & Y & kinesin-like protein ncd; non-claret disjunctional; claret segregational (ncd) & Y \\
\hline loki; checkpoint kinase 2 (lok; chk2) & Y & $\begin{array}{l}\text { kinesin-13 motor; kinesin-like protein 10a; kinesin-like protein a } \\
\text { (in Bombyx mori)(klp10a; klpa) }\end{array}$ & Y \\
\hline always early; a ling homolog (aly) & Y & similar to Bombyx mori kinesin-like protein b (klpb) & Y \\
\hline pavarotti; kinesin family member 23 (kif23; pav) & Y & crossover suppressor on 2 of Manheim (mei-910; c(2)M) & N \\
\hline morula (anaphase-promoting complex subunit) (mr) & Y & crossover suppressor on 3 of Gowen $(c(3) G)$ & N \\
\hline $\begin{array}{l}\text { proliferating cell nuclear antigen (mutagen-sensitive 209) } \\
\text { (mus209; pcna) }\end{array}$ & Y & corona (cona) & $\mathrm{N}$ \\
\hline mutagen-sensitive 304 (atrip; mus304) & N & nipped-B (nipped-B) & Y \\
\hline myb oncogene-like (myb) & Y & pch2 (pch2) & $\mathrm{N}$ \\
\hline the myb-muvb complex subunit lin-52 (lin-52) & Y & Guanylate kinase-associated protein mars; hurp (hurp; dhrp/Gkap; mars) & Y \\
\hline
\end{tabular}

Genes identified mainly from the Drosophila melanogaster literature that influence the cell cycle - regulators of mitosis (e.g. endocycling and selective amplification of chorion genes) and meiosis. Presence $(\mathrm{Y})$ or absence $(\mathrm{N})$ of orthologous transcripts in the Pararge aegeria transcriptome is indicated.

in Lepidoptera as males do display crossing-over [141,142]. These include both mei-W68 and mei-218 but in particular includes the essential meiotic checkpoint gene pch2 (references in Additional file 1). Female $P$. aegeria did not express any of these genes (Table 16 and Additional file 1 ). The $P$. aegeria oogenesis transcriptome described here is thus in accordance with the previous observations made during cytological studies on female Lepidoptera [141-143].

\section{Vitellogenesis and lipid storage}

Not only is cell cycle regulation coordinated with oocyte differentiation in D. melanogaster [140], but also with resource provisioning of the oocyte [22]. The gene greatwall $(g w l)$, for example, is both essential in D. melanogaster for maternal provisioning of the egg during vitellogenesis and to ensure secondary meiotic arrest by stage 14 of oogenesis in metaphase I [22]. It is a highly conserved gene in Metazoa and $P$. aegeria females did express this gene during oogenesis (Table 16 and Additional file 1). Furthermore, $g w l$ (antagonistically) interacts with polo kinase (polo) in mitotic regulation particularly during early embryogenesis, and is maternally provided (references in Additional file 1). Transcripts of both were detected in $P$. aegeria oocytes (Table 16; Additional files 1 and 2).

Vitellogenesis during insect oogenesis is characterised by the accumulation in the developing oocytes of large lipid transfer proteins (LLTPs; i.e. yolk protein precursors), such as Vitellogenin (Vtg/Vg) and Apolipophorins (ApoLPs) [8,9]. Predominantly, LLTPs are produced in the fat bodies and secreted into the hemolymph $[8,9]$, but not all yolk proteins are extraovarian [146]. Follicle cells not only allow extraovarian yolk protein to reach the oocytes, they also produce significant amounts of LLTPs themselves in a number of insect species, including D. melanogaster [146]. Vitellogenic behaviour of follicle cells is under hormonal control [146]. LLTPs are transported into the oocytes via clathrin-dependent endocytosis mediated by the receptors VgR (in D. melanogaster Yolkless, Yl) and LpR $[9,147]$. Nurse cells transport $y l / V g R$ RNA into previtellogenic oocytes, thus preparing the oocyte for Vtg uptake [148]. Pararge aegeria females expressed not only $V t g / V g$, apoLp-III, apoLp, their receptors $y l / V g R$ and $L p R$, but also the genes described in $D$. melanogaster vitellogenic endocytosis (references in Additional file 1). These genes include clathrin heavy and light chain (chc and $c l c$ ), sec5, sec6, garnet $(G)$ and jagunal (jagn) (Figure 4 qPCR results; Tables 2 and 17; further references in Additional file 1).

The major yolk proteins, such as vitellogenins, share sequence similarities with lipases. Although not catalytically active, the vitellogenin region with sequence similarity to lipases is argued to be involved in steroid hormone binding, thus providing a possibility for a direct interaction with the hormones that regulate their production [149]. For example, maternal ecdysteroids are bound as ecdysteroid-phosphates to the Vtg cleaved product Vitellin ( $\mathrm{Vn}$ ) in yolk granules in B. mori and released as ecdysteroids during yolk uptake in the embryo as a result of dephosphorylation by ecdysteroidphosphate phosphatase (EPPase)[150]. Pararge aegeria did express EPPase (Table 18). Furthermore, a significant component of yolk in a $B$. mori egg is the ovarian egg-specific protein ESP, a minor yolk protein [151]. The gene encoding ESP is intriguing, as convincing orthologs for minor yolk proteins outside the moths Galleria mellonella (yolk protein/yolk polypeptide 2) and Samia cynthia (ESP) had not been found [149]. More recently, however, a further two sequences with strong sequence similarity to $G$. mellonella yolk protein 2 have been discovered in D. plexippus and Plodia interpunctella, whilst ESP does show significant sequence similarity with genes encoding the KK-42 binding proteins in Antheraea moth species [152] (Additional file 9). Sharing 
Table 17 Reproductive physiology and vitellogenesis

\begin{tabular}{|c|c|c|}
\hline apolipophorin-III (apoLp-III) & Y & $\begin{array}{l}\text { homologous to Bombyx juvenile hormone epoxide hydrolase-like } \\
\text { protein } 3 \text { (jheh-Ip3) }\end{array}$ \\
\hline apolipophorin precursor; Drosophila CG1 1064 (apoLp; apolp1/2) & Y & $\begin{array}{l}\text { homologous to Bombyx juvenile hormone epoxide hydrolase-like } \\
\text { protein } 5 \text { (jheh-Ip5) }\end{array}$ \\
\hline lipophorin receptor (Lpr1/2) & Y & $\begin{array}{l}\text { juvenile hormone binding protein; homologous to Drosophila } \\
\text { CG1532 (JHbp) }\end{array}$ \\
\hline arylphorin (subunit beta); sex-specific storage-protein 2 (hex2; sp2) & Y & juvenile hormone binding protein (hemolymph) (hJHbp) \\
\hline $\begin{array}{l}\text { vitellogenin (protein cleaved into vitellin light chain (vl), vitellin light } \\
\text { chain rare isoform, vitellin heavy chain rare isoform and vitellin heavy } \\
\text { chain (vh)) (Vg; Vtg) }\end{array}$ & Y & cytosolic juvenile hormone binding protein $36 \mathrm{KDa}$ subunit (cJHbp) \\
\hline vitellogenin receptor; yolkless (yl; VgR) & Y & takeout (to) \\
\hline spherulin-2a (similar to Plodia interpunctella yp4)(yp4) & Y & $\begin{array}{l}\text { similar to niemann-pick type c-2; ecdysteroid-regulated } 16 \mathrm{kDa} \\
\text { protein precursor (npc2a; esr16) }\end{array}$ \\
\hline chico (chico; IRS) & Y & ecdysone-induced protein 63e (Eip63E; cdc2-63E) \\
\hline Bombyxin genes(bbxA1; bbxA3) & Y & similar to sgt1 protein homolog ecdysoneless (ecd) \\
\hline insulin-like receptor (InR) & Y & cytochrome p450 (E-class, group I) protein disembodied (dib; cyp302a1) \\
\hline ribosomal protein $110 a(r p / 10 a b)$ & Y & halfway; singed wings (hfw; swi) \\
\hline 60s ribosomal protein 110; $\mathrm{gm}$ protein homolog ( $\mathrm{gm}$ ) & Y & clathrin light chain (chc) \\
\hline string of pearls; ribosomal protein s2 (sop; rp2) & Y & clathrin heavy chain (clc) \\
\hline resistance to juvenile hormone; methoprene-tolerant (met) & Y & ced-6 (ced-6) \\
\hline ultraspiracle; rxr type hormone receptor (usp; cfl) & Y & wht receptor I(2)43Ea boca (boca) \\
\hline ecdysone receptor (ECR) & Y & jagunal (jagn) \\
\hline start1 (start1) & Y & exocyst complex component sec5 (sec5) \\
\hline $\begin{array}{l}\text { defective in the avoidance of repellents dare; adrenodoxin reductase } \\
\text { (dare) }\end{array}$ & Y & exocyst complex component sec6 (sec6) \\
\hline ecdysone-induced protein 74 (E74) & $\mathrm{N}$ & $\begin{array}{l}\text { protein phosphatase } 2 a \text { regulatory subunit b'; widerborst } \\
\left(w d b ; P P 2 A b^{\prime}\right)\end{array}$ \\
\hline ecdysone-induced protein $75 b(75 a, b, c$ and d) (E75) & Y & $\begin{array}{l}\text { protein phosphatase } 2 \text { a regulatory subunit b 55kDa; twins } \\
(P P 2 A b 55 \mathrm{kDa})\end{array}$ \\
\hline $\begin{array}{l}\text { homologous to Bombyx mori c-cbl-associated protein (cap) } \\
\text { transcript variant a (bmcap-a) }\end{array}$ & Y & protein phosphatase 2a regulatory subunit b gamma (PP2Agamma) \\
\hline follicle specific protein (fsp-l) & $\mathrm{N}$ & $\begin{array}{l}\text { protein phosphatase } 2 a \text { regulatory subunit a }(65 \mathrm{kDa}) \text {; homologous } \\
\text { to Drosophila protein phosphatase } 2 a \text { at } 296(P P 2 A a)\end{array}$ \\
\hline similar to Bombyx mori egg-specific protein (LOC693022) (ESP) & $\mathrm{N}$ & $\begin{array}{l}\text { microtubule star; protein phosphatase } 2 \text { a catalytic subunit c } \\
\text { (mts; PP } 2 A c)\end{array}$ \\
\hline calmodulin (cam) & Y & lipid storage droplet 1; perilipin 1 (Isd1; plin-1; plin1) \\
\hline $\begin{array}{l}\text { calmodulin-binding protein (striatin); weak homology to CG7392 } \\
\text { (striatin) }\end{array}$ & Y & lipid storage droplet 2 (Isd2) \\
\hline calmodulin dependent protein kinase (camk) & Y & lipase-1 (lip-1) \\
\hline hormone receptor 3; Drosophila hormone receptor-like in 46 (hr3; hr46) & Y & serine/threonine protein kinase akt (akt; akt1) \\
\hline hepatocyte nuclear factor 4 isoform a (hnf-4a) & Y & liquid facets-related (lqfr) \\
\hline hepatocyte nuclear factor 4 isoform b (hnf-4b) & Y & liquid facets (laf) \\
\hline juvenile hormone esterase (jhe) & $\mathrm{N}$ & garnet $(g)$ \\
\hline $\begin{array}{l}\text { juvenile hormone esterase binding protein; weak homology to } \\
\text { Drosophila CG3776 (JHEbp; DMP29) }\end{array}$ & Y & cationic amino acid transporter; slimfast (slif) \\
\hline juvenile hormone epoxide hydrolase (JHEH) & Y & ornithine decarboxylase (odc) \\
\hline $\begin{array}{l}\text { homologous to Bombyx juvenile hormone epoxide hydrolase-like } \\
\text { protein } 1 \text { (iheh-lp1) }\end{array}$ & Y & ornithine decarboxylase antizyme; gutfeeling (guf; Oda; az) \\
\hline
\end{tabular}


Table 18 Yolk consumption

\begin{tabular}{|c|c|c|c|}
\hline $\begin{array}{l}\text { cathepsin 1-like cysteine protease; Bombyx cysteine protease; } \\
\text { cysteine proteinase-1 (bcp; } c l ; c p 1)\end{array}$ & Y & vacuolar proton atpase; vacuolar $h+$ atpase subunit 100-2 (vha100-2) & Y \\
\hline cathepsin b; cathepsin b-like cysteine proteinase (catb) & Y & $\begin{array}{l}\text { h+ transporting atpase v0 subunit d; vacuolar h+ atpase subunit ac39-1 } \\
\text { (vhaac39-1) }\end{array}$ & Y \\
\hline cathepsin d; aspartic protease (catd) & Y & $\begin{array}{l}\text { vacuolar atp synthase subunit d; vacuolar } h+\text { atpase subunit 36-1 } \\
\text { (mvd; vha36-1) }\end{array}$ & Y \\
\hline cathepsin f-like cysteine protease; CG12163 (catf) & Y & CG7899; acid phosphatase 1 (acph-1; ap) & $\mathrm{N}$ \\
\hline ecdysteroid-phosphate phosphatase (EPPase) & Y & primo-1; acid phosphatase isoenzyme (primo-1) & Y \\
\hline $\begin{array}{l}\text { vacuolar proton atpase; vacuolar } h+\text { atpase subunit 100-1 } \\
\text { (mva; v100; vha100-1) }\end{array}$ & Y & & \\
\hline
\end{tabular}

the same ABhydrolase lipase region, The KK-42 binding proteins and the minor yolk proteins also show strong sequence similarity to lipases identified in species such as D. melanogaster, in particular lipase-1 and 3 (lip-1 and 3) [149]. Lepidoptera may have evolved to use paralogs of these genes in yolk formation. Rather interestingly, although not functioning as a yolk protein, lip-1, but not lip-3, is expressed in vitellogenic follicles in D. melanogaster [149]. An orthologs of lip-1, and possibly lip-3 (very short partial contig), was expressed by $P$. aegeria, whilst no clear ortholog of a minor yolk protein was found (Table 17; Additional files 2 and 9).

Among the most highly transcribed genes in $P$. aegeria ovarioles is an ortholog of the slime mold Physarum polycephalum gene spherulin- $2 A$. No transcripts were found for this gene in eggs (Table 2 and Additional file 2). Lepidopteran orthologs of the protein encoded by this gene have been shown to function as a subunit Yp4 of follicular epithelium yolk protein produced by follicle cells [153].

Yolk is a food source for the developing embryo and a number of genes encoding Cathepsins and Vacuolar Proton ATP-ases are maternally expressed during oogenesis to facilitate yolk uptake in the embryos (references in Additional file 1). Pararge aegeria females were found to express all described yolk uptake genes, with the exception of the acid phosphatase 1 gene (acph-1) (Table 18 and Additional file 1).

\section{Physiology of oogenesis}

Reproductive output depends on female nutritional status which not only affects the rate and duration of oogenesis significantly, but also whether previtellogenic egg chambers will enter the vitellogenic stage or apoptose [154]. Two signalling systems are involved; insulin and hormone signalling [155]. In D. melanogaster, for example, absence of the insulin receptor substrate (IRS) Chico precludes vitellogenesis, whilst a sharp increase in 20-hydroxy-ecdysone (20E) relative to juvenile hormone $(\mathrm{JH})$ results in apoptosis of the egg chamber before vitellogenesis is initiated or completed [16,155]. Although the two signalling systems operate simultaneously and interact, both have been shown to be able to independently terminate egg chamber progression before vitellogenesis takes place in D. melanogaster [155]. Furthermore, the Lepidoptera express a set of unique genes encoding insulin-like peptides, the Bombyxins (Bbx) [156]. The $b b x$ genes are expressed predominantly in the brain, but some may also be expressed in ovaries [156]. Moths, in particular B. mori, possess a large number of $b b x$-like genes in their genome [156], but the genome of the butterfly $D$. plexippus appears to have only three such genes [50]. Orthologs of 2 of these 3 (bbxA1-like and $b b x A 3-$ like) were transcribed in $P$. aegeria ovarioles, whilst a third partial IRS transcript showed more sequence similarity to chico than to any $b b x$-like gene (Table 17 and Additional file 1). The insulin-like receptor $(I n R)$ was also expressed by $P$. aegeria during oogenesis (Table 17 and Additional file 1). Furthermore, P. aegeria expressed a large number of downstream target genes of insulin signalling including genes encoding the serine/ threonine protein kinase Akt, the various protein phosphatase 2A subunits (PP2A, e.g. Widerborst) and the lipid storage droplet proteins 1 and 2 (Lsd1 and Lsd2). Please refer to Table 17 and references in Additional file 1 for additional details.

Apart from nutritional status, environmental factors such as temperature can affect hormone concentrations, providing a possibility for environmental control of reproductive output $[7,26]$. The interplay between $20 \mathrm{E}$ and $\mathrm{JH}$ is dynamic and complex, as both $20 \mathrm{E}$ and $\mathrm{JH}$ also play a role in regulating choriogenesis [157]. Both hormones have a range of pleiotropic effects during oogenesis and their exact developmental role is not only titre related, but also dependent on the dynamic spatiotemporal expression patterns of the receptors and modulators of hormone signalling [157].

There has been extensive investigation of $\mathrm{JH}$ signalling $[7,26]$, but the signal transduction pathway, including the $\mathrm{JH}$ receptor, remains poorly understood 
[158-160]. The most likely candidate gene for the $\mathrm{JH}$ receptor proposed to date is the basic helix-loop-helix (bHLH)/Per-Arnt-Sim (PAS) domain gene methoprenetolerant (met) [158-160]. It may form a homodimer, or possibly may form a JH-dependent transcriptionally active complex with another member of the bHLH-PAS family. The most likely candidate for the complex is the steroid co-activator NCoA-1/p160 FISC, encoded by the gene taiman (tai) in D. melanogaster $[158,160]$. The tai gene was originally discovered as a gene that was expressed in follicle cells in the functional context of border cell migration and was described as an ecdysone co-receptor (Table 6; references in Additional file 1). Pararge aegeria females expressed both met and tai (Tables 6 and 17 and S2; contigs for tai PACG7006 and PACG13674 in Additional file 2). An ortholog for tai (UNIPROT: G6DPV9) can also been found in the genome of $D$. plexippus [50].

Not much is known about which genes are transcriptionally regulated by the $\mathrm{JH}$ activated receptor complex [161]. The gene kruppel-homolog 1 (krh1) has been described as a $\mathrm{JH}$ response gene, inhibiting 20E induced broad (br) expression in $D$. melanogaster, but not in the specific context of oogenesis [159]. Both khrl and $b r$ were expressed by $P$. aegeria females (Additional file 1). Furthermore, JH may either directly or indirectly upregulate ornithine decarboxylase $(o d c)$, which regulates polyamine biosynthesis and appears to be essential for vitellogenesis [162]. Both odc and its antagonist gutfeeling (oda), also a mitotic cell-cycle regulator, were expressed in $P$. aegeria. Maternal transcripts of $o d c$ and oda were found in eggs (Figure 4 qPCR results; Table 17, Additional files 1 and 2).

In order to regulate the precise amount of $\mathrm{JH}$ in both hemolymph and organs, two sets of enzymes are involved in $\mathrm{JH}$ degradation; the $\mathrm{JH}$ epoxide hydrolases (JHEHs) and the JH esterases (JHEs) [163]. JHEs function predominantly in the hemolymph and degradation is reversible, whilst $\mathrm{JHEH}$ s regulate the amount of $\mathrm{JH}$ in organs and degradation is irreversible [163]. Apart from $\mathrm{JHEH}$, five recently discovered JHEH-like protein genes have been characterised in B. mori [163] and in addition to JHEH, P. aegeria expressed orthologs of three of these; jheh-lp1, jheh-lp3 and jheh-lp5 (Table 17 and Additional file 1). With the exception of jheh-lp5, moderate amounts of transcripts of JHEHs were found in the eggs (Additional file 2). The females did not express a clear ortholog of $j h e$, but did express an ortholog of a gene encoding an intracellular binding protein of JHE presumed to be involved in its transport (JHEbp or DmP29, Drosophila mitochondrial protein 29, Table 17). Significant amounts of maternal JHEbp transcripts were found in $P$. aegeria eggs (Additional file 2).

Juvenile hormone itself may be bound by JH binding proteins (JHbp) to enable immobilisation, regulate degradation or enable transport [28]. Four complete $J H b p$ CDSs were identified in P. aegeria ovaries; JHbp, cytosolic JHbp (cJHbp), hemolymph $\mathrm{JHbp}(\mathrm{hJHbp}$ ) and a sequence showing strong orthology to takeout (to) identified in D. melanogaster as involved in $\mathrm{JH}$ binding (Table 17). Transcripts of both cJHbp and to were transferred to the eggs by $P$. aegeria (Additional file 2). Given that $\mathrm{JH}$ itself can be transferred maternally into eggs in Lepidoptera, it has been argued that $\mathrm{JH}$ binding proteins such as $\mathrm{cJHbp}$ will protect the developing embryo against the teratogenic effects of any excess $\mathrm{JH}$ transferred from the mother [28].

There is a significant amount of life-history variation among insects and consequently in the relative importance of $20 \mathrm{E}$ and $\mathrm{JH}$ on oogenesis [26], even within Lepidoptera [8]. Lepidoptera have been categorised into four (physiological) groups based on the hormones used to initiate vitellogenesis, choriogenesis and thus the timing of mature egg production [7]. Nymphalids, like $P$. aegeria, have been argued to best match the criteria for group 4 [7] where $\mathrm{JH}$ is the essential gonadotropic hormone. Juvenile hormone in this group is necessary for: a) synthesis of Vtg in the fat body and possibly the ovary (results supporting the latter in this study); b) inducing patency of ovarioles; c) uptake of Vtg by the oocyte (follicle cells deform to facilitate this uptake and this deformation is under $\mathrm{JH}$ control) and $\mathrm{d}$ ) choriogenesis by the follicle cells. Whilst 20E modulates $\mathrm{JH}$ signalling in Nymphalids, it plays a more significant role in vitellogenesis and choriogenesis regulation in $B$. mori and D. melanogaster $[7,146]$.

Ecdysone signalling, including its target genes, is in general better understood than JH signalling [164]. Bombyx mori appears to be capable of producing ecdysteroids in the ovaries [8], as does D. melanogaster [165]. Drosophila melanogaster expresses start1 during oogenesis in significant amounts in nurse cells, most likely in response to ecdysone signalling. The cholesterol transporter Start1 may in turn facilitate ecdysteroid production from cholesterolbased precursors [165]. Another gene expressed in the nurse cells essential during $D$. melanogaster cholesterol conversion in the ovaries is defective in the avoidance of repellents (dare), which encodes an Adrenodoxin reductase [166]. Furthermore, in D. melanogaster the SGT1 protein homolog ecdysoneless (ecd) and disembodied (dib) have been described as essential for ecdysone, both for functionality and its production in the ovaries [165,167]. Maternal transcripts of $D$. melanogaster start 1 are hypothesised to be deposited into the egg to facilitate ecdysteroid signalling in the developing embryo [165]. Rather intriguingly $P$. aegeria females did not express $d i b$, but did express ecd, start1, and dare. We observed the transfer of transcripts of all three genes into the oocytes (Table 17 and Additional file 2). Start1 has been implicated in ecdysteroid synthesis in the prothoracic gland in B. mori [168]. Further investigation is needed to determine whether ecdysteroids 
can be produced in $P$. aegeria ovaries and if the transfer of maternal start1 and dare transcripts is involved in ecdysteroid signalling in early embryos. In common with the majority of insects [8,157], $P$. aegeria females did express ecdysone receptor $(E c R)$ and its partner ultraspiracle (usp; labelled chorion factor 1 (cfl) in B. mori) in the ovaries (Table 17). Although JH may be the gonadotropic hormone in $P$. aegeria, it is clear from the expression results presented here that $20 \mathrm{E}$ signalling does play a significant role in vitellogenesis and that there may be maternal regulation of ecdysteroid signalling in early embryos.

Among the so-called early genes in the hierarchy of genes up-regulated in response to activation of EcR in $B$. mori ovaries are the orphan nuclear receptor genes $h r 3$ and $E 75(a, b, c$ and $d)$, the transcription factor gene E74 and the Broad-Complex gene Br-C [151]. The genes encoding the two receptors Hepatocyte nuclear factor $4 \mathrm{a}$ and $4 \mathrm{~B}$ (HNF4A and HNF4B) are up-regulated with a delay in $B$. mori and their expression increases during vitellogenesis [169]. With the exception of E74, all of these genes were expressed in $P$. aegeria (Tables 6, 17 and Additional file 1). In $B$. mori $\mathrm{Hr} 3$ regulates the expression of ESP during vitellogenesis, and it regulates the expression of GATAbeta (i.e. transcription factor BCFI) during choriogenesis [151]. As discussed before, $P$. aegeria females did not express ESP, but did express the related gene lip-3 (Table 17). Furthermore, they also expressed GATAbeta (Table 19 and Additional file 1).

\section{Vitelline membrane formation and choriogenesis}

Vitellogenesis and choriogenesis are carefully coordinated, primarily by hormone signalling. The vitelline membrane (i.e. the inner eggshell layer) is formed halfway through vitellogenesis [170], for which RTK signalling is necessary as discussed elsewhere in this paper. The formation of the vitelline membrane is of significance in maternal regulation of embryonic AP and DV patterning, as some maternal factors become localised in the perivitelline space in $D$. melanogaster and interact with localised factors inside the oocyte [170]. This also appears to be the case in $B$. mori [94], although the genes involved remain uncharacterised. As discussed before, $\mathrm{Ndl}$ protein (also tellingly called ovarian serine protease in B. mori) is expressed in all follicle cells and is essential for DV patterning of the embryo in D. melanogaster [171]. Ndl is an unusual protein in that not only is its structure reminiscent of an extracellular matrix protein, but that it also has a catalytically active serine/protease domain [171]. As such, it is involved in both vitelline membrane formation as well as acting as the basis of the serine/protease cascade ventrally, essential for the maternally regulated DV patterning of the D. melanogaster embryo [170]. Pararge aegeria females expressed $n d l$ and as in D. melanogaster, no transcripts were found in the oocyte (Table 6 and Additional file 2). It remains to be seen whether Ndl plays a similar dual role in $P$. aegeria.

Insect vitelline membrane protein (VMP) genes show tremendous sequence diversity. For example, no clear orthologs can be found for D. melanogaster VMP genes outside the genus Drosophila. The best-characterised $V M P$ gene in Lepidoptera is VMP30 [172], for which orthologs can be found in both moths and butterflies and which was also expressed in $P$. aegeria ovarioles.

Table 19 Eggshell formation

\begin{tabular}{|c|c|c|c|}
\hline $\begin{array}{l}\text { weak homology to Bombyx mori vitelline membrane associated } \\
\text { protein p30 (VMP30) }\end{array}$ & Y & chorion peroxidase; peroxinectin-related protein (pxt) & Y \\
\hline Bombyx mori vitelline membrane protein 90 (VMP90) & $\mathrm{N}$ & gataß; transcription factor BCFI (GATA $\beta)$ & Y \\
\hline vitelline membrane 32e (VM32e; VMP32e) & $\mathrm{N}$ & chorion transcription factor cf2 (cf2) & $\bar{Y}$ \\
\hline vitelline membrane $26 a$ (VM26a) & N & chorion b-ZIP transcription factor (CbZ) & Y \\
\hline vitelline membrane 266 (VM26b) & $\mathrm{N}$ & chorion protein 15 (Drosophila melanogaster); CG6519 (cp15; s15) & N \\
\hline vitelline membrane 26ac (VM26Ac; tu-3) & $\mathrm{N}$ & chorion protein 16 (Drosophila melanogaster); CG6533 (cp16; s16) & N \\
\hline vitelline membrane 34ca (VM34C) & $\mathrm{N}$ & chorion protein 18 (Drosophila melanogaster); CG6517 (cp18; s18) & N \\
\hline femcoat (femcoat) & $\mathrm{N}$ & chorion protein 19 (Drosophila melanogaster); CG6524 (cp19; s19) & $\mathrm{N}$ \\
\hline follicle cell protein 26Aa; palisade (psd; fcp26Aa; tu-1) & $\mathrm{N}$ & chorion protein 36 (Drosophila melanogaster); CG1478 (cp36; s36) & N \\
\hline cad99c (cad99c; ca-10) & Y & chorion protein 38 (Drosophila melanogaster); CG11213 (cp38; s38) & $\mathrm{N}$ \\
\hline crinkled; myosin-VIla (ck; myoVIla) & Y & chorion protein a at 7f (Drosophila melanogaster); CG33962 (cp7fa) & $\mathrm{N}$ \\
\hline vitelline membrane like ( $\mathrm{vml}$ ) & $\mathrm{N}$ & chorion protein b at $7 f$ (Drosophila melanogaster); CG15350 (cp7fb) & $\mathrm{N}$ \\
\hline high mobility group protein a (HMGa) & Y & chorion protein c at $7 f$ (Drosophila melanogaster); CG15351 (cp7fc) & $\mathrm{N}$ \\
\hline egg protein 80 (EP80) & Y & defective chorion 1 (dec1) & $\mathrm{N}$ \\
\hline follicle cell protein $3 c$ (fcp3c) & Y & Lepidopteran chorion genes (see Additional file 9) & Y \\
\hline
\end{tabular}

Genes identified mainly from the Drosophila melanogaster and Bombyx mori literature involved in eggshell formation; vitelline membrane formation and choriogenesis. Presence $(\mathrm{Y})$ or absence $(\mathrm{N})$ of orthologous transcripts in the Pararge aegeria transcriptome is indicated. See Additional file 9 for details on lepidopteran chorion genes. 
Once again, no transcripts were found in the oocyte (Table 19 and Additional file 2).

After the follicle cells have secreted proteins to form the vitelline membrane, endocycling takes place in D. melanogaster and clusters of chorion genes are selectively amplified or expressed at very high levels $[170,173]$. Perhaps rather surprisingly, $P$. aegeria did not express an ortholog of G1/S specific $c y c E$, which in D. melanogaster is essential for chorion gene amplification and endocycling in general ([173]; Table 16; further references in Additional file 1). There is a possibility that Lepidoptera do not selectively amplify the chorion genes prior to the onset of choriogenesis, as no evidence was found for this in B. mori [174]. However, nurse cells do become polyploid during $B$. mori oogenesis [8]. Pararge aegeria females did express the G1/S specific genes $c y c C$ and $c y c D$, as well as the S-phase regulators $E 2 f 1$ and $d p$ (Table 16; further references in Additional file 1).

Choriogenesis as a whole is coordinated by genes such as chorion peroxidase ( $p x t)$ in D. melanogaster [170], which was also expressed by $P$. aegeria (Table 19). Furthermore, apart from aforementioned GATAbeta, a number of specific transcription factors are involved in the critical regulation of the spatio-temporal expression patterns of the various chorion genes in the later stages of oogenesis in Lepidoptera. All chorion genes in B. mori have multiple cis-regulatory binding sites for CCAAT/enhancer binding protein $(\mathrm{C} / \mathrm{EBP})$ transcription factors and their expression levels are C/EBP concentration dependent [175]. The D. melanogaster ortholog of C/EBP is slbo, which is also expressed in follicle cells though predominantly involved in border cell migration (references in Additional file 1). High mobility group protein A (HMGA) is essential for $B$. mori choriogenesis as it induces chorion gene promoter bending and recruits C/EBP and GATAbeta [176]. Pararge aegeria expressed $C / E B P$ (i.e. slbo), its negative regulator tribbles (trbl) and HMGa (Tables 6, 16 and 19), but it is not known in which functional context slbo is used. Another transcription factor for which cis-regulatory binding sites have been identified for chorion genes, in both $D$. melanogaster and $B$. mori, is the $\mathrm{C}_{2} \mathrm{H}_{2}$ zinc finger protein Chorion factor 2 (Cf2) [177]. Furthermore, a chorion-specific b-ZIP transcription factor ( $\mathrm{CbZ}$ ) has been described in B. mori [175] and orthologs can be found in butterfly genomes, such as that of $D$. plexippus [50]. However, the exact function of $\mathrm{CbZ}$ during choriogenesis has not been characterised. Both $c f 1$ and $C b Z$ were transcribed by $P$. aegeria, with transcripts of the latter rather intriguingly found to be present in the oocyte (Figure 4 qPCR results; Table 19).

Chorion protein (cp) genes evolve possibly even faster than vitelline membrane protein genes [178] and sequence similarity between $D$. melanogaster $c p$ genes with those identified in Lepidoptera, including $P$. aegeria, is very low indeed (Table 19; further references in Additional file 1). The infraorder Heteroneura, to which B. mori and butterflies belong, possess unique helicoidal lamellar chorions, which may provide additional strength [61]. Furthermore, the two species for which chorion genes have been characterised and studied in some detail, Lymantria dispar and B. mori, have an extensively derived chorion in which the helicoidal lamellar framework is modified by expansion and densification [61]. Expression patterns of these chorion genes are also dynamically very complex. Gene families in Lepidoptera encoding the structural chorion proteins are characterised by numerous gene duplications, occasional subsequent gene loss, gene conversion, and in general rapid sequence divergence $[61,179]$. As a result, determining orthology between individual chorion genes of different species is very difficult and chorion protein phylogenetic trees are characterised by speciesspecific clusters (i.e. families) of genes [179]. Automatic annotation of butterfly chorion genes in the $D$. plexippus genome and from our $P$. aegeria ovarian transcriptome was performed on the basis of the most significant BLAST hit to available moth chorion gene sequences (Additional file 2 and Table 19). It is very doubtful, however, that true orthology has been uncovered in this way, as chorion genes within a species tend to be more similar to each other than to those found in other species. The phylogenetic tree of Lepidopteran chorion genes in Additional file 9 shows distinct clustering between moths and butterflies for each of the chorion gene families. Pararge aegeria chorion genes were highly transcribed during oogenesis (Table 2 and Additional file 1). As well as expressing these chorion gene families, Bombyx mori expresses a gene encoding protein 80 (BmEP80), which forms part of the eggshell and is produced by the follicle cells [180]. BmEP80 is also highly transcribed during $P$. aegeria oogenesis (Tables 2 and 19; Additional data file 1).

\section{Apoptosis and autophagy}

Programmed cell death is an essential process during oogenesis in D. melanogaster and B. mori, with nurse and follicle cells undergoing apoptosis as oogenesis progresses, while complete egg chambers may apoptose in response to environmentally induced hormonal signals such as starvation $[15,16,154,181]$. Often, apoptosis and autophagy operate synergistally [181] and are to some extent integrated in $D$. melanogaster ovaries, where the effector caspase Dcp-1 and the inhibitor of apoptosis protein BIR-superfamily domain protein Bruce (also called survivin in B. mori) regulate both autophagy and starvation-induced cell death [182]. Recently, all apoptosisrelated genes have been characterised in B. mori, and the results of the study by Zhang and co-workers showed that most of these genes are highly conserved [183]. 
Furthermore they demonstrated that a number of gene duplications have occurred in the Lepidoptera (e.g. genes ecoding BIR-superfamily domain proteins)[183]. Many of the known genes involved in autophagy and apoptosis have been studied in a reproductive context in D. melanogaster (references in Additional file 1) and the majority of these were expressed during oogenesis by $P$. aegeria (Table 20). In particular, $P$. aegeria expressed buffy, three orthologs of bruce (Additional file 2) and the Lepidopteran ortholog of D. melanogaster dcp1, caspase-1 (Table 20).

\section{General growth regulators (including the Hippo Pathway)} Hippo is a highly conserved serine-threonine kinase 3-like signalling protein (also called STE20). It is essential for regulating tissue size and growth [184]. Hippo signalling interacts with various other cellular processes in this functional context, including programmed cell death and cell cycling [184]. Hippo signalling is, however, required in a wide variety of developmental contexts, not just tissue growth [184]. In D. melanogaster oogenesis, for example, it is essential for establishing AP polarity in the oocyte as it regulates the expression of the downstream effector of Notch signalling, the gene hindsight/pebbled $(h n t)$, which is required for posterior follicle cell maturation [184]. Orthologs of all the Hippo signalling related genes (i.e. Hippo signalling components, as well as up- and downstream factors) have been identified as being essential in D. melanogaster oogenesis (references in Additional file 1 ) and were transcribed by $P$. aegeria, with possibly two exceptions: merlin (mer; ERM2) and mob as tumor suppressor (mats, mob1) (Table 21). Merlin/ERM2 is a member of the band 4.1 protein superfamily and is characterised by a highly conserved FERM (Four.1 protein, Ezrin, Radixin, Moesin) domain involved in crosslinking the cell membrane and the actin cytoskeleton and so is thus important in localising proteins [184]. Pararge aegeria expressed a highly similar gene, ERM1 (Table 9), which in $P$. aegeria shows a highly significant sequence similarity to

Table 20 Growth regulation, apoptosis and autophagy

\begin{tabular}{|c|c|c|c|}
\hline p53 (p53) & Y & quaking related 54b; sam50 (qkr; sam50) & $Y$ \\
\hline p35 (p35) & $\mathrm{N}$ & held out wings (how) & $Y$ \\
\hline death executioner Bcl-2 homologue (debcl) & $\mathrm{N}$ & spinster (spin) & $\bar{Y}$ \\
\hline $\begin{array}{l}\text { homologous to bruce and Bombyx bir-superfamily domain } \\
\text { protein - survivin-1 (bruce; survivin-1) }\end{array}$ & Y & $\begin{array}{l}\text { death executioner caspase related to apopain/yama; decay; } \\
\text { caspase } 3 \text { (decay) }\end{array}$ & $\mathrm{N}$ \\
\hline $\begin{array}{l}\text { bir-superfamily domain protein - inhibitor of apoptosis 1; } \\
\text { thread (iap 1; th; diap1) }\end{array}$ & Y & death caspase $1(d c p-1)$ & $\lambda$ \\
\hline $\begin{array}{l}\text { bir-superfamily domain protein - inhibitor of apoptosis } 2 \\
\text { (iap2; diap2) }\end{array}$ & Y & death related ced-3/nedd2-like protein; dredd/dcp-2 (dredd) & $Y$ \\
\hline ubiquitin conjugation enzyme E2; bendless (ubc13; ben) & Y & ice; drice; caspase-1 (in Bombyx mori) (ice) & $Y$ \\
\hline b-cell lymphoma protein 2 (bcl-2) protein - buffy (buffy) & Y & dronc; nedd2-like caspase (dronc; nc) & Y \\
\hline $\begin{array}{l}\text { autophagy-specific gene 1; serine/threonine-protein kinase } \\
\text { unc-51 (atg1) }\end{array}$ & Y & dynamin related protein 1 (drp1) & Y \\
\hline autophagy-specific gene 2 (atg2) & Y & similar to optic atrophy 1-like (opa 1-like) & $Y$ \\
\hline autophagy-specific gene 3 (atg3; aut1) & Y & resistance to juvenile hormone; methoprene-tolerant (met) & Y \\
\hline autophagy-specific gene 4 (atg4) & Y & deterin (det) & N \\
\hline autophagy-specific gene 5 (atg5) & Y & tao-1 (tao-1) & $\bar{Y}$ \\
\hline autophagy-specific gene 6; beclin-1 (atg6) & Y & melted (melt) & $\mathrm{N}$ \\
\hline autophagy-specific gene 7 (atg7) & Y & midway (mdy) & $\mathrm{N}$ \\
\hline autophagy-specific gene 8 (atg8) & Y & pita (pita) & $\bar{Y}$ \\
\hline autophagy-specific gene 12 (atg12) & Y & plenty of sh3s (posh) & $\mathrm{N}$ \\
\hline autophagy-specific gene 13 (atg13) & $\mathrm{N}$ & phosphoinositide-dependent kinase 1 dstpk61 (dstpk61) & Y \\
\hline phosphotidylinositol 3 kinase $59 f$ (pi3k59f; vps34) & Y & dream (strica; dream) & $\bar{N}$ \\
\hline cell death activator-b (cide-b) & Y & target of rapamycin (tor) & Y \\
\hline cell cycle and apoptosis regulatory protein 1 (ccar1) & Y & thor (thor) & $\mathrm{N}$ \\
\hline longitudinals-lacking (Iola) & Y & death associated molecule related to mch2; daydream (damm) & $\mathrm{N}$ \\
\hline translationally controlled tumour protein (tctp) & Y & $\begin{array}{l}\text { ecdysone-induced protein 28/29kD; methionine-s-sulfoxide } \\
\text { reductase (Eip28/29; Eip71CD) }\end{array}$ & Y \\
\hline apoptosis linked protein 2 (alg-2) & Y & $\begin{array}{l}\text { modifier of rpr and grim, ubiquitously expressed; weak homology } \\
\text { to ubiquitin-conjugating enzyme E2 D4 (morgue) }\end{array}$ & \\
\hline
\end{tabular}

Genes identified mainly from the Drosophila melanogaster literature involved in regulation of growth during oogenesis (apoptosis, autophagy - response to starvation). Presence $(\mathrm{Y})$ or absence $(\mathrm{N})$ of orthologous transcripts in the Pararge aegeria transcriptome is indicated. 
Table 21 Growth regulation and Hippo pathway

\begin{tabular}{llll}
\hline serine/threonine kinase 3-like (hippo; STE20)(hpo) & $\mathrm{Y}$ & expanded (ex) & Y \\
\hline salvador (sav) & $\mathrm{Y}$ & merlin (mer; ERM2) & $\mathrm{N}$ \\
\hline warts (wts) & $\mathrm{Y}$ & kibra; CG33967 (kibra) & Y \\
\hline mob as tumor suppressor (mats; mob1) & $\mathrm{N}$ & yorkie; yap65-like protein (yki) & Y \\
\hline mob-2 (mob2) & $\mathrm{Y}$ & phosphatidylinositol 4-kinase alpha (PI4kllalpha) & $\mathrm{Y}$ \\
\hline preimplantation protein; mps one binder kinase activator-like 4 (mob4-like) & $\mathrm{Y}$ & bitesize; synaptotagmin-like (btsz) & $\mathrm{Y}$ \\
\hline hindsight; pebbled (hnt) & $\mathrm{Y}$ & par-domain protein 1; CG17888 (pdp1) & $\mathrm{Y}$ \\
\hline Genes identified mainly from the Drosophila melanogaster literature involved in regulation of growth during oogenesis (including the Hippo pathway). Presence
\end{tabular}

$(\mathrm{Y})$ or absence $(\mathrm{N})$ of orthologous transcripts in the Pararge aegeria transcriptome is indicated.

ERM2 (Table 9). In D. melanogaster ERM1 is important for Osk localisation [185], but clearly it cannot function in this way in $P$. aegeria, which lacks Osk. Likewise, $P$. aegeria appeared to express paralogs that are significantly similar to mob1; mob2 and mob4-like (i.e. preimplantation protein in B. mori) (Table 21). The latter is most likely the Lepidopteran ortholog of $D$. melanogaster mob1.

\section{Heat shock proteins and their control of protein abundance during oogenesis}

Heat shock proteins (Hsps) provide a possible mechanism for environmental control of development in ovaries and as maternal effects. The transcription of genes encoding Hsps, or molecular chaperones in general, is not only regulated in response to various environmental factors (e.g. temperature), but is also essential during many developmental processes, including oogenesis. It is thought that Hsps are important for both developmental buffering and differentiation [72,186](further references in Additional file 1). The functional contexts in which Hsps operate are incredibly varied [186]. In D. melanogaster, for example, Hsp60C is essential in organising and maintaining cytoskeletal and cell adhesion components and thus for establishing AP and DV oocyte polarity [186], whilst Hsp70 affects border cell migration through its effects on the actin cytoskeleton [187]. A large number of genes encoding Hsps and related proteins have been described in a functional context during D. melanogaster oogenesis (references in Additional file 1) and orthologs of all of these were transcribed during $P$. aegeria ovarioles, often very abundantly (e.g. heat shock protein cognate 3, hsc3) (Tables 2 and 22; Additional file 2).

\section{Ribosomal machinery needed for increased ovarian protein synthesis and early embryogenesis}

Genes encoding ribosomal proteins, rRNA and other proteins involved in translation (e.g. RpA1) are among the most highly transcribed genes during Metazoan oogenesis, as large amounts of the translation machinery are needed both during oogenesis and by the developing embryo [188]. Just like Hsps, specific ribosomal proteins have been studied in a wide variety of functional contexts during $D$. melanogaster oogenesis and early embryogenesis (Tables 12 and 18; further references in Additional file 1). Ribosomal genes were also among the most highly transcribed in $P$. aegeria oogenesis (Table 2; Additional file 2).

\section{Immune defense and Wolbachia infection}

Orthologs of the majority of the genes identified from the literature as being involved in immune response during oogenesis were also found to be expressed by $P$. aegeria and present as maternal transcripts in the oocytes (Table 23; Additional files 1 and 2). Apart from the aforementioned Toll innate immune defense pathway, which may have been co-opted for DV patterning of the embryo (Table 13), these include a large number of genes encoding Serpins (Table 23). Drosophila melanogaster spn $27 A$ (the ortholog of which is called serpin-3 in B. mori), has been implicated in DV axis formation [120].

The facultative reproductive parasite Wolbachia sp. is an endocytosymbiont in many arthropod species affecting oogenesis in a multitude of ways and the Bacterium is maternally transmitted [189-191]. In D. mauritiana, Wolbachia increases egg production by affecting the maintenance and division of germ-line stem cells [20], while in the wasp Asobara tabida, Wolbachia confers a reproductive advantage to the females by properly regulating apoptosis during oogenesis via its regulation of iron metabolism and ferritin expression [190,192]. However, in D. melanogaster highly infected females suffer from a range of oogenesis defects mediated via grk signalling [193]. Pararge aegeria females were also found to be infected with Wolbachia, but how this affects oogenesis in this species is at present not known. However, we did observe that the gene encoding an ortholog of the Ferritin 2 light chain protein (FER2-LCH) was amongst the most highly transcribed genes during $P$. aegeria oogenesis (Tables 2 and 23), but at present it is unknown whether this effect is due to Wolbachia or whether elevated expression levels are a normal part of female $P$. aegeria reproduction. 


\section{Table 22 Heat shock proteins}

\begin{tabular}{|c|c|c|c|}
\hline similar to heat shock factor a2 (Bombyx mori) (hsf-2a) & Y & $\begin{array}{l}\text { heat shock cognate protein 70; heat shock protein cognate } 3 \text { (hsc70; } \\
\text { hsc3; hsc70-3) }\end{array}$ & Y \\
\hline similar to heat shock factor b (Bombyx mori) (hsfb) & Y & heat shock cognate protein 70cb (hsc70cb) & Y \\
\hline similar to heat shock factor c (Bombyx mori) (hsfc) & Y & heat shock protein cognate 5 (hsc5; hsp70-5) & Y \\
\hline heat shock factor binding protein 1-like; CG5446 (hsfbp1; hsbpsb) & Y & $\begin{array}{l}\text { similar to Bombyx mori heat shock protein } 40 \text { homolog DNAj-1 } \\
\text { (hsp40; DNAj) }\end{array}$ & Y \\
\hline 19.5 kDa heat shock protein (Bombyx mori) (19.5hsp) & Y & heat shock protein 60 (hsp60) & Y \\
\hline trap1; hsp90-like (trap1) & Y & similar to heat shock protein 68; heat shock protein 70-like (hsp70) & Y \\
\hline $\begin{array}{l}\text { (Bombyx mori) heat shock protein 1; similar to Drosophila lethal (2) } \\
\text { essential for life and hsp27 (hsp1) }\end{array}$ & Y & heat shock protein 83; heat shock protein 90 (hsp90) & Y \\
\hline $\begin{array}{l}\text { (Bombyx mori small heat shock protein, shsp) - heat shock protein } \\
\text { 19.9; similar to Drosophila lethal (2) essential for life (hsp19.9) }\end{array}$ & Y & $\begin{array}{l}\text { endoplasmin; } 94 \text { kDa glucose-regulated protein; similar to Drosophila } \\
\text { glycoprotein 93; heat shock protein } 90 \text { kDa beta member } 1 \text { (gp93) }\end{array}$ & Y \\
\hline $\begin{array}{l}\text { (Bombyx mori small heat shock protein, shsp) - heat shock protein } \\
\text { 20.1; similar to Drosophila lethal (2) essential for life (hsp20.1) }\end{array}$ & Y & hsc70/hsp90-organisng protein hop (hop) & Y \\
\hline $\begin{array}{l}\text { (Bombyx mori small heat shock protein, shsp) - heat shock protein } \\
\text { 20.4; similar to Drosophila lethal (2) essential for life (hsp20.4) }\end{array}$ & Y & CG11267; heat shock 10kDa protein (CG11267) & Y \\
\hline $\begin{array}{l}\text { (Bombyx mori small heat shock protein, shsp) - heat shock protein } \\
\text { 20.8; similar to Drosophila lethal (2) essential for life (hsp20.8) }\end{array}$ & Y & $\begin{array}{l}\text { CG1416; activator of } 90 \text { kDa heat shock protein ATPase homolog; } \\
\text { Bombyx mori bm44 (bm44) }\end{array}$ & Y \\
\hline $\begin{array}{l}\text { (Bombyx mori small heat shock protein, shsp) - heat shock protein } \\
\text { 23.7; similar to Drosophila lethal (2) essential for life (hsp23.7) }\end{array}$ & Y & RNA polymerase I/ 140kD subunit (rp/l140) & Y \\
\hline heat shock protein 21.4 (hsp21.4) & Y & samui (samui) & Y \\
\hline
\end{tabular}

Genes encoding heat shock proteins (in ovaries and as maternal effects) and their control of protein abundance during oogenesis identified mainly from the Drosophila melanogaster literature. Presence $(\mathrm{Y})$ or absence $(\mathrm{N})$ of orthologous transcripts in the Pararge aegeria transcriptome is indicated.

\section{Table 23 Immune defense}

\begin{tabular}{|c|c|c|c|}
\hline hemolin; p4 (p4) & Y & MAPKK4 (mkk4; MAPKK4) & Y \\
\hline hemolin interacting protein; yippee (yip) & Y & $\begin{array}{l}\text { similar to Bombyx mori clip domain serine protease 4; similar to } \\
\text { manduca sexta hemolymph proteinase } 17 \text { (bmclip4) }\end{array}$ & Y \\
\hline yippee interacting protein 2 (yip2) & Y & $\begin{array}{l}\text { similar to Bombyx mori clip domain serine protease 11; similar to } \\
\text { manduca sexta serine proteinase-like protein } 1 \text { (bmclip 11) }\end{array}$ & Y \\
\hline cecropin A (cecA) & Y & transferrin $(t f ; t s f)$ & Y \\
\hline weak homology to cecropin $B$ (cecB) & Y & Ferritin 2 - light chain homolog (FER2-LCH) & Y \\
\hline $\begin{array}{l}\text { homology to Bombyx serpin-1 and Drosophila spn4/42Da } \\
\text { (srp1; spn4/42Da) }\end{array}$ & Y & Ferritin 1/3 - heavy chain homolog (FER1/3-HCH) & Y \\
\hline $\begin{array}{l}\text { homology to Bombyx serpin-2 and Drosophila spn4/42Da } \\
\text { (srp2; spn4/42Da) }\end{array}$ & Y & $\begin{array}{l}\text { FK506-binding protein 2; FK506-binding protein } 12 \text { (in Bombyx mori) } \\
\text { (FKBP12) }\end{array}$ & Y \\
\hline $\begin{array}{l}\text { homology to Bombyx serpin-3 and Drosophila spn27A } \\
\text { (srp3; spn27A) }\end{array}$ & Y & FK506-binding protein 1 (FKBP39) & Y \\
\hline $\begin{array}{l}\text { homology to Bombyx serpin-4 and Drosophila spn28D } \\
\text { (srp4; spn28D) }\end{array}$ & Y & weakly similar to refractory to sigma $p(\operatorname{ref}(2) p)$ & Y \\
\hline $\begin{array}{l}\text { homology to Bombyx serpin-5 and Drosophila spn77Ba } \\
\text { (srp5; spn77Ba) }\end{array}$ & Y & $\begin{array}{l}\text { similar to bmrelish } 1 \text { and bmrelish2; nuclear factor nf-kappa-b p110 } \\
\text { subunit isoform } 1 \text { or 2; weakly similar to Drosophila melanogaster } \\
\text { relish (rel) }\end{array}$ & Y \\
\hline $\begin{array}{l}\text { homology to Bombyx serpin-6 and Drosophila spn88Ea } \\
\text { (srp6; spn88Ea) }\end{array}$ & Y & hemomucin (rrm5; hmu) & Y \\
\hline $\begin{array}{l}\text { homology to Bombyx serpin-10 and Drosophila spn100a } \\
\text { (srp10; spn100A) }\end{array}$ & Y & smt3 activating enzyme 2 (sae2; sip2; uba2) & Y \\
\hline $\begin{array}{l}\text { homology to Bombyx serpin-11 and Drosophila spn100A } \\
\text { (srp11; spn100A) }\end{array}$ & Y & galactin; galactose specific c-type lectin (lectin-galc1) & $\mathrm{N}$ \\
\hline
\end{tabular}

(srp13; spn28D)

Genes identified mainly from the Drosophila melanogaster literature involved in immune defense during oogenesis. Presence $(\mathrm{Y})$ or absence (N) of orthologous transcripts in the Pararge aegeria transcriptome is indicated. 
Egg activation, ovulation, gene regulation in oviduct upon mating and maternal effect genes involved in fertilisation

As discussed elsewhere in this paper, after vitellogenesis both the $D$. melanogaster and the Lepidopteran oocyte are in a secondary meiotic arrest in metaphase I $[60,194]$. Unlike in Lepidoptera [60], egg activation in D. melanogaster is not triggered by the act of fertilisation, but due to the mechanical pressure experienced by the oocyte when moving from the ovary into the small and tight oviducts [194]. Egg activation involves eggshell modifications, resumption of meiosis, translation and subsequent degradation of maternal mRNAs, and cytoskeletal changes [194]. A small number of genes have been described as important in D. melanogaster in the latter stages of oogenesis in the general functional context of egg activation (references in Additional file 1). Orthologs for only around half of these were found in the $P$. aegeria transcriptome (Table 24), which may indicate observed differences in the mechanism of egg activation between the Lepidoptera and D. melanogaster. Among the genes found in the $P$. aegeria transcriptome is wispy ( $f(1) M 19 /$ wisp) (Table 24). In D. melanogaster it is a maternal effect gene, encoding a GLD-2 family protein with polynucleotide adenylyltransferase activity and is essential for the oocyteto-embryo transition [195]. The D. melanogaster Wisp protein is required for poly(A) tail elongation of $b c d$, toll, and tor transcripts upon egg activation. It is thus important for proper patterning of the embryo [195], but is also required to maintain a high level of active (phospho-) mitogenactivated protein kinases (MAPKs)[195]. Given that $P$. aegeria females did not express $b c d$ and tor, it remains to be investigated whether wisp is of any importance in patterning of the embryo.

\section{Conclusions}

A large proportion of the genes currently described in the literature as being essential during insect oogenesis (in particular D. melanogaster oogenesis) were transcribed by $P$ aegeria and transcripts were transferred to the oocytes. As this was an ovarian transcriptome study, the precise functional context in which these genes were transcribed has not been identified. Differences in the functional context in which particular genes are expressed are to be expected compared to model organisms such as D. melanogaster and even B. mori. What is perhaps more revealing, however, is the absence of certain transcripts in the database, in particular where these transcripts concern paradigms of maternal regulation for various aspects of early insect embryogenesis [3-5,24]. Pararge aegeria differed most significantly from D. melanogaster (and quite a number of other insect species), both in terms of stem cell maintenance or differentiation in the germarium and in establishing (and maintaining) polarity along AP, DV and at the termini of the oocyte. In particular, although Pararge aegeria females expressed an ortholog of a spi/krn-like EGF ligand and possibly its receptor, many components of the EGF pathway involved in patterning of the axes in D. melanogaster embryos, as well as pipe and mirror, were not expressed. This may either suggest that there is not much evidence for a significant role of EGF signalling in establishing $P$. aegeria oocyte polarity, or that its functional role and genes involved is divergent from other insects. This requires further study, as well as the functional role and significance of Dpp and Notch signalling in this context.

Although the more derived species such as B. mori within the Ditrysia are argued to be long germ bandlike [94], it is more appropriate to describe them as intermediate germ band $[53,54]$, as they have a very unusual preblastoderm stage. Like $D$. melanogaster, cleavage in $B$. mori and the butterfly Pieris rapae is superficial but nuclear migration to the periphery of the oocyte and subsequent cellularisation occurs in an anterior to posterior gradient, after which they display long germ band characteristics [60]. It is very likely that this has a bearing on maternal effect gene expression regulating axes patterning after oocyte polarity has been established during the pre-vitellogenic stages in Ditrysia compared to D. melanogaster, and this could be reflected in the

Table 24 Egg activation

\begin{tabular}{|c|c|c|c|}
\hline $\begin{array}{l}\text { cathepsin I-like cysteine protease; Bombyx cysteine protease; } \\
\text { cysteine proteinase-1 (bcp; } c l ; c p 1)\end{array}$ & Y & vacuolar proton atpase; vacuolar $h+$ atpase subunit 100-2 (vha100-2) & Y \\
\hline cathepsin b; cathepsin b-like cysteine proteinase (catb) & Y & $\begin{array}{l}\text { h+ transporting atpase v0 subunit d; vacuolar h+ atpase subunit ac39-1 } \\
\text { (vhaac39-1) }\end{array}$ & Y \\
\hline cathepsin d; aspartic protease (catd) & Y & $\begin{array}{l}\text { vacuolar atp synthase subunit d; vacuolar } h+\text { atpase subunit 36-1 } \\
\text { (mvd; vha36-1) }\end{array}$ & Y \\
\hline cathepsin f-like cysteine protease; CG12163 (catf) & Y & CG7899; acid phosphatase 1 (acph-1; ap) & $\mathrm{N}$ \\
\hline ecdysteroid-phosphate phosphatase (EPPase) & Y & primo-1; acid phosphatase isoenzyme (primo-1) & Y \\
\hline $\begin{array}{l}\text { vacuolar proton atpase; vacuolar } h+\text { atpase subunit 100-1 } \\
\text { (mva; v100; vha100-1) }\end{array}$ & Y & & \\
\hline
\end{tabular}

Genes identified mainly from the Drosophila melanogaster literature involved in egg activation, ovulation, gene regulation in oviduct upon mating and maternal effect genes involved in fertilisation. Presence $(\mathrm{Y})$ or absence $(\mathrm{N})$ of orthologous transcripts in the Pararge aegeria transcriptome is indicated. 
gene expression data presented in this study (e.g. the absence of maternal expression of $h b$ ). Although progress has been made in investigating $B$. mori embryonic patterning $[53,54]$, how polarity is established during oogenesis in Ditrysia and in the Lepidoptera as a whole is not known. This needs further investigation, and $P$. aegeria may prove an ideal model these future studies.

Unfortunately, maternal effect gene expression and regulation have received significantly less research attention in Lepidoptera compared to vitellogenesis, choriogenesis and reproductive physiology [8]. This is reflected in the discussion of the results in this paper. Although the latter aspects of oogenesis are well suited to studies of reproductive output under a variety of environmental conditions, many of the genes discussed in this study highlight the interconnectedness of all stages during oogenesis, for example eggshell production and oocyte polarity. Furthermore, key candidate genes that have the potential to play an important role in transgenerational maternal effects have been identified. Among these are genes encoding heat shock proteins and proteins involved in chromatin remodelling.

This study has taken a much-needed first step in determining the conserved and divergent elements of the butterfly oogenesis GRN (including maternal regulation of embryonic patterning) and establishes $P$. aegeria as an eco-evo-devo model system for the study of butterfly oogenesis. In order to fully unscramble butterfly oogenesis, an investigation of the spatio-temporal expression patterns of the genes discussed in this study, as well as establishment of their function, is required. Further studies are also required to establish the function and expression patterns of the uncharacterised contigs identified in this study, which make up $30 \%$ of the total contigs found, and are undoubtedly composed of genes that are of high importance in butterfly oogenesis.

\section{Methods}

\section{Butterfly rearing and sample collection}

As butterflies were used in this study, no ethical approval was required. Eggs were collected from a large outbred laboratory population of $P$. aegeria (kept at 300-400 individuals per generation). This population originated from a woodland population from the south of Belgium (St. Hubert; established from 50 eggs) and by the time of the experiment, the butterflies had been reared in the laboratory for 10 generations. Newly hatched larvae were placed on potted host plants (4 larvae per plant) of Poa trivialis L. with access to ad libitum food and were reared until eclosion in a climate room under a regime $\left(24 \pm 0.3^{\circ} \mathrm{C}\right.$, LD 16:8) that promotes direct development (i.e. no diapause). On the day of eclosion (i.e. day -1 , between 9 and 12 h) females from this laboratory stock placed individually in netted cages $\left(0.5 \mathrm{~m}^{3}\right)$ along with a potted $P$. trivialis plant for oviposition and an artificial flower containing a
$10 \%$ honey solution [55]. Later the same day (between 13.00 and $16.00 \mathrm{~h}$ ) a virgin male was introduced to the cage and the mating pair was left undisturbed for $24 \mathrm{~h}$.

Eggs from 50 mated 4-day old females were collected within 20 minutes of being laid, which is well before the onset of cleavage and thus early embryogenesis in butterflies [60]. The eggs were placed immediately in $1 \mathrm{ml}$ TRIReagent (Sigma-Aldrich, Dorset, UK) and homogenised thoroughly. Furthermore, 2 mated females aged 4 days were sacrificed by severing the nerve cord, after which the abdomen was removed and the ovaries dissected out in ice-cold PBS $(1 \times)$, with dissection taking no longer than 15 minutes to avoid RNA degradation. The ovaries were pooled and likewise homogenised immediately in $1 \mathrm{ml}$ TRI-Reagent.

\section{RNA extraction and quality control}

The homogenate (both of eggs and ovarioles/ovary) was first centrifuged at $13000 \mathrm{~g}$ for $10 \mathrm{~min}$ primarily to remove the yolk, after which the supernatant was vortexed with $200 \mu \mathrm{l}$ of chloroform. Phases were separated at $13000 \mathrm{~g}$ for $15 \mathrm{~min}$ at room temperature. The aqueous phase was removed and precipitated in $0.5 \mathrm{ml}$ isopropanol [196]. The RNA samples were further purified using the RNeasy Mini Kit and re-eluted in $30 \mu \mathrm{l}$ nuclease-free water, following the manufacturer's instructions (Qiagen, Hilden, Germany). Preliminary yield and quality for each RNA extraction were assayed using a Nanodrop, while RNA integrity was verified using the Agilent BioAnalyzer 2100 PicoRNA Chip (Agilent Technologies, Winnersh, UK) (Additional file 10).

\section{De novo transcriptome assembly}

Pararge aegeria egg and ovary RNA was sequenced by Source BioScience (Nottingham, UK) using Illumina short read RNA-Seq technology. Both total RNA samples went through polyA selection, fragmentation and double stranded cDNA conversion to produce two separate libraries (300bp insert size) in accordance with the Illumina mRNA-seq library preparation protocol (Illumina, San Diego, USA). Sequencing was performed on the Illumina Genome Analyzer IIx platform with one flowcell lane allocated to each library. A total of $61,400,070$ single-reads of 38 base pairs (bp) in length were obtained from the ovary and egg flowcell lanes $(31,836,256$ and $29,563,814$ reads for ovary and egg samples respectively) which were pooled to produce a de novo assembly in CLC Genomics Workbench v4.0 (CLC bio, Aarhus, Denmark) using the default settings for short read data (automatic word and bubble size) [197]. The assembly generated 25266 contigs (Additional file 2) of an average length of 535bp (N50=671bp), $41.06 \%$ GC content and an estimated average coverage of $124 \times$ per nucleotide. 
The RNA-seq data was analysed by FASTQC on the Galaxy platform $[198,199]$. Adaptor dimer or overruns in the reads (stretches of sequence matching the library preparation primers/adaptors) were trimmed from both egg and ovary data sets using CLC Genomics Workbench. Furthermore, the sequences were trimmed down to 25 bp from the 5 ' end and sequencing artefacts discarded using the FASTX-Toolkit on Galaxy. Subsequently, the trimmed reads were mapped using default parameters against the de novo assembly using TopHat on the Galaxy server [200]. FPKM values were estimated from the TopHat output using Cufflinks [201] with quartile normalisation and multi read correct enabled. The estimates were limited to a reference general feature format file containing locations of the predicted coding regions from the automated annotation if available.

\section{Annotation}

The 25,266 contigs generated by the de novo assembly (Additional file 2) were processed through a similaritybased annotation workflow. Open reading frames (ORF) over 200 bp were identified and extracted with the EMBOSS tool "getorf" in Galaxy. The GC content increased to $42.23 \%$ when limited to possible coding regions. The predicted ORF and contig sequences were then processed through different BLAST strategies to provide the most suitable annotation possible (Additional files 11 and 12). The alpha group compared the predicted ORF sequences against protein databases to identify complete or highly conserved transcripts. The beta group compared the full contigs against protein databases to identify incomplete or out of frame transcripts. Sequences not identified in the alpha and beta group were compared further against nucleic acid coding sequences (delta) and finally the whole nucleotide database (zeta). Each search strategy was attributed a different rank, ranging from A to I. Identity was inferred based on similarity to the top ranking hit. Similarity scores (SS) were assigned to each hit based on the bitscore $\left(S^{\prime}\right)$, number of positives in each alignment (P) and original contig length (L). Similarity score was calculated using the formula:

$$
S S=S^{\prime} \frac{P}{L}
$$

Effectively this required hits with higher bitscores to also have good query coverage and positive matches. Any hit attaining an SS below 18 (lower SS threshold) was discarded from each rank, using the next best hit (which may be in a lower rank or group) (Additional file 11). Hits were sorted based on group, positives, rank and SS to determine the top hit that would be used to infer the nature of each sequence. Similarity scores also allowed an initial indication of possible homology; SS above the upper threshold $(>/=40)$ were considered High, those above the lower SS threshold $(>/=18)$ were considered Mild and any others were considered Low. Any hit with a bitscore below 40 was excluded from inferring any possible identity or homology (Additional files 12 and 13).

The output from the automated annotation was checked manually for any errors (Additional file 2). Furthermore, using FlyBase [62] and SilkBase [63] as a starting point, a comprehensive literature search was conducted to identify those genes that have been studied in the context of insect oogenesis and maternal regulation of early embryogenesis (1035 genes, of which 994 have been studied in D. melanogaster; fully referenced in Additional file 1). For a further 56 genes functionality during oogenesis can be inferred, but their expression during oogenesis has not always been verified experimentally. The presence or absence of orthologous $P$. aegeria transcripts in both the oocyte and the ovarioles was verified for each of the 1091 genes and these transcripts were further annotated manually (indicated as such in Additional file 2).

The final BLAST results (1 top hit per sequence) used for annotation, including those genes annotated manually, were used as input in the BLAST2GO software [202] and assigned with Gene Ontology (GO) terms where possible. To help provide an overview of the GO based on the BLAST results, the GO terms were condensed using the generic GO Slim subset.

\section{Transcript abundance and qPCR of genes involved in oogenesis and maternal regulation of early embryogenesis}

For of a subset of 19 genes the expression in the ovarioles and the presence of transcripts in the oocyte were confirmed further by means of RT-qPCR (Additional file 3). For both ovary and oocyte, cDNA was generated from 500 - 1000 ng of RNA using the Verso RT Kit (Thermo Fisher, Surrey, UK). The reverse transcriptions were primed by a 3:1 mix of random hexamers:oligo-dT taking place in $20 \mu \mathrm{l}$ total volume reactions at $42^{\circ} \mathrm{C}$ for $30 \mathrm{~min}$ after an initial 5 min denaturation step at $70^{\circ} \mathrm{C}$. Negative reverse transcription (NRT) controls were run in parallel without both Verso RT enzyme mix and primers. A final heat deactivation at $95^{\circ} \mathrm{C}$ for 2 min was also implemented to deactivate the $\mathrm{RT}$ enhancer. The resulting cDNA was stored at $-20^{\circ} \mathrm{C}$.

For the qPCR stage, suitable primer pairs were selected automatically using the online Primer3+ primer design service and tested in-silico via the Integrated DNA Technologies online structure prediction package (Oligo Analyzer). Only those primers exhibiting the best stability were selected. Each primer pair was tested on a 3-step 5-fold dilution series of the ovary cDNA in triplicate, which enabled the primer pair efficiencies to be determined using the CFX Manager software (Bio-Rad Laboratories, California, 
USA). Primers with adequate efficiency $(>65 \%)$ were then used for investigating the transcript abundance in the egg and ovary cDNA (Additional file 3).

All qPCR runs were performed on the CFX96 RealTime PCR Detection System (Bio-Rad) on white 96-well plates in ABsolute Blue qPCR SYBR Green Mastermix (Thermo Fisher, Surrey, UK) with the recommended amount of ROX reference dye (Additional file 14). Test samples were measured in triplicate, while no template controls (NTC) and NRTs were present in duplicate on each plate. The CFX96 data generated was recorded by the CFX manager program using automatic threshold determination. The quantification cycle $(\mathrm{Cq})$ values are listed in Additional file 4.

Relative transcript abundance (i.e. ovary versus egg) was used to reveal whether any individual transcript was used as a maternal effect gene transcript or was merely necessary for oocyte production. Relative transcript abundance in the ovaries and eggs were obtained using the relative expression software tool REST v2.0.13.0 software package [203], which used the 3 available reference genes to normalise the measurements obtained from the egg and ovary derived cDNA (Additional file 5).

The number of reads mapping to a transcript of a particular gene in RNA-seq data was argued to be correlated linearly with the number of transcripts of that gene [204]. Rather than using read counts, it is considered to be more appropriate to use a corrected relative value, taking transcript length and total number of mapped reads into account [204]. Cufflinks generated such corrected values, the FPKM values, which can be used for the reliable determination of transcript abundance for each of the genes discussed in this study (Additional file 2). In fact, for the 22 genes in the $P$. aegeria transcriptome investigated by means of $\mathrm{qPCR}$, transcript abundance calculated on the basis of $\mathrm{Cq}$ values by means of the methods described in [205] showed significant positive correlation with FPKM values in the combined oocyte and ovary transcriptome (Pearson regression, with null hypothesis that correlation is $>0: \mathrm{t}_{41}=2.37, \mathrm{P}=$ 0.011; Additional file 6).

\section{Annotated contigs and accession numbers of raw data}

The sequence read data reported in this manuscript have been deposited in the NCBI Sequence Read Archive and are available under the accession numbers SRR771147 (ovarian reads) and SRR772253 (oocyte reads). Additional file 15 provides the fasta format sequences of the assembled contigs, including the suggested annotated names (top BLAST results as well as information on the manual annotation listed in Additional file 2). Additional file 2 provides information on the start and end of the coding regions in the contigs.

\section{Additional files}

Additional file 1: Oogenesis genes. Contains a tabulated and fully referenced list of genes identified from the literature, which have been studied in the context of insect oogenesis and maternal regulation of early embryogenesis. The vast majority of papers concern the fruitfly Drosophila melanogaster and the silkmoth Bombyx mori. Many genes have multiple functions during oogenesis, but to avoid repetition, and keep the size of the Table manageable, each gene has been listed only once in the functional context for which it is probably best known. Referencing has been kept to a minimum, highlighting key papers and databases. Hyperlinks have been provided for almost all of the genes listed, which will provide full database information on their myriad functions and further references. Presence $(Y)$ or absence $(N)$ of orthologs in the Pararge aegeria combined oocyte and ovariole transcriptome are indicated.

Additional file 2: Annotation summary of the combined transcriptome of the Pararge aegeria ovarioles and oocytes. Details the results of both automatic and manual annotation of 25266 contigs. Egg and ovary FPKM values are given for each contig. Each column contains a pop-up comment box with an explanation of the column contents.

Additional file 3: Overview of the primer pair properties and performance in qPCR conditions. Gives an overview of the forward and reverse primers designed for $\mathrm{QPCR}$ of a set of 19 oogenesis and 3 housekeeping genes. Efficiency and $R^{2}$ values are provided for each of the primers.

Additional file 4: Data generated by the CFX96 qPCR experiments. Details the measurements from a total of 8 96-well white plates. Cq are given for each gene of interest or reference gene.

Additional file 5: Relative Abundance Data generated by REST. Gives the results from using REST v2.0.13.0 to process Cq measurements and efficiencies in order to estimate relative transcript abundance, and thus compare relative transcript abundance between ovaries and eggs.

Additional file 6: Transcript abundance: Cq - FPKM correlation. Provides the results of the correlation analyses between two measures of transcript abundance: $\mathrm{Cq}$ and FPKM-values.

Additional file 7: Mapping of raw RNA-seq reads against egfr and wingless coding sequences as predicted from the draft Pararge aegeria genome. Provides the complete egfr and wingless (wg) CDS fasta information from our unpublished $P$. aegeria genome. Furthermore, raw RNA-seq reads were mapped against these sequences and coverage determined.

Additional file 8: Phylogenetic analysis of Nanos. Provides a phylogenetic analysis of insect Nanos protein sequences.

Additional file 9: Phylogenetic analyses of both chorion and minor yolk proteins in Lepidoptera. Provides the phylogenetic analyses of both chorion and minor yolk proteins in Lepidoptera.

Additional file 10: Oocyte and ovarian RNA quality. Provides the Agilent BioAnalyzer Electropherograms detailing oocyte and ovarian RNA quality prior to CDNA synthesis.

Additional file 11: Filtering of BLAST hits in the automated annotation. Provides a visualisation of the similarity score distribution and thresholds applied in the automated annotation of the $P$. aegeria transcriptome.

Additional file 12: Automated annotation based on different BLAST Strategies. Provides a summary of the automated annotation method, detailing the different queries.

Additional file 13: Distribution of similarity classes across BLAST sources. Provides details regarding the number of Pararge aegeria contigs in each of the similarity classes, according to the BLAST strategy used in the automated annotation.

Additional file 14: Thermocycler and $q$ PCR reaction setup. Provides details regarding the reaction conditions and thermocycler programming parameters for successful qPCR amplification for each qPCR measurement reported in this study. 
Additional file 15: Combined annotated ovarian and oocyte transcriptome of Pararge aegeria. Provides the fasta format sequences of the contigs, which in Additional file 2 had a YES in the SubmitFlag column (i.e. to be submitted to NCBI TSA). Suggested annotated names are given on the basis of the BLAST results listed in Additional file 2, and as described in the main text. The start and end of the open reading frames can be found in the final two columns of Additional file 2.

\section{Abbreviations}

GRN: Gene Regulatory Network; eco-evo-devo: Ecological evolutionary development; AP: Anterior-posterior; DV: Dorso-ventral; RNA-seg: RNAsequencing; RNP: Ribonucleoprotein; RTK: Receptor Tyrosine Kinase; CDK: Cyclin-dependent kinase; SC: Synaptonemal Complex;

RN: Recombination Nodules; IRS: Insulin Receptor Substrate; 20E: 20-hydroxyecdysone; JH: Juvenile Hormone; FPKM: Fragments Per Kilobase of exon per Million of fragments mapped; ORF: Open Reading Frame; SS: Similarity Score; GO: Gene Ontology; RT-qPCR: Real-time reverse transcription quantitative polymerase chain reaction; NRT: Negative reverse transcription; NTC: No template control.

\section{Competing interests}

The authors declare that they have no competing interests.

\section{Authors' contributions}

JMC collected and analysed RT-qPCR data, designed the automatic annotation pipeline, performed bioinformatic analyses, and co-wrote the manuscript. SCB assisted in RT-qPCR study design and data collection. RP and DRFC prepared RNA samples for RNA-seq. AC performed phylogenetic analyses of nanos. JT assisted in manual annotation of the transcriptome. MG and $\mathrm{CJB}$ designed and supervised the study, performed the manual annotation of the transcriptome, and co-wrote the manuscript. All authors have provided comments on earlier drafts of the manuscript and approved the final version of the manuscript for publication.

\section{Acknowledgements}

Research funding for JMC and CJB was provided by the Faculty of Health and Life Sciences, Department of Biological and Medical Sciences, Oxford Brookes University (Jnl no 105595 and 103324) and a NERC studentship quota award. In particular we would like to thank Peter Holland, Laura Ferguson and Ferdinand Marletaz for the collaboration on the Pararge aegeria genome. Furthermore, we would like to thank Alistair McGregor and the two anonymous reviewers for helpful comments on earlier versions of the manuscript, Maarten Hilbrant for discussions on maternal effect genes, Tom Annat for his help with chorion gene phylogenetic analyses, Luca Livraghi for discussions on caudal translational repression, as well as the numerous undergraduate students who have worked in the lab of CJB on butterfly oogenesis.

\section{Author details}

'Evolutionary Developmental Biology Research Group, Faculty of Health and Life Sciences, Department of Biological and Medical Sciences, Oxford Brookes University, Gipsy Lane, Headington, Oxford OX3 OBP, UK. ${ }^{2}$ Bioline Reagents Ltd, 16 The Edge Business Centre, Humber Road, London NW2 6EW, UK. ${ }^{3}$ Non-coding RNA Research Group, Faculty of Health and Life Sciences, Department of Biological and Medical Sciences, Oxford Brookes University, Gipsy Lane, Headington, Oxford OX3 OBP, UK. ${ }^{4}$ NERC Centre for Ecology and Hydrology, Maclean Building, Benson Lane, Crowmarsh Gifford, Wallingford OX10 8BB, UK.

\section{Received: 11 January 2013 Accepted: 5 April 2013}

Published: 26 April 2013

\section{References}

1. Ewen-Campen B, Srouji JR, Schwager EE, Extavour CG: Oskar predates the evolution of germ plasm in insects. Curr Biol 2012, 22:2278-2283.

2. Berg GJ, Gassner G: Fine structure of the blastoderm embryo of the pink bollworm, Pectinophora Gossypiella (saunders) (lepidoptera: Gelechiidae). Int J Insect Morphol Embryol 1978, 7:81-105.

3. Lynch JA, Ozuak O, Khila A, Abouheif E, Desplan C, Roth S: The phylogenetic origin of oskar coincided with the origin of maternally provisioned germ plasm and pole cells at the base of the Holometabola. PLoS Genet 2011, 7:e1002029.

4. Lynch JA, Roth S: The evolution of dorsal-ventral patterning mechanisms in insects. Genes Dev 2011, 25:107-118.

5. Rosenberg MI, Lynch JA, Desplan C: Heads and tails: evolution of anteroposterior patterning in insects. Biochim Biophys Acta 2009, 1789:333-342.

6. Ziegler R, Van Antwerpen R: Lipid uptake by insect oocytes. Insect Biochem Mol Biol 2006, 36:264-272.

7. Ramaswamy SB, Shu SQ, Park YI, Zeng FR: Dynamics of juvenile hormonemediated gonadotropism in the Lepidoptera. Arch Insect Biochem Physiol 1997, 35:539-558.

8. Telfer WH: Egg formation in Lepidoptera. J Insect Sci 2009, 9:1-21.

9. Tufail M, Takeda M: Insect vitellogenin/lipophorin receptors: Molecular structures, role in oogenesis, and regulatory mechanisms. I Insect Physiol 2009, 55:88-104.

10. Gibbs M, Van Dyck H, Karlsson B: Reproductive plasticity, ovarian dynamics and maternal effects in response to temperature and flight in Pararge aegeria. J Insect Physiol 2010, 56:1275-1283.

11. Gibbs M, Breuker CJ, Van Dyck H: Flight during oviposition reduces maternal egg provisioning and influences offspring development in Pararge aegeria (L.). Physiol Entomol 2010, 35:29-39.

12. Rotem K, Agrawal AA, Kott L: Parental effects in Pieris rapae in response to variation in food quality: adaptive plasticity across generations? Ecol Entomol 2003, 28:211-218.

13. Skora AD, Spradling AC: Epigenetic stability increases extensively during Drosophila follicle stem cell differentiation. Proc Natl Acad Sci 2010, 107:7389-7394.

14. Li X, Han Y, Xi R: Polycomb group genes Psc and Su(z)2 restrict follicle stem cell self-renewal and extrusion by controlling canonical and noncanonical Wnt signaling. Genes Dev 2011, 24:933.

15. McCall K: Eggs over easy: cell death in the Drosophila ovary. Dev Biol 2004, 274:3-14

16. Terashima J, Takaki K, Sakurai S, Bownes M: Nutritional status affects 20-hydroxyecdysone concentration and progression of oogenesis in Drosophila melanogaster. J Endocrinol 2005, 187:69-79.

17. Xie T, Spradling AC: A niche maintaining germ line stem cells in the Drosophila ovary. Science 2000, 290:328-330.

18. Dansereau DA, Lasko P: The development of germline stem cells in Drosophila. Methods Mol Biol 2008, 450:3-26.

19. Neumuller RA, Betschinger J, Fischer A, Bushati N, Poernbacher I, Mechtler K, Cohen SM, Knoblich JA: Mei-P26 regulates microRNAs and cell growth in the Drosophila ovarian stem cell lineage. Nature 2008, 454:241-245.

20. Fast EM, Toomey ME, Panaram K, Desjardins D, Kolaczyk ED, Frydman HM: Wolbachia enhance Drosophila stem cell proliferation and target the germline stem cell niche. Science 2011, 334:990-992.

21. Bastock R, St Johnston D: Drosophila oogenesis. Curr Biol 2008, 18:R1082-R1087.

22. Archambault V, Zhao X, White-Cooper H, Carpenter ATC, Glover DM: Mutations in Drosophila Greatwall/Scant reveal its roles in mitosis and meiosis and interdependence with polo kinase. PLOS Genet 2007, 3:e200

23. Wilson MJ, Abbott H, Dearden PK: The evolution of oocyte patterning in insects: multiple cell-signaling pathways are active during honeybee oogenesis and are likely to play a role in axis patterning. Evol Dev 2011, 13:127-137.

24. Lynch JA, Peel AD, Drechsler A, Averof M, Roth S: EGF Signaling and the Origin of Axial Polarity among the Insects. Curr Biol 2010, 20(11):1042-1047.

25. Roth S, Lynch JA: Symmetry Breaking During Drosophila Oogenesis. Cold Spring Harb Perspect Biol 2009, 1(2):a001891.

26. Nijhout FH: Insect hormones. New Jersey: Princeton University Press; 1994

27. Riddiford LM: Effects of juvenile hormone on the programming of postembryonic development in eggs of the silkworm, Hyalophora cecropia. Dev Biol 1970, 22:249-263.

28. Orth AP, Tauchman SJ, Doll SC, Goodman WG: Embryonic expression of juvenile hormone binding protein and its relationship to the toxic effects of juvenile hormone in Manduca sexta. Insect Biochem Mol Biol 2003, 33:1275-1284

29. Khila $A$, Abouheif $E$ : Evaluating the role of reproductive constraints in ant social evolution. Philos Trans R Soc Lond B Biol Sci 2010, 365:617-630.

30. Wheeler D: The role of nourishment in oogenesis. Annu Rev Entomol 1996, 41:407-431. 
31. Uller T: Developmental plasticity and the evolution of parental effects. Trends Ecol Evol 2008, 23:432-438.

32. Khila A, Abouheif E: Reproductive constraint is a developmental mechanism that maintains social harmony in advanced ant societies. Proc Natl Acad Sci 2008, 105:17884-17889.

33. Rossiter MC: Maternal effects generate variation in life history: consequences of egg weight plasticity in the Gypsy Moth. Funct Ecol 1991, 5:386-393.

34. Ginzburg LR, Taneyhill DE: Population cycles of forest Lepidoptera - A maternal effect hypothesis. J Anim Ecol 1994, 63:79-92.

35. St Johnston D, Nüsslein-Volhard C: The origin of pattern and polarity in the Drosophila embryo. Cell 1992, 68:201-220.

36. Munn K, Steward R: The anterior-posterior and dorsal-ventral axes have a common origin in Drosophila melanogaster. Bioessays 1995, 17:920-922.

37. Christians E, Davis AA, Thomas SD, Benjamin IJ: Embryonic development Maternal effect of Hsf1 on reproductive success. Nature 2000, 407:693-694.

38. Yatsu J, Hayashi M, Mukai M, Arita K, Shigenobu S, Kobayashi S: Maternal RNAs encoding transcription factors for germline-specific gene expression in Drosophila embryos. Int J Dev Biol 2008, 52:913-923.

39. Gilbert SF: The morphogenesis of evolutionary developmental biology. Int J Dev Biol 2003, 47:467-477.

40. Roff DA: Life history evolution. Sunderland, Mass: Sinauer; 2002.

41. Johnson NA, Porter AH: Toward a new synthesis: population genetics and evolutionary developmental biology. Genetica 2001, 112-113:45-58.

42. Jenner RA, Wills MA: The choice of model organisms in evo-devo. Nat Rev Genet 2007, 8:311-319.

43. Springer $\mathrm{P}$, Boggs $\mathrm{CL}$ : Resource allocation to oocytes - heritable variation with altitude in Colias philodice eriphyle (Lepidoptera). Am Nat 1986, 127:252-256.

44. Gibbs M, Van Dyck H, Breuker CJ: Development on drought-stressed host plants affects life history, flight morphology and reproductive output relative to landscape structure. Evol App/ 2012, 5:66-75.

45. Gibbs M, Van Dyck H: Reproductive plasticity, oviposition site selection, and maternal effects in fragmented landscapes. Behav Ecol Sociobiol 2009, 64:1-11.

46. Jervis $M A$, Boggs $C L$, Ferns $P N$ : Egg maturation strategy and survival trade-offs in holometabolous insects: a comparative approach. Biol J Linn Soc 2007, 90:293-302.

47. Papanicolaou A, Gebauer-Jung S, Blaxter ML, Owen McMillan W, Jiggins CD: ButterflyBase: a platform for lepidopteran genomics. Nucleic Acids Res 2008, 36:D582-D587.

48. Wheat CW, Fescemyer HW, Kvist J, Tas EVA, Vera JC, Frilander MJ, Hanski I, Marden JH: Functional genomics of life history variation in a butterfly metapopulation. Mol Ecol 2011, 20:1813-1828.

49. Beldade P, Rudd S, Gruber JD, Long AD: A wing expressed sequence tag resource for Bicyclus anynana butterflies, an evo-devo model. BMC Genomics 2006, 7:130.

50. Zhan S, Merlin C, Boore JL, Reppert SM: The monarch butterfly genome yields insights into long-distance migration. Cell 2011, 147:1171-1185.

51. Consortium THG: Butterfly genome reveals promiscuous exchange of mimicry adaptations among species. Nature 2012, 487:94-98.

52. O'Neil S, Dzurisin J, Carmichael R, Lobo N, Emrich S, Hellmann J: Population-level transcriptome sequencing of nonmodel organisms Erynnis propertius and Papilio zelicaon. BMC Genomics 2010, 11:310.

53. Nakao H: Anterior and posterior centers jointly regulate Bombyx embryo body segmentation. Dev Biol 2012, 371:293-301.

54. Nakao H, Matsumoto T, Oba Y, Niimi T, Yaginuma T: Germ cell specification and early embryonic patterning in Bombyx mori as revealed by nanos orthologues. Evol Dev 2008, 10:546-554.

55. Gibbs M, Breuker CJ, Hesketh H, Hails R, Van Dyck H: Maternal effects, flight versus fecundity trade-offs, and offspring immune defence in the Speckled Wood butterfly, Pararge aegeria. BMC Evol Biol 2010, 10:345.

56. Karlsson B: Variation in egg weight, oviposition rate and reproductive reserves with female age in a natural population of the speckled wood butterfly, Pararge aegeria. Ecol Entomol 1987, 12:473-476.

57. Berger D, Olofsson M, Friberg M, Karlsson B, Wiklund C, Gotthard K, Gilburn A: Intraspecific variation in body size and the rate of reproduction in female insects - adaptive allometry or biophysical constraint? J Anim Ecol 2012, 81(6):1244-1258.

58. Wickman PO, Wiklund $\mathrm{C}$ : Territorial defense and its seasonal decline in the Speckled Wood Butterfly (Pararge aegeria). Anim Behav 1983, 31:1206-1216
59. Karlsson B: Feeding habits and change of body composition with age in three Nymphalid butterfly species. Oikos 1994, 69:224-230.

60. Kobayashi Y, Tanaka M, Ando H: Chapter 19: Embryology. In Lepidoptera, moths and butterflies: volume 2 - morphology, physiology and development. Edited by Kristensen NP. Berlin: Walter de Gruyter; 2003:495-544

61. Regier JC, Friedlander T, Leclerc RF, Mitter C, Wiegmann BM: Lepidopteran phylogeny and applications to comparative studies of development. In Molecular model systems in Lepidoptera. Edited by Goldsmith MR, Wilkins AS. Cambridge: Cambridge University Press; 1995:107-137.

62. FlyBase. http://www.flybase.org.

63. SilkBase. http://silkbase.ab.a.u-tokyo.ac.jp.

64. Gelbart WM, Emmert DB: FlyBase high throughput expression pattern data Beta Version. 2010. Flybase ID: FBrf0212041.

65. Fisher B, Weiszmann R, Frise E, Hammonds A, Tomancak P, Beaton A, Berman B, Quan E, Shu S, Lewis S, Rubin G, Barale C, Laguertas E, Quinn J, Ghosh A, Hartenstein V, Ashburner M, Celniker S. BDGP insitu homepage 2012. http://flybase.org/reports/FBrf0219073.html

66. Roth S, Neuman-Silberberg FS, Barcelo G, Schüpbach T: Cornichon and the EGF receptor signaling process are necessary for both anteriorposterior and dorsal-ventral pattern formation in Drosophila. Cell 1995, 81:967.

67. Galasso A, Pane LS, Russo M, Grimaldi MR, Verrotti AC, Gigliotti S, Graziani F: dSTAM expression pattern during wild type and mutant egg chamber development in D. melanogaster. Gene Expr Patterns 2007, 7:730-737.

68. Mesilaty-Gross S, Reich A, Motro B, Wides R: The Drosophila STAM gene homolog is in a tight gene cluster, and its expression correlates to that of the adjacent gene ial. Gene 1999, 231:173-186.

69. Song $X$, Xie T: Wingless signaling regulates the maintenance of ovarian somatic stem cells in Drosophila. Development 2003, 130:3259-3268.

70. Forbes AJ, Spradling AC, Ingham PW, Lin H: The role of segment polarity genes during early oogenesis in Drosophila. Development 1996, 122:3283-3294.

71. Xie T, Spradling AC: Decapentaplegic is essential for the maintenance and division of germline stem cells in the Drosophila ovary. Cell 1998 94:251-260

72. Funaguma S, Hashimoto S, Suzuki Y, Omuro N, Sugano S, Mita K, Katsuma S, Shimada T: SAGE analysis of early oogenesis in the silkworm, Bombyx mori. Insect Biochem Mol Biol 2007, 37:147-154.

73. Wrana JL, Tran H, Attisano L, Arora K, Childs SR, Massague J, O'Connor MB: Two distinct transmembrane serine/threonine kinases from Drosophila melanogaster form an activin receptor complex. Mol Cell Biol 1994, 14:944-950.

74. Liu Z, Matsuoka S, Enoki A, Yamamoto T, Furukawa K, Yamasaki Y, Nishida Y, Sugiyama S: Negative modulation of bone morphogenetic protein signaling by Dullard during wing vein formation in Drosophila. Dev Growth Differ 2011, 53:822-841.

75. Chen Y, Schüpbach T: The role of brinker in eggshell patterning. Mech Dev 2006, 123:395-406.

76. Shravage BV, Altmann G, Technau M, Roth S: The role of Dpp and its inhibitors during eggshell patterning in Drosophila. Development 2007 134:2261-2271.

77. Casanueva MO, Ferguson EL: Germline stem cell number in the Drosophila ovary is regulated by redundant mechanisms that control Dpp signaling. Development 2004, 131:1881-1890.

78. Culi J, Mann RS: Boca, an endoplasmic reticulum protein required for wingless signaling and trafficking of LDL receptor family members in Drosophila. Cell 2003, 112:343-354.

79. Fu J, Posnien N, Bolognesi R, Fischer TD, Rayl P, Oberhofer G, Kitzmann P, Brown SJ, Bucher G: Asymmetrically expressed axin required for anterior development in Tribolium. Proc Natl Acad Sci 2012, 109:7782-7786.

80. Cohen ED, Mariol MC, Wallace RMH, Weyers J, Kamberov YG, Pradel J, Wilder EL: DWnt4 regulates cell movement and focal adhesion kinase during Drosophila ovarian morphogenesis. Dev Cell 2002, 2:437-448.

81. Gorfinkiel N, Sierra J, Callejo A, Ibanez C, Guerrero I: The Drosophila ortholog of the human Wnt inhibitor factor Shifted controls the diffusion of lipidmodified Hedgehog. Dev Cell 2005, 8:241-253.

82. Goodrich JS, Clouse KN, Schüpbach T: Hrb27C, Sqd and Otu cooperatively regulate gurken RNA localization and mediate nurse cell chromosome dispersion in Drosophila oogenesis. Development 2004, 131:1949-1958. 
83. Gonzalez-Reyes A, St Johnston D: The Drosophila AP axis is polarised by the cadherin-mediated positioning of the oocyte. Development 1998, 125:3635-3644.

84. de Cuevas M, Spradling AC: Morphogenesis of the Drosophila fusome and its implications for oocyte specification. Development 1998, 125:2781-2789.

85. Airoldi SJ, McLean PF, Shimada Y, Cooley L: Intercellular protein movement in syncytial Drosophila follicle cells. J Cell Sci 2011, 124:4077-4086.

86. Lin H, Spradling AC: Fusome asymmetry and oocyte determination in Drosophila. Dev Genet 1995, 16:6-12.

87. Cox DN, Lu B, Sun T-Q, Williams LT, Jan YN: Drosophila par-1 is required for oocyte differentiation and microtubule organization. Curr Biol 2001, 11:75-87.

88. Gonzalez-Reyes A, Elliott H, St Johnston D: Polarization of both major body axes in Drosophila by gurken-torpedo signalling. Nature 1995, 375:654-658.

89. Yakoby N, Bristow CA, Gong D, Schafer X, Lembong J, Zartman JJ, Halfon MS, Schüpbach T, Shvartsman SY: A combinatorial code for pattern formation in Drosophila oogenesis. Dev Cell 2008, 15:725-737.

90. McDonald JA, Pinheiro EM, Kadlec L, Schüpbach T, Montell DJ: Multiple EGFR ligands participate in guiding migrating border cells. Dev Biol 2006, 296:94-103

91. Technau M, Knispel M, Roth S: Molecular mechanisms of EGF signalingdependent regulation of pipe, a gene crucial for dorsoventral axis formation in Drosophila. Dev Genes Evol 2012, 222:1-17.

92. Zhang Z, Zhu X, Stevens LM, Stein D: Distinct functional specificities are associated with protein isoforms encoded by the Drosophila dorsalventral patterning gene pipe. Development 2009, 136:2779-2789.

93. Carneiro K, Fontenele M, Negreiros E, Lopes E, Bier E, Araujo H: Graded maternal short gastrulation protein contributes to embryonic dorsalventral patterning by delayed induction. Dev Biol 2006, 296:203-218

94. Myohara M: Fate mapping of the silkworm, Bombyx mori, using localized UV irradiation of the egg at fertilization. Development 1994, 120:2869-2877.

95. Schober M, Rebay I, Perrimon N: Function of the ETS transcription factor Yan in border cell migration. Development 2005, 132:3493-3504.

96. Larkin MK, Deng WM, Holder K, Tworoger M, Clegg N, Ruohola-Baker H: Role of Notch pathway in terminal follicle cell differentiation during Drosophila oogenesis. Dev Genes Evol 1999, 209:301-311.

97. Zhao D, Woolner S, Bownes M: The Mirror transcription factor links signalling pathways in Drosophila oogenesis. Dev Genes Evol 2000, 210:449-457.

98. Schoppmeier M, Fischer S, Schmitt-Engel C, Loehr U, Klingler M: An ancient anterior patterning system promotes caudal repression and head formation in Ecdysozoa. Curr Biol 2009, 19:1811-1815.

99. Singh N, Morlock H, Hanes SD: The Bin3 RNA methyltransferase is required for repression of caudal translation in the Drosophila embryo. Dev Biol 2011, 352:104-115.

100. Murata Y, Wharton RP: Binding of pumilio to maternal hunchback mRNA is required for posterior patterning in Drosophila embryos. Cell 1995, 80:747-756

101. Patel NH, Hayward DC, Lall S, Pirkl NR, DiPietro D, Ball EE: Grasshopper hunchback expression reveals conserved and novel aspects of axis formation and segmentation. Development 2001, 128:3459-3472.

102. Kobayashi S, Yamada M, Asaoka M, Kitamura T: Essential role of the posterior morphogen nanos for germline development in Drosophila. Nature 1996, 380:708-711.

103. Anne J, Mechler BM: Valois, a component of the nuage and pole plasm, is involved in assembly of these structures, and binds to Tudor and the methyltransferase Capsuléen. Development 2005, 132:2167-2177.

104. Andrews S, Snowflack DR, Clark IE, Gavis ER: Multiple mechanisms collaborate to repress nanos translation in the Drosophila ovary and embryo. RNA 2011, 17:967-977.

105. Zaessinger S, Busseau I, Simonelig M: Oskar allows nanos mRNA translation in Drosophila embryos by preventing its deadenylation by Smaug/CCR4. Development 2006, 133:4573-4583.

106. Kim-Ha J, Kerr K, Macdonald PM: Translational regulation of oskar mRNA by Bruno, an ovarian RNA-binding protein, is essential. Cell 1995 81:403-412

107. Cook HA, Koppetsch BS, Wu J, Theurkauf WE: The Drosophila SDE3 homolog armitage is required for oskar mRNA silencing and embryonic axis specification. Cell 2004, 116:817-829.

108. Anne J: Targeting and anchoring Tudor in the pole plasm of the Drosophila oocyte. PLoS One 2010, 5:e14362.
109. Patil VS, Kai T: Repression of retroelements in Drosophila germline via piRNA pathway by the tudor domain protein tejas. Curr Biol 2010, 20:724-730

110. Handler D, Olivieri D, Novatchkova M, Gruber FS, Meixner K, Mechtler K, Stark A, Sachidanandam R, Brennecke J: A systematic analysis of Drosophila TUDOR domain-containing proteins identifies Vreteno and the Tdrd12 family as essential primary piRNA pathway factors. EMBO J 2011, 30:3977-3993.

111. Callebaut I, Mornon J-P: LOTUS, a new domain associated with small RNA pathways in the germline. Bioinformatics 2010, 26:1140-1144.

112. Malone CD, Brennecke J, Dus M, Stark A, McCombie WR, Sachidanandam R, Hannon GJ: Specialized piRNA pathways act in germline and somatic tissues of the Drosophila ovary. Cell 2009, 137:522-535.

113. Cox DN, Chao A, Baker J, Chang L, Qiao D, Lin H: A novel class of evolutionarily conserved genes defined by piwi are essential for stem cell self-renewal. Genes Dev 1998, 12:3715-3727

114. Sato K, Nishida KM, Shibuya A, Siomi MC, Siomi H: Maelstrom coordinates microtubule organization during Drosophila oogenesis through interaction with components of the MTOC. Genes Dev 2011, 25:2361-2373.

115. Pane A, Wehr K, Schüpbach T: Zucchini and squash encode two putative nucleases required for rasiRNA production in the Drosophila germline. Dev Cell 2007, 12:851-862.

116. Lin MD, Jiao X, Grima D, Newbury SF, Kiledjian M, Chou TB: Drosophila processing bodies in oogenesis. Dev Biol 2008, 322:276-288.

117. Fan S-J, Marchand V, Ephrussi A: Drosophila Ge-1 promotes P Body formation and oskar mRNA localization. PLoS One 2011, 6:e20612.

118. Jongens $T A$, Hay $B$, Jan $L Y$, Jan $Y N$ : The germ cell-less gene product: a posteriorly localized component necessary for germ cell development in Drosophila. Cell 1992, 70:569-584.

119. Lecuyer E, Yoshida H, Parthasarathy N, Alm C, Babak T, Cerovina T, Hughes TR, Tomancak P, Krause HM: Global analysis of mRNA localization reveals a prominent role in organizing cellular architecture and function. Cell 2007, 131:174-187

120. Reeves GT, Stathopoulos A: Graded Dorsal and differential gene regulation in the Drosophila embryo. Cold Spring Harb Perspect Biol 2009, 1(4):a000836.

121. Chen LY, Wang JC, Hyvert $Y$, Lin HP, Perrimon N, Imler JL, Hsu JC: Weckle is a zinc finger adaptor of the Toll pathway in dorsoventral patterning of the Drosophila embryo. Curr Biol 2006, 16:1183-1193.

122. Kleve CD, Siler DA, Syed SK, Eldon ED: Expression of 18-wheeler in the follicle cell epithelium affects cell migration and egg morphology in Drosophila. Dev Dyn 2006, 235:1953-1961.

123. Imamura M, Yamakawa M: Molecular cloning and expression of a Toll receptor gene homologue from the silkworm, Bombyx mori. Biochim Biophys Acta 2002, 1576:246-254.

124. Huang JD, Dubnicoff T, Liaw GJ, Bai Y, Valentine SA, Shirokawa JM, Lengyel JA, Courey AJ: Binding sites for transcription factor NTF-1/Elf-1 contribute to the ventral repression of decapentaplegic. Genes Dev 1995, 9:3177-3189.

125. Araujo H, Bier E: Sog and dpp exert opposing maternal functions to modify Toll signaling and pattern the dorsoventral axis of the Drosophila embryo. Development 2000, 127:3631

126. George $H$, Terracol R: The vrille gene of Drosophila is a maternal enhancer of decapentaplegic and encodes a new member of the bZIP family of transcription factors. Genetics 1997, 146:1345-1363.

127. Bartoszewski S, Luschnig S, Desjeux I, Grosshans J, Nüsslein-Volhard C: Drosophila p24 homologues eclair and baiser are necessary for the activity of the maternally expressed Tkv receptor during early embryogenesis. Mech Dev 2004, 121:1259-1273.

128. Ait-Ahmed O, Thomas-Cavallin M, Joblet C, Capri M: Expression in the central nervous system of a subset of the yema maternally acting genes during Drosophila embryogenesis. Post-embryonic expression extends to imaginal discs and spermatocytes. Cell Diff Dev 1990, 31:53-65

129. Zarnescu DC, Jin P, Betschinger J, Nakamoto M, Wang $Y$, Dockendorff TC, Feng $Y$, Jongens TA, Sisson JC, Knoblich JA, et al: Fragile $X$ protein functions with lgl and the par complex in flies and mice. Dev Cell 2005, 8:43-52

130. Ventura G, Furriols M, Martín N, Barbosa V, Casanova J: Closca, a new gene required for both Torso RTK activation and vitelline membrane integrity. Germline proteins contribute to Drosophila eggshell composition. Dev Biol 2010, 344:224-232. 
131. Klingler M, Erdelyi M, Szabad J, Nüsslein-Volhard C: Function of torso in determining the terminal anlagen of the Drosophila embryo. Nature 1988, 335:275-277

132. Savant-Bhonsale S, Montell DJ: Torso-like encodes the localized determinant of Drosophila terminal pattern formation. Genes Dev 1993 7:2548-2555.

133. Schoppmeier M, Schroder R: Maternal torso signaling controls body axis elongation in a short germ insect. Curr Biol 2005, 15:2131-2136.

134. Dearden PK, Wilson MJ, Sablan L, Osborne PW, Havler M, McNaughton E, Kimura K, Milshina NV, Hasselmann M, Gempe T, et al: Patterns of conservation and change in honey bee developmental genes. Genome Res 2006, 16:1376-1384.

135. Wilson MJ, Dearden PK: Tailless patterning functions are conserved in the honeybee even in the absence of Torso signaling. Dev Biol 2009, 335:276-287.

136. Bornemann D, Miller E, Simon J: The Drosophila Polycomb group gene Sex comb on midleg $(\mathrm{Scm})$ encodes a zinc finger protein with similarity to polyhomeotic protein. Development 1996, 122:1621-1630.

137. Narbonne K, Besse F, Brissard-Zahraoui J, Pret AM, Busson D: Polyhomeotic is required for somatic cell proliferation and differentiation during ovarian follicle formation in Drosophila. Development 2004, 131:1389-1400.

138. Li Z, Tatsuke T, Sakashita K, Zhu L, Xu J, Mon H, Lee JM, Kusakabe T: Identification and characterization of Polycomb group genes in the silkworm, Bombyx mori. Mol Biol Rep 2012, 39:5575-5588.

139. Kiefer JC: Epigenetics in development. Dev Dyn 2007, 236:1144-1156.

140. Sugimura I, Lilly MA: Bruno inhibits the expression of mitotic cyclins during the prophase I meiotic arrest of Drosophila oocytes. Dev Cell 2006, 10:127-135.

141. Suomalainen E, Cook LM, Turner JRG: Achiasmatic oogenesis in the Heliconiine butterflies. Hereditas 1973, 74:302-304

142. Rasmussen SW, Raveh D, Cowen J, Lewis KR: Meiosis in Bombyx mori females. Philos Trans R Soc Lond B Biol Sci 1977, 277:343-350.

143. Rasmussen SW: The transformation of the Synaptonemal Complex into the 'elimination chromatin' in Bombyx mori oocytes. Chromosoma 1977, 60:205-221.

144. von Wettstein D: The synaptonemal complex and genetic segregation. Symp Soc Exp Biol 1984, 38:195-231.

145. Gause M, Webber HA, Misulovin Z, Haller G, Rollins RA, Eissenberg JC, Bickel SE, Dorsett D: Functional links between Drosophila Nipped-B and cohesin in somatic and meiotic cells. Chromosoma 2008, 117:51-66.

146. Carney GE, Bender M: The Drosophila ecdysone receptor ( $E c R)$ gene is required maternally for normal oogenesis. Genetics 2000, 154:1203-1211.

147. Sommer B, Oprins A, Rabouille C, Munro S: The exocyst component Sec5 is present on endocytic vesicles in the oocyte of Drosophila melanogaster. J Cell Biol 2005, 169:953-963.

148. Schonbaum CP, Perrino JJ, Mahowald AP: Regulation of the vitellogenin receptor during Drosophila melanogaster oogenesis. Mol Biol Cell 2000, 11:511-521

149. Pistillo D, Manzi A, Tino A, Boyl PP, Graziani F, Malva C: The Drosophila melanogaster lipase homologs: a gene family with tissue and developmental specific expression. J Mol Biol 1998, 276:877-885.

150. Yamada R, Yamahama Y, Sonobe H: Release of ecdysteroid-phosphates from egg yolk granules and their dephosphorylation during early embryonic development in silkworm, Bombyx mori. Zool Sci 2005, 22:187-198.

151. Eystathioy $T$, Swevers $L$, latrou $K$ : The orphan nuclear receptor BmHR3A of Bombyx mori: hormonal control, ovarian expression and functional properties. Mech Dev 2001, 103:107-115.

152. Liu Y-Q, Chen M-M, Li Q, Li Y-P, Xu L, Wang H, Zhou Q-K, Sima Y-H, Wei Z-J, Jiang D-F: Characterization of a gene encoding KK-42-binding protein in Antheraea pernyi (Lepidoptera: Saturniidae). Ann Entomol Soc Am 2012, 105:718-725.

153. Perera OP, Shirk PD: cDNA of YP4, a follicular epithelium yolk protein subunit, in the moth, Plodia interpunctella. Arch Insect Biochem Physiol 1999, 40:157-164.

154. Terashima J, Bownes M: Translating available food into the number of eggs laid by Drosophila melanogaster. Genetics 2004, 167:1711-1719.

155. Richard DS, Rybczynski R, Wilson TG, Wang Y, Wayne ML, Zhou Y, Partridge L, Harshman LG: Insulin signaling is necessary for vitellogenesis in Drosophila melanogaster independent of the roles of juvenile hormone and ecdysteroids: female sterility of the chico 1 insulin signaling mutation is autonomous to the ovary. $J$ Insect Physiol 2005, 51:455-464

156. Iwami M, Tanaka A, Hano N, Sakurai S: Bombyxin gene expression in tissues other than brain detected by reverse transcription-polymerase chain reaction (RT-PCR) and in situ hybridization. Experientia 1996, 52:882-887.

157. Swevers L, Drevet JR, Lunke MD, latrou K: The silkmoth homolog of the Drosophila ecdysone receptor (BI Isoform): Cloning and analysis of expression during follicular cell differentiation. Insect Biochem Mol Biol 1995, 25:857-866

158. Charles J-P, Iwema T, Epa VC, Takaki K, Rynes J, Jindra M: Ligand-binding properties of a juvenile hormone receptor, Methoprene-tolerant. Proc Natl Acad Sci 2011, 108:21128-21133.

159. Abdou MA, He Q, Wen D, Zyaan O, Wang J, Xu J, Baumann AA, Joseph J, Wilson TG, Li S, Wang J: Drosophila Met and Gce are partially redundant in transducing juvenile hormone action. Insect Biochem Mol Biol 2011, 41:938-945.

160. Li M, Mead EA, Zhu J: Heterodimer of two bHLH-PAS proteins mediates juvenile hormone-induced gene expression. Proc Natl Acad Sci 2011, 108:638-643.

161. Willis DK, Wang J, Lindholm JR, Orth A, Goodman WG: Microarray analysis of juvenile hormone response in Drosophila melanogaster S2 cells. J Insect Sci 2010, 10:66.

162. Birnbaum MJ, Gilbert Ll: Juvenile hormone stimulation of ornithine decarboxylase activity during vitellogenesis in Drosophila melanogaster. J Comp Physiol B 1990, 160:145-151.

163. Seino A, Ogura T, Tsubota T, Shimomura M, Nakakura T, Tan A, Mita K, Shinoda T, Nakagawa Y, Shiotsuki T: Characterization of juvenile hormone epoxide hydrolase and related genes in the larval development of the silkworm Bombyx mori. Biosci Biotechnol Biochem 2010, 74:1421-1429

164. Buszczak M, Freeman MR, Carlson JR, Bender M, Cooley L, Segraves WA: Ecdysone response genes govern egg chamber development during mid-oogenesis in Drosophila. Development 1999, 126:4581-4589.

165. Roth GE, Gierl MS, Vollborn L, Meise M, Lintermann R, Korge G: The Drosophila gene Start1: a putative cholesterol transporter and key regulator of ecdysteroid synthesis. Proc Natl Acad Sci 2004, 101:1601-1606.

166. Freeman MR, Dobritsa A, Gaines P, Segraves WA, Carlson JR: The dare gene: steroid hormone production, olfactory behavior, and neural degeneration in Drosophila. Development 1999, 126:4591-4602.

167. Gaziova I, Bonnette PC, Henrich VC, Jindra M: Cell-autonomous roles of the ecdysoneless gene in Drosophila development and oogenesis. Development 2004, 131:2715-2725.

168. Sakudoh T, Tsuchida K, Kataoka H: BmStart1, a novel carotenoid-binding protein isoform from Bombyx mori, is orthologous to MLN64, a mammalian cholesterol transporter. Biochem Biophys Res Commun 2005, 336:1125-1135.

169. Swevers $L$, latrou K: The orphan receptor BmHNF-4 of the silkmoth Bombyx mori: ovarian and zygotic expression of two mRNA isoforms encoding polypeptides with different activating domains. Mech Dev 1998, 72:3-13.

170. Tootle TL, Williams D, Hubb A, Frederick R, Spradling A: Drosophila eggshell production: identification of new genes and coordination by Pxt. PLOS One 2011, 6:e19943.

171. Hong CC, Hashimoto C: An unusual mosaic protein with a protease domain, encoded by the nudel gene, is involved in defining embryonic dorsoventral polarity in Drosophila. Cell 1995, 82:785-794.

172. Kendirgi F, Swevers L, latrou K: An ovarian follicular epithelium protein of the silkworm (Bombyx mori) that associates with the vitelline membrane and contributes to the structural integrity of the follicle. FEBS Lett 2002, 524:59-68.

173. Calvi BR, Lilly MA, Spradling AC: Cell cycle control of chorion gene amplification. Genes Dev 1998, 12:734-744.

174. Jones CW, Kafatos FC: Linkage and evolutionary diversification of developmentally regulated multigene families: tandem arrays of the 401/18 chorion gene pair in silkmoths. Mol Cell Biol 1981, 1:814-828.

175. Sourmeli S, Papantonis A, Lecanidou R: A novel role for the Bombyx Slbo homologue, BmC/EBP, in insect choriogenesis. Biochem Biophys Res Commun 2005, 337:713-719.

176. Papantonis A, Van den Broeck J, Lecanidou R: Architectural factor HMGA induces promoter bending and recruits C/EBP and GATA during silkmoth chorion gene regulation. Biochem J 2008, 416:85-97. 
177. Shea MJ, King DL, Conboy MJ, Mariani BD, Kafatos FC: Proteins that bind to Drosophila chorion cis-regulatory elements: a new $\mathrm{C}[[2]] \mathrm{H}[[2]]$ zinc finger protein and a C[[2]]C[[2]] steroid receptor-like component. Genes Dev 1990, 4:1128.

178. Jagadeeshan S, Singh RS: Rapid evolution of outer egg membrane proteins in the Drosophila melanogaster subgroup: a case of ecologically driven evolution of female reproductive traits. Mol Biol Evol 2007, 24:929-938.

179. Leclerc RF, Regier JC: Evolution of chorion gene families in lepidoptera: characterization of 15 cDNAs from the gypsy moth. J Mol Evol 1994, 39:244-254.

180. Xu Y, Fu Q, Li S, He N: Silkworm egg proteins at the germ-band formation stage and a functional analysis of BmEP80 protein. Insect Biochem Mol Bio 2011, 41:572-581.

181. Mpakou VE, Nezis IP, Stravopodis DJ, Margaritis LH, Papassideri IS: Different modes of programmed cell death during oogenesis of the silkmoth Bombyx mori. Autophagy 2008, 4:97-100.

182. Hou YC, Chittaranjan S, Barbosa SG, McCall K, Gorski SM: Effector caspase Dcp-1 and IAP protein Bruce regulate starvation-induced autophagy during Drosophila melanogaster oogenesis. J Cell Biol 2008, 182:1127-1139.

183. Zhang J-Y, Pan M-H, Sun Z-Y, Huang S-J, Yu Z-S, Liu D, Zhao D-H, Lu C: The genomic underpinnings of apoptosis in the silkworm, Bombyx mori. BMC Genom 2010, 11:611

184. Yu J, Zheng Y, Dong J, Klusza S, Deng W-M, Pan D: Kibra functions as a tumor suppressor protein that regulates Hippo signaling in conjunction with Merlin and Expanded. Dev Cell 2010, 18:288.

185. Jankovics F, Sinka R, Lukacsovich T, Erdelyi M: Moesin crosslinks actin and cell membrane in Drosophila oocytes and is required for Oskar anchoring. Curr Biol 2002, 12:2060-2065.

186. Sarkar S, Lakhotia SC: Hsp60C is required in follicle as well as germline cells during oogenesis in Drosophila melanogaster. Dev Dyn 2008, 237:1334-1347.

187. Cobreros L, Fernández-Miñán A, Luque CM, González-Reyes A, MartínBermudo MD: A role for the chaperone $\mathrm{Hsp} 70$ in the regulation of border cell migration in the Drosophila ovary. Mech Dev 2008, 125:1048-1058.

188. Qian S, Hongo S, Jacobs-Lorena M: Antisense ribosomal protein gene expression specifically disrupts oogenesis in Drosophila melanogaster Proc Natl Acad Sci 1988, 85:9601-9605.

189. Starr DJ, Cline TW: A host parasite interaction rescues Drosophila oogenesis defects. Nature 2002, 418:76-79.

190. Kremer N, Voronin D, Charif D, Mavingui P, Mollereau B, Vavre F: Wolbachia interferes with ferritin expression and iron metabolism in insects. PLOS Path 2009, 5:e1000630.

191. Stouthamer R, Breeuwer JAJ, Hurst GDD: Wolbachia pipientis: Microbial manipulator of arthropod reproduction. Annu Rev Microbiol 1999, 53:71-102.

192. Dedeine F, Vavre F, Fleury F, Loppin B, Hochberg ME, Boulétreau M: Removing symbiotic Wolbachia bacteria specifically inhibits oogenesis in a parasitic wasp. Proc Natl Acad Sci 2001, 98:6247-6252.

193. Serbus LR, Ferreccio A, Zhukova M, McMorris CL, Kiseleva E, Sullivan W: A feedback loop between Wolbachia and the Drosophila gurken mRNP complex influences Wolbachia titer. J Cell Sci 2011, 124:4299-4308.

194. Horner VL, Wolfner MF: Transitioning from egg to embryo: Triggers and mechanisms of egg activation. Dev Dyn 2008, 237:527-544.

195. Cui J, Sackton KL, Horner VL, Kumar KE, Wolfner MF: Wispy, the Drosophila homolog of GLD-2, is required during oogenesis and egg activation. Genetics 2008, 178:2017-2029.

196. Chomczynski P, Sacchi N: Single-step method of RNA isolation by acid guanidinium thiocyanate-phenol-chloroform extraction. Anal Biochem 1987, 162:156-159.

197. Li J, Li X, Chen Y, Yang Z, Guo S: Solexa sequencing based transcriptome analysis of Helicoverpa armigera larvae. Mol Biol Rep 2012, 39:11051-11059.

198. Goecks J, Nekrutenko A, Taylor J, Team TG: Galaxy: a comprehensive approach for supporting accessible, reproducible, and transparent computational research in the life sciences. Genome Biol 2010, 11:R86.

199. Blankenberg D, Gordon A, Von Kuster G, Coraor N, Taylor J, Nekrutenko A: Team tG: Manipulation of FASTQ data with Galaxy. Bioinformatics 2010, 26:1783-1785

200. Trapnell C, Pachter L, Salzberg SL: TopHat: discovering splice junctions with RNA-Seq. Bioinformatics 2009, 25:1105-1111.

201. Roberts A, Trapnell C, Donaghey J, Rinn J, Pachter L: Improving RNA-Seq expression estimates by correcting for fragment bias. Genome Biol 2011 , $12: R 22$
202. Conesa A, Götz S, García-Gómez JM, Terol J, Talón M, Robles M: Blast2GO: a universal tool for annotation, visualization and analysis in functional genomics research. Bioinformatics 2005, 21:3674-3676.

203. Pfaffl MW, Horgan GW, Dempfle L: Relative expression software tool (REST@) for group-wise comparison and statistical analysis of relative expression results in real-time PCR. Nucleic Acids Res 2002, 30:e36.

204. Tarazona S, García-Alcalde F, Dopazo J, Ferrer A, Conesa A: Differential expression in RNA-seq: A matter of depth. Genome Res 2011, 21:2213-2223.

205. Colborn JM, Byrd BD, Koita OA, Krogstad DJ: Estimation of copy number using SYBR Green: confounding by AT-rich DNA and by variation in amplicon length. Am J Trop Med Hyg 2008, 79:887-892.

doi:10.1186/1471-2164-14-283

Cite this article as: Carter et al:: Unscrambling butterfly oogenesis. BMC Genomics 2013 14:283.

\section{Submit your next manuscript to BioMed Central and take full advantage of:}

- Convenient online submission

- Thorough peer review

- No space constraints or color figure charges

- Immediate publication on acceptance

- Inclusion in PubMed, CAS, Scopus and Google Scholar

- Research which is freely available for redistribution 